\title{
Halden In-Reactor Test to Exhibit PWR Axial Offset Anomaly
}

This report describes research sponsored by EPRI and the U.S. Department of Energy under the Nuclear Energy Plant Optimization (NEPO) Program.

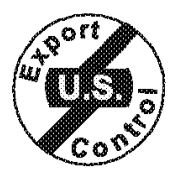





\section{Halden In-Reactor Test to Exhibit PWR Axial Offset Anomaly}

1008106

Final Report, December 2004

Cosponsor

U.S. Department of Energy

Washington, DC

EPRI Project Manager

J. Deshon 


\section{DISCLAIMER OF WARRANTIES AND LIMITATION OF LIABILITIES}

THIS DOCUMENT WAS PREPARED BY THE ORGANIZATION(S) NAMED BELOW AS AN ACCOUNT OF WORK SPONSORED OR COSPONSORED BY THE ELECTRIC POWER RESEARCH INSTITUTE, INC. (EPRI). NEITHER EPRI, ANY MEMBER OF EPRI, ANY COSPONSOR, THE ORGANIZATION(S) BELOW, NOR ANY PERSON ACTING ON BEHALF OF ANY OF THEM:

(A) MAKES ANY WARRANTY OR REPRESENTATION WHATSOEVER, EXPRESS OR IMPLIED, (I) WITH RESPECT TO THE USE OF ANY INFORMATION, APPARATUS, METHOD, PROCESS, OR SIMILAR ITEM DISCLOSED IN THIS DOCUMENT, INCLUDING MERCHANTABILITY AND FITNESS FOR A PARTICULAR PURPOSE, OR (II) THAT SUCH USE DOES NOT INFRINGE ON OR INTERFERE WITH PRIVATELY OWNED RIGHTS, INCLUDING ANY PARTY'S INTELLECTUAL PROPERTY, OR (III) THAT THIS DOCUMENT IS SUITABLE TO ANY PARTICULAR USER'S CIRCUMSTANCE; OR

(B) ASSUMES RESPONSIBILITY FOR ANY DAMAGES OR OTHER LIABILITY WHATSOEVER (INCLUDING ANY CONSEQUENTIAL DAMAGES, EVEN IF EPRI OR ANY EPRI REPRESENTATIVE HAS BEEN ADVISED OF THE POSSIBILITY OF SUCH DAMAGES) RESULTING FROM YOUR SELECTION OR USE OF THIS DOCUMENT OR ANY INFORMATION, APPARATUS, METHOD, PROCESS, OR SIMILAR ITEM DISCLOSED IN THIS DOCUMENT.

ORGANIZATION(S) THAT PREPARED THIS DOCUMENT

Institutt for energiteknikk

\section{ORDERING INFORMATION}

Requests for copies of this report should be directed to EPRI Orders and Conferences, 1355 Willow Way, Suite 278, Concord, CA 94520, (800) 313-3774, press 2 or internally x5379, (925) 609-9169, (925) 609-1310 (fax).

Electric Power Research Institute and EPRI are registered service marks of the Electric Power Research Institute, Inc. EPRI. ELECTRIFY THE WORLD is a service mark of the Electric Power Research Institute, Inc.

Copyright @ 2004 Electric Power Research Institute, Inc. All rights reserved. 


\section{CITATIONS}

This report was prepared by

Institutt for energiteknikk

OECD Halden Reactor Project

PO Box 173

1751 Halden

Norway

Principal Investigator

P. Bennett

Investigators

B. Beverskog

R. Suther

This report describes research sponsored by EPRI and the U.S. Department of Energy under the Nuclear Energy Plant Optimization (NEPO) Program, NEPO Task FY02 5-234.

Any opinions, findings, and conclusions or recommendations expressed in this material are those of the authors(s) and do not necessarily reflect the views of the Department of Energy.

The report is a corporate document that should be cited in the literature in the following manner:

Halden In-Reactor Test to Exhibit PWR Axial Offset Anomaly, EPRI, Palo Alto, CA: 2004. 1008106. 



\section{REPORT SUMMARY}

Many PWRs have encountered the axial offset anomaly (AOA) since the early 1990s, and these experiences have been reported widely. AOA is a phenomenon associated with localized boron hideout in corrosion product deposits (crud) on fuel surfaces. Several mitigation approaches have been developed or are underway to either delay the onset of AOA or avoid it entirely. This study describes the first phase of an experimental program designed to investigate whether the use of enriched boric acid (EBA) in the reactor coolant can mitigate AOA.

\section{Background}

Fuel reliability and economics continue to be of primary importance in nuclear plant operation. Finding measures to avoid AOA in the PWR fleet has been a focus of EPRI's Fuel Reliability Program and a major challenge for a PWR industry seeking to improve fuel performance and economics. One of the measures under investigation is the use of EBA, but testing this method requires prior qualification under test reactor conditions. Before the efficacy of EBA can be shown in a test facility, it was necessary that the symptoms of AOA experienced in commercial reactors first be demonstrated (Phase 1) in the same facility. This preliminary experiment was carried out at the Halden reactor in Norway because of its relatively long (100 days) operating period.

\section{Objectives}

To entrain boron within fuel crud deposits and measure the resulting flux depression under prototypical PWR conditions.

\section{Approach}

The project team performed Phase 1 tests in a pressure flask located in a fuel channel in the Halden reactor. The pressure flask was connected to a test loop to simulate PWR water chemistry and thermal-hydraulic conditions. The team irradiated a bundle of eight tests rods with an active fuel length of $60 \mathrm{~cm}$ for 349 full power days over three test cycles. On-line, in-core instrumentation included a diameter gauge to detect crud deposition and neutron detectors and coolant thermocouples to detect flux/power depressions. The team used several methods to accelerate crud deposition, including injections of simulated crud particles and colloids, oxygen injections, $\mathrm{pH}$ transients and the addition of Fe-Ni-EDTA solution. After irradiation, the team collected crud samples for post irradiation examination to investigate crud composition and morphology.

\section{Results}

In the first cycle, the thermal-hydraulic conditions were controlled such that the mass evaporation rate of the coolant on the fuel clad was similar to that calculated for PWRs that have 
experienced AOA. No crud was deposited during the cycle. For the second cycle, several steps were undertaken to increase iron and nickel levels in the loop coolant to accelerate crud deposition, including operation for periods at low $\mathrm{pH}_{300^{\circ} \mathrm{C}}(6.5)$ and injection of an Fe-Ni-EDTA solution. Since these methods did not result in crud deposition, towards the end of the cycle both the fuel bundle power and coolant temperature were increased, with the result that the mass evaporation rate was doubled. These changes resulted in deposition of a crud layer of 15 - 20 $\mu \mathrm{m}$. During the third cycle, the neutron flux in the upper section of the fuel bundle decreased with respect to both the power in the lower section of the fuel bundle and to the power in neighboring test rigs. Significant lithium return was measured in the loop coolant during the reactor shutdown. It was concluded that these effects were due to incorporation of boron into the crud layer — an AOA effect.

\section{EPRI Perspective}

EPRI's Fuel Reliability Program has been charged with finding measures to avoid AOA and allow utilities to improve fuel cycle economics. Results from these efforts thus far have been the introduction of ultrasonic fuel cleaning technology (EPRI reports 1001052 and 1003229), and chemistry program demonstrations at Comanche Peak Unit 2 (elevated and constant pH, EPRI reports 1006282 and 1003408) and Callaway (zinc injection, EPRI report 1007857). An additional measure being researched is the application of enriched boric acid to mitigate AOA. However, due to the significant capital investment associated with converting a plant to EBA, it was prudent to first demonstrate EBA would be successful in a research reactor. Prior to this, it was necessary to prove that a research reactor could develop the symptoms of AOA under prototypical or near proto-typical PWR conditions. The Halden Reactor Project afforded the best opportunity to demonstrate this capability and the scientists there have done so successfully. The task now is to conduct further tests to prove EBA can be used to delay the onset of AOA or avoid it entirely under similar aggressive PWR conditions. If proven successful, industry will have an additional option to use when addressing the AOA phenomenon.

\section{Keywords}

PWR

Axial offset anomaly

AOA

Enriched boric acid

EBA

In-reactor test

Research reactor 


\section{ABSTRACT}

Many PWRs have suffered from the axial offset anomaly (AOA) since the early 1990s. AOA is a phenomenon associated with localised boron hideout in corrosion product deposits (crud) on fuel surfaces formed because of the presence of sub-cooled nucleate boiling. Since boron absorbs neutrons, the reactor experiences a shift in power output towards the bottom of the core. AOA has caused one plant to de-rate and forced other utilities to design less efficient cores to avoid the phenomenon. This study is the first phase in an experimental program to investigate whether AOA can be delayed or avoided by using enriched boric acid (EBA) in the coolant. The objectives of this first phase were to demonstrate the symptoms of the AOA: i.e. to deposit crud on fuel rods and measure the resulting flux depression.

A bundle of eight tests rods (active fuel length $60 \mathrm{~cm}$ ) was irradiated in the Halden reactor for 349 full power days under PWR water chemistry and thermal-hydraulic conditions. On-line, incore instrumentation included a diameter gauge to detect crud deposition, and neutron detectors and coolant thermocouples to detect flux/power depressions. Several methods were used to accelerate crud deposition, including injections of simulated crud particles and colloids, oxygen injections, $\mathrm{pH}$ transients and addition of an Fe-Ni-EDTA solution. After irradiation, crud samples were collected for post irradiation exposure (PIE) to investigate their composition and morphology.

The test was conducted over three reactor cycles. In the first cycle, the thermal-hydraulic conditions were controlled such that the mass evaporation rate (steaming rate) of the coolant on the fuel clad was similar to that calculated for PWRs that have experienced AOA. No crud was deposited during the cycle. For the second cycle, several steps were undertaken to increase Fe and $\mathrm{Ni}$ levels in the loop coolant to accelerate crud deposition, including operation for periods at low $\mathrm{pH}_{300^{\circ} \mathrm{C}}(6.5)$ and injection of an Fe-Ni-EDTA solution. These methods did not result in crud deposition, and towards the end of the cycle both the test fuel power and coolant temperature were increased, with the result that the mass evaporation rate was doubled. These changes resulted in deposition of a crud layer of $15-20 \mu \mathrm{m}$. During the third cycle, the neutron flux in the upper section of the fuel bundle decreased with respect to both the power in the lower section of the fuel bundle and to the power in neighboring test rigs. Corroborating evidence of entrained boron on the fuel surface came at shutdown at the end of the cycle. Significant lithium return was measured in the loop coolant, similar to measurements experienced at commercial reactors that have experienced AOA. It was concluded that these effects were due to incorporation of boron into the crud layer; i.e. an AOA effect. 



\section{ACKNOWLEDGEMENTS}

The authors would like to express their thanks to:

Dr. George Sabol (EPRI Consultant, USA) and Professor Derek Lister (University of New Brunswick, Canada) for their advice and helpful comments throughout the experiment;

Dr. Art Byers (Westinghouse, USA) for material support;

Dr. Dave Guzonas (AECL, Canada) for material support;

Eagle-Picher Technologies, LLC (USA) for donation of enriched boric acid;

The many Halden staff involved in the design and operation of the test. 



\section{CONTENTS}

1 INTRODUCTION

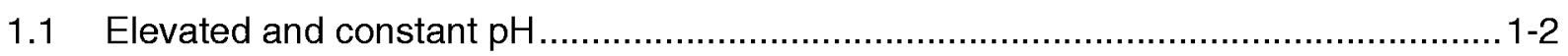

1.2 Zinc injection ...........................................................................................

1.3 Enriched boric acid ...................................................................................

2 DESCRIPTION OF IN-CORE TEST RIG AND LOOP SYSTEM ....................................... 2-1

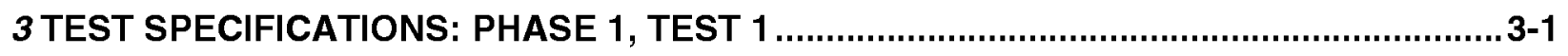

3.1 Water Chemistry Conditions .............................................................................

3.2 Thermal-Hydraulic Conditions............................................................................ $3-2$

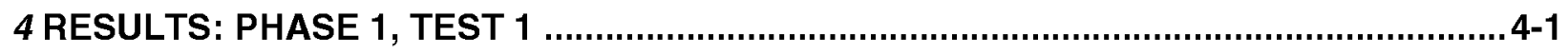

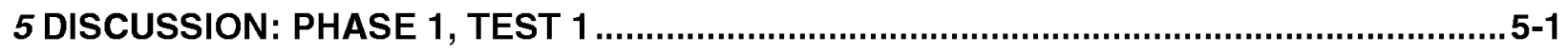

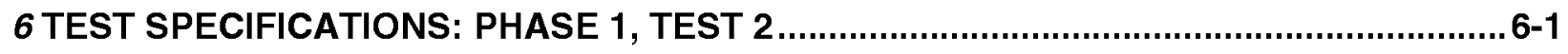

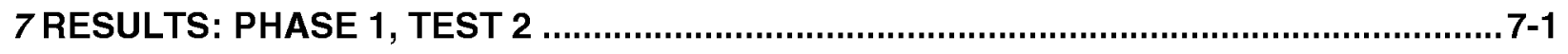

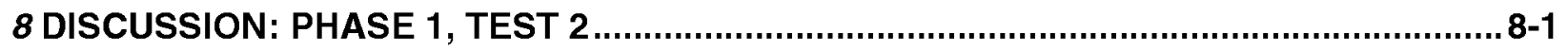

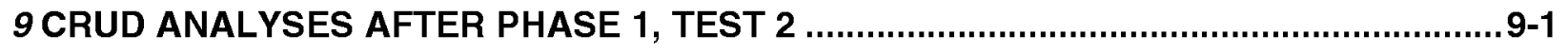

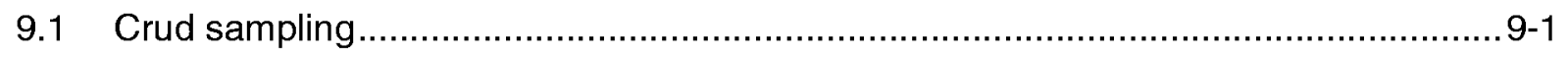

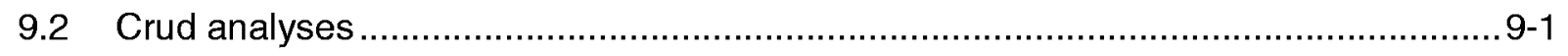

Light optical microscopy (stereo microscope) ………............................................... 9-1

Scanning electron microscopy (SEM) ………………......................................... $9-1$

Elemental analysis by energy dispersive $\mathrm{x}$-ray analysis (EDS) .................................... $9-2$

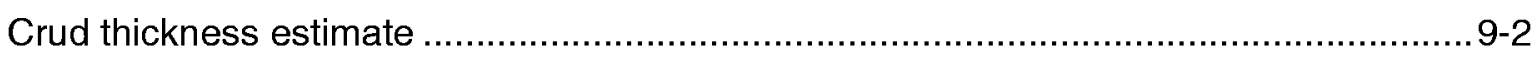

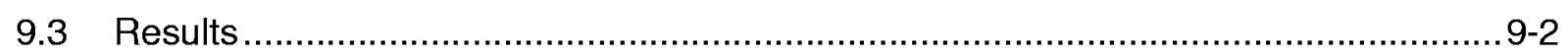

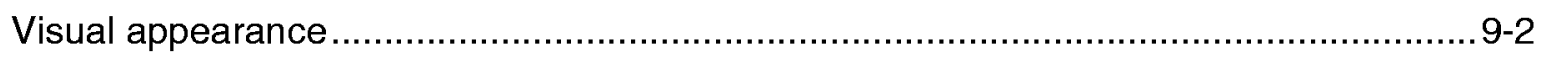




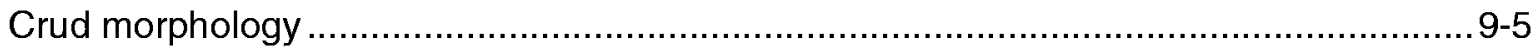

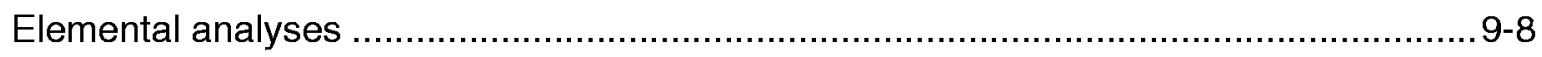

Estimate of crud thickness......................................................................... $9-9$

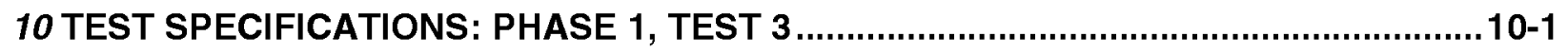

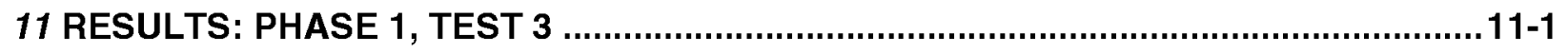

12 DISCUSSION: PHASE 1, TEST 3 ...................................................................12-1

12.1 Correlation between Lithium Return and Measured Flux Depression .......................12-2

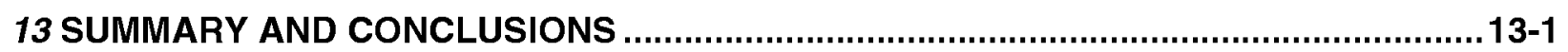

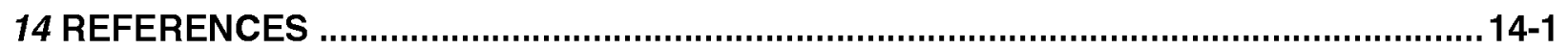




\section{LIST OF FIGURES}

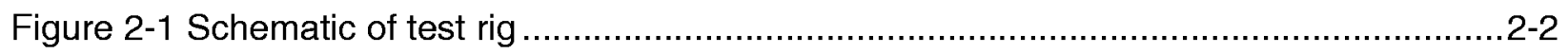

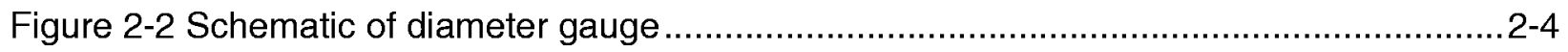

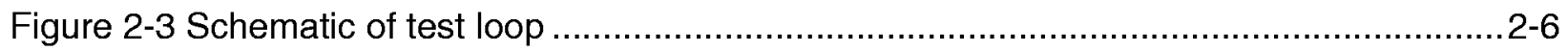

Figure 2-4 Schematic of water analysis system............................................................... $2-7$

Figure 3-1 Nuclear calculations showing the effect of ${ }^{10} \mathrm{~B}$ enrichment on neutron flux and

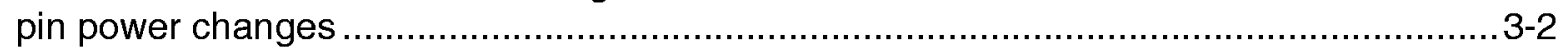

Figure 3-2 Flux / power profile to give required thermal-hydraulic conditions........................... 3-4

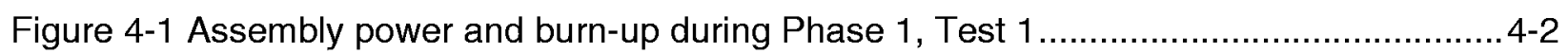

Figure 4-2 Water chemistry conditions during Phase 1, Test 1 ........................................ $4-3$

Figure 4-3 Thermal-hydraulic conditions during Phase 1, Test 1 .......................................4-4

Figure 4-4 Heat fluxes at the clad surface during Phase 1, Test 1 .....................................4-5

Figure 4-5 Axial power profile along fuel bundle ............................................................ $4-6$

Figure 4-6 Thermal-hydraulic evaluation ................................................................. 4-6

Figure 4-7 SEM micrograph of particles from coolant following a crud burst injection..............4-8

Figure 4-8 Coolant Fe and Ni concentrations during Phase 1, Test 1 ................................. 4-9

Figure 4-9 Fe:Ni ratios during Phase 1, Test 1 .............................................................. $4-9$

Figure 4-10 Fe and Ni concentrations after crud burst injection ..................................... 4-10

Figure 4-11 Coolant inlet flowrate during $\mathrm{pH}$ transients ............................................... 4-11

Figure 4-12 Soluble $\mathrm{Fe}$ and $\mathrm{Ni}$ concentrations during $\mathrm{pH}$ transients ..................................4-12

Figure 4-13 Insoluble Fe and Ni concentrations during $\mathrm{pH}$ transients ...............................4-12

Figure 4-14 Hydrogen and oxygen concentrations during oxygen injections 2 and 3 (1.5

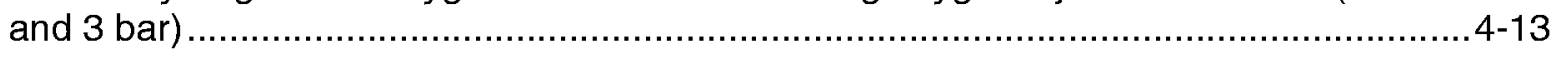

Figure 4-15 Hydrogen and oxygen concentrations during oxygen injections 4 and 5 (5

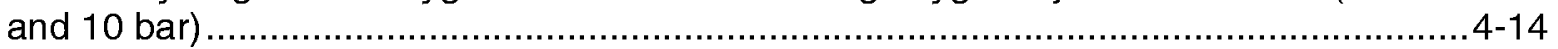

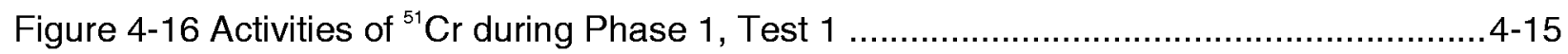

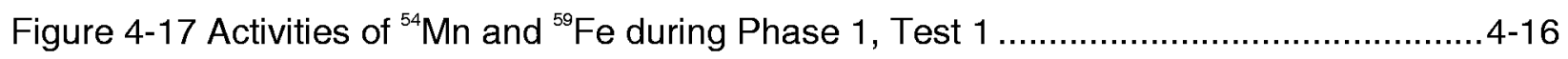

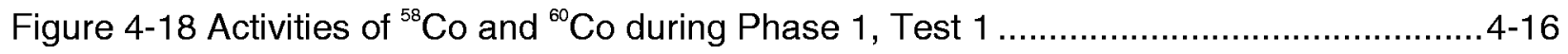

Figure 4-19 Diameter traces taken at 0.2 (Run 7275) and 161 (Run 7606) FPD ..................4-18

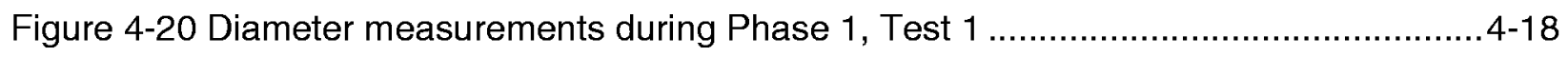

Figure 4-21 Ratios of neutron detector signals on outside of pressure flask to those inside test rig, over lower $(0-200 \mathrm{~mm})$, middle $(201-400 \mathrm{~mm})$ and upper (401 $600 \mathrm{~mm}$ ) sections of the fuel bundle. 
Figure 4-22 Increase in coolant temperature over lower (0 - $200 \mathrm{~mm})$, middle (201 - 400

$\mathrm{mm}$ ) and upper (401-600 $\mathrm{mm}$ ) sections of the fuel bundle.

Figure 4-23 Fuel temperature and cladding elongation measurements during Phase 1, Test 1

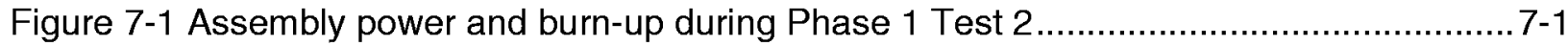

Figure 7-2 Water chemistry conditions during Phase 1 Test 2 .......................................... $7-2$

Figure 7-3 Thermal-hydraulic conditions during Phase 1 Test 2 ......................................... $7-3$

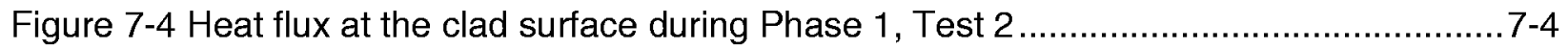

Figure 7-5 Increased power from fresh fuel rods installed for Phase 1 Test 2 ....................... 7-5

Figure 7-6 Details of injection of Fe-Ni-EDTA solution during Phase 1 Test 2 ....................... 7-6

Figure 7-7 Theoretical crud thickness on upper $40 \mathrm{~cm}$ of fuel rods from injected Fe and $\mathrm{Ni}$

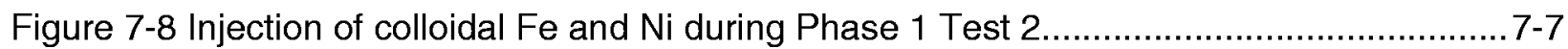

Figure $7-9$ Increases in coolant flowrate due to colloid injections ....................................... 7-8

Figure 7-10 Formate and acetate concentrations in the coolant during Phase 1 Test 2........... 7-9

Figure 7-11 Coolant Fe and Ni concentrations during Phase 1 Test 2 .............................. 7-10

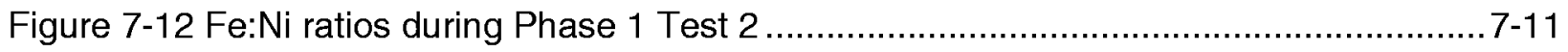

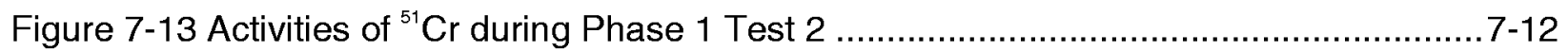

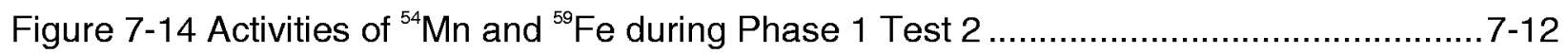

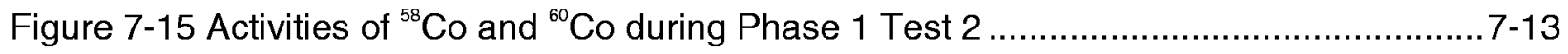

Figure 7-16 Comparison of diameter traces taken before EDTA solution was injected and before assembly power and coolant temperature were increased........................... $7-14$

Figure 7-17 Comparison of diameter traces taken before assembly power and coolant temperature were increased and 25 FPD later

Figure 7-18 Normalised neutron detector signals during Phase 1 Test 2 ............................7-15

Figure 7-19 Increase in coolant temperature over lower $(0-200 \mathrm{~mm})$, middle (201 - 400 $\mathrm{mm})$ and upper $(401-600 \mathrm{~mm})$ sections of the fuel bundle.................................... 7-16

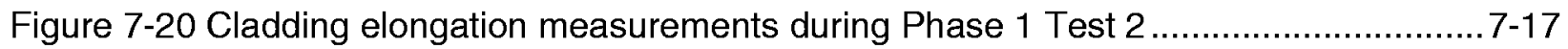

Figure 9-1 Crud deposits on upper section of fuel bundle ................................................ 9-3

Figure 9-2 Photograph showing crud deposition commencing at boundary between low and high enrichment fuel ................................................................................ 9-4

Figure 9-3 LOM analyses of sample 10-57 cm, illuminated from below (Face 1) .................... 9-5

Figure 9-4 LOM analyses of sample $10-57 \mathrm{~cm}$, illuminated from above (Face 2)...................9-6

Figure 9-5 SEM analyses of sample $10-57 \mathrm{~cm}$ : 50x magnification ..................................... 9-7

Figure 9-6 SEM analyses of sample $10-57 \mathrm{~cm}$ : 4000x magnification ..................................... 9-8

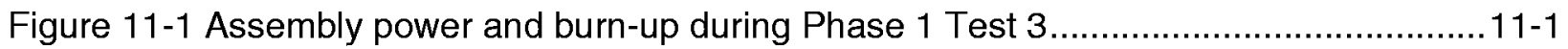

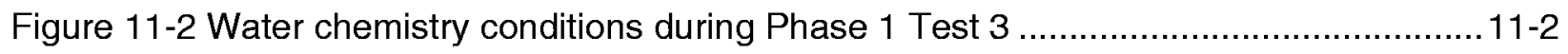

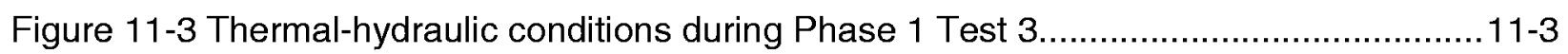

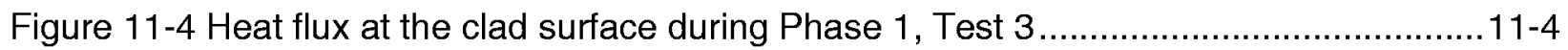

Figure 11-5 Details of injection of Fe-Ni-EDTA solution during Phase 1 Test 3 ...................11-5 
Figure 11-6 Formate and acetate concentrations in the coolant during Phase 1 Test 3..........11-6

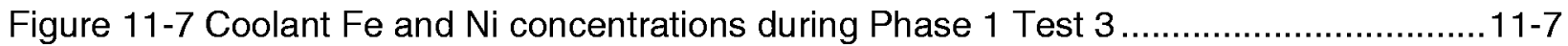

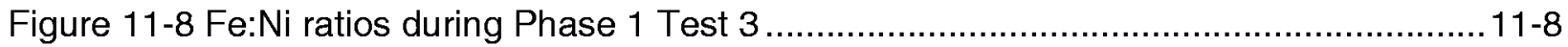

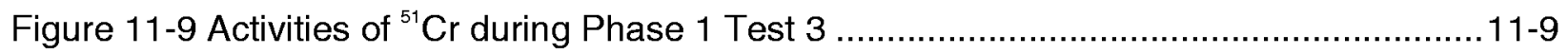

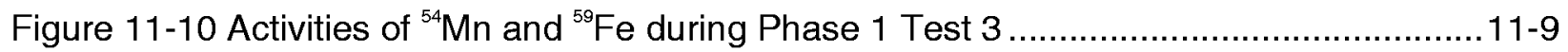

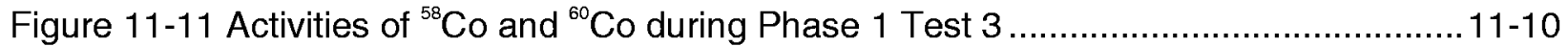

Figure 11-12 Increase in coolant temperature over lower $(0-200 \mathrm{~mm})$, middle (201 - 400

$\mathrm{mm})$ and upper $(401-600 \mathrm{~mm})$ sections of the fuel bundle..................................11-11

Figure 11-13 ND signals from IFA-665, the rig pressure flask and three neighbouring test

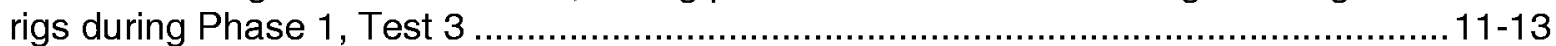

Figure 11-14 IFA-665 and pressure flask ND signals normalised to neighbouring test rig ND signals during Phase 1, Test 3

Figure 11-15 IFA-665 coolant temperature rise over fuel bundle, normalised to pressure flask ND signals during Phase 1, Test 3

Figure 11-16 Cladding elongation measurements during Phase 1 Test 3.........................11-16

Figure 11-17 Coolant Lithium Return during Phase 1 Test 3 Shutdown $11-17$

Figure 12-1 Calculated flux depression in Phase 1, Test 3 from Li return data and extrapolation of Figure 3-1 



\section{LIST OF TABLES}

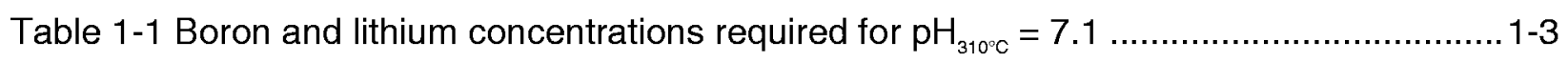

Table 2-1 Description of test rods .........................................................................

Table 4-1 Summary of diameter measurements, crud burst injections, $\mathrm{pH}$ transients and

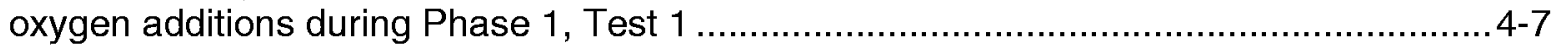

Table 5-1 Void fractions and steam quality in IFAs 585 and 665 and Test 2......................... 5-4

Table 5-2 Water chemistry conditions in IFAs 585 and 665 and Test 2.............................. 5-4

Table 6-1 Half life of Fe-EDTA complex from autoclave testing ....................................... 6-1

Table 7-1 Development of thermal-hydraulic conditions ................................................. $7-3$

Table 8-1 Comparison of thermal-hydraulic conditions in IFA-665 with those in a PWR..........8-2

Table 9-1 Ni : Fe ratios in crud samples ................................................................. 9-9

Table 11-1 Mass evaporation rates during Phase 1, Test 3 ...........................................11-4

Table 11-2 Neutron detectors used in analysis....................................................... 11-12 



\section{1 \\ INTRODUCTION}

Crud is the term given to corrosion product deposits on fuel cladding and primary system surfaces. It is produced from dissolved and particulate corrosion products in the coolant, and consists mainly of iron and nickel oxides. Many pressurised water reactors (PWRs) are currently operating with higher fuel ratings and coolant temperatures, and thus with higher surface heat fluxes at the fuel clad surface, than were common previously. Such operation results in a portion of the total heat transfer to the coolant occurring by sub-cooled nucleate boiling (SNB). Although favourable for thermal efficiency, SNB is known to enhance the formation of crud on the clad surface. This process can lead to a higher susceptibility to crud-related problems, such as increased pressure drop, increased cladding corrosion and failure, radiation field build-up, and the axial power offset anomaly (AOA) [1,2].

The axial offset (AO) of a reactor core describes the relative axial power profile, and can be defined as:

$$
A O=\frac{P_{t}-P_{b}}{P_{t}+P_{b}}
$$

where $P_{t}$ is the integrated power in the top half, and $P_{b}$ the integrated power in the bottom half of the core. The quotient is then typically multiplied by 100 to express the value as a percent [3]. AOA is the phenomenon where boron concentrates in corrosion product deposits on the upper spans of the fuel assemblies. Once sufficient boron has accumulated, measurable shifts in neutron flux occur. In order for the reactor to maintain power, these shifts occur axially downward to the lower half of the core. This results in a more negative AO, i.e. $P_{b}$ becomes greater than predicted. The AOA thus erodes shutdown margins and reduces unit reliability. For many utilities, AOA has become the main limiting operational impediment to improving plant efficiency.

In fuel cycles that have shown AOA, the largest deviation in $\mathrm{AO}$ was in the fuel assemblies with the highest power. These assemblies represented those with the highest predicted amount of SNB, and they also displayed the highest concentration of corrosion products (as observed in poolside observations and from crud scrap data).

The root cause of AOA is thought to be deposition of boron within crud on fuel cladding surfaces. For this to occur, three conditions are necessary [3]:

- sub-cooled nucleate boiling;

- corrosion products in the coolant;

- soluble boron in the coolant. 
Enhanced sub-cooled boiling accelerates corrosion product deposition. As the crud thickens, evaporation occurs at the liquid - vapour interface within pores in the deposit. Surface tension forces reduce pressure on the liquid side, drawing liquid into the deposit. Evaporation concentrates chemical species within the crud deposit.

There are two main theories for the mechanism of boron deposition. The first is precipitation of lithium metaborate $\left(\mathrm{LiBO}_{2}\right)$, which has retrograde solubility with temperature [4]. A significant concentration factor is required for precipitation to occur. According to this mechanism, changes in the $\mathrm{pH}$ of the reactor coolant system (RCS) (i.e. changes in the LiOH concentration) will affect AOA. Observations of lithium return during transients appear to support such a mechanism.

The second boron deposition theory is physi-sorption, in which boron, as non-ionic boric acid $\left(\mathrm{H}_{3} \mathrm{BO}_{3}\right)$ or borate ion, is adsorbed onto the porous crud. This mechanism requires a local (nearclad) concentration of boric acid. Laboratory experiments under proto-typical conditions sponsored by EPRI have concluded that this is a plausible mechanism [5].

Analyses of crud [6] formed under severe AOA conditions revealed the presence of flakes up to $125 \mu \mathrm{m}$ thick, with a dense population of boiling chimneys. Bonaccordite $\left(\mathrm{Ni}_{2} \mathrm{FeBO}_{5}\right)$ formed at the clad - crud interface, at concentrations up to approximately $50 \mathrm{wt} \%$. Other observed compounds included $\mathrm{m}-\mathrm{ZrO}_{2}(\sim 30 \mathrm{wt} \%)$, found mostly between wick boiling chimneys at 20 $50 \%$ of the crud depth from the clad surface; $\mathrm{NiO}(\sim 10 \mathrm{wt} \%)$ concentrated at the crud - coolant interface; and $\mathrm{NiFe}_{2} \mathrm{O}_{4}$ (nickel ferrite) at $\sim 10 \mathrm{wt} \%$. The Ni:Fe ratio in the crud can be greater than 2, compared with a value of $\sim 0.6$ in the crud observed in non-AOA plants.

The current strategy for avoiding AOA is to reduce the fuel duty, with obvious economic penalties. However, several more satisfactory strategies are under development. One method applied during shutdowns is ultrasonic cleaning of the fuel elements [7,8]; however, most methods rely on water chemistry changes in the RCS. Some of these methods are briefly described below.

\subsection{Elevated and constant $\mathrm{pH}$}

Current industry (EPRI) guidelines limit RCS LiOH concentrations to $3.5 \mathrm{ppm}$. However, there is an active elevated and constant $\mathrm{pH}$ program demonstration taking place at Comanche Peak Unit 2 in which $\mathrm{pH}_{\text {Tave }}$ is currently being operated at 7.4 with a maximum of $6 \mathrm{ppm}$ lithium concentration $[9,10]$. Crud management is the primary focus behind implementing this program: the perceived benefits are a reduction in generation, transport and deposition of corrosion products on the fuel clad (higher alkalinity results in lower releases of corrosion products and in higher solubility at high temperature of Fe-based compounds). 


\subsection{Zinc injection}

Zinc has been added to the RCS water in a number of PWRs for either primary water stress corrosion cracking (PWSCC) mitigation or primary circuit radiation field management. A side benefit may be avoidance of AOA, as the corrosion rate of austenitic alloys should be considerably reduced. There has been no reported adverse effect of zinc on crud thickness or fuel performance in non-AOA susceptible cores [11]. EPRI is sponsoring the first application of zinc at an extended cycle high duty PWR between 2002 and 2005 [12]. Crud scrapes and oxide measurements are being obtained during refuelling outages.

\subsection{Enriched boric acid}

In PWRs, boric acid is used as a soluble reactivity control agent (chemical shim) because of the high capture cross section ( 3815 barns) for thermal neutrons of the ${ }^{10} \mathrm{~B}$ isotope. Natural boron, containing approximately 20 percent ${ }^{10} \mathrm{~B}$ is used. At beginning of cycle (BOC), depending on core configurations, the coolant boron concentration can exceed $1500 \mathrm{ppm}$. A potential mitigation for AOA is use of enriched boric acid (EBA). This will allow the total amount of soluble boron (and $\mathrm{LiOH}$ ) to be lower [13]; an example is given in Table 1-1.

Table 1-1

Boron and lithium concentrations required for $\mathrm{pH}_{310^{\circ} \mathrm{C}}=7.1$

\begin{tabular}{|l|l|l|}
\hline & \multicolumn{1}{|c|}{ Natural boron } & \multicolumn{1}{|c|}{$80 \%$ enriched ${ }^{10} \mathrm{~B}$} \\
\hline Boron, ppm & 1500 & 375 \\
\hline LiOH, ppm & 4 & 0.85 \\
\hline
\end{tabular}

Use of EBA has a number of perceived advantages:

- EBA allows coolant operation at optimum pH throughout the fuel cycle. There should be a smaller mass of corrosion products depositing on the fuel clad, and thus a positive impact on one of the three conditions necessary for AOA to occur.

- The total amount of boron in the coolant will be reduced, thus delaying the onset of $\mathrm{LiBO}_{2}$ precipitation and/or more significantly, reducing the rate of physi-sorption.

- As deposits are reduced, primary circuit radiation fields may be lower (ALARA).

- Lithium concentrations will be reduced correspondingly with boron. This may reduce the risk of PWSCC and fuel clad corrosion.

The first phase of an in-core test has been performed in the Halden reactor to study the effect of EBA on the AOA. The objective of this phase was to deposit crud on fuel rods and measure the resulting flux depression due to boron hide-out.

This report describes the test rig and associated loop, the test conditions for Phase 1 of the test, and presents the results obtained. 



\section{DESCRIPTION OF IN-CORE TEST RIG AND LOOP SYSTEM}

The Halden Boiling Water Reactor (HBWR) is a test reactor with a maximum power of $20 \mathrm{MW}$ that is cooled and moderated by boiling heavy water (normal operating temperature $235^{\circ} \mathrm{C}$ and pressure 34 bar). For tests requiring representative light water reactor (LWR) conditions, test rigs are housed in pressure flasks that are positioned in fuel channels in the reactor and connected to dedicated water loops. Typically, the reactor operates for two 100 day reactor cycles each year. Typical fast fluxes are $3 \times 10^{13} \mathrm{n} \mathrm{cm}^{-2} \mathrm{~s}^{-1}$, equivalent to an accumulated fluence of $6 \times 10^{20} \mathrm{n} \mathrm{cm}^{-2}$ in a calendar year.

A rig schematic is shown in Figure 2-1. The pressure flask was constructed from AISI 316 stainless steel with an inside diameter of $45 \mathrm{~mm}$. The test rig included eight fuel rods in a square array; four of $9.50 \mathrm{~mm}$ diameter at orientations of $0,90,180$ and $270^{\circ}$, with four rods of 7.25 $\mathrm{mm}$ at the corner positions (limitations in the size of pressure flask did not allow all eight rods to be of the larger diameter). The down-comer flow tube was positioned in the centre of the test rig. One of the larger rods could be hydraulically withdrawn into the upper part of the pressure flask and scanned by a diameter gauge. The rods were fuelled with fresh $\mathrm{UO}_{2}$ pellets, with the enrichments determined so that the required thermal-hydraulic conditions were obtained - see Chapter 3. The cladding material was Zircaloy-4. Details of the fuel rods are given in Table 2-1.

A diagram of a diameter gauge is shown in Figure 2-2. The gauge consists of a differential transformer with primary and secondary coils arranged symmetrically on an E-shaped ferritic core. A ferritic armature is arranged along the face of the $\mathrm{E}$, and is pivoted in the middle. Two or three feelers at different radial positions on a fuel rod transmit diameter variations to the armature. A fixture with three spring loaded fingers keeps the differential transformer in position close to the rod.

Diameter traces were obtained by moving the fuel rod axially along the gauge, which generated a complete profile, in arbitrary units, of the rod diameter. A sinusoidal position indicator attached to the piston recorded the axial location of each diametral measurement. Each diameter trace was analysed by comparing the average diameter along the fuel with the diameter of one of the calibration steps that are machined on the end and middle plugs of the rods. This value was converted from arbitrary units to $\mu \mathrm{m}$ from the known magnitude of the calibration steps $(50 \mu \mathrm{m})$. Diameter measurements could be taken as often as every 10 minutes and to an accuracy of $\bullet$ approximately $2 \mu \mathrm{m}$. 


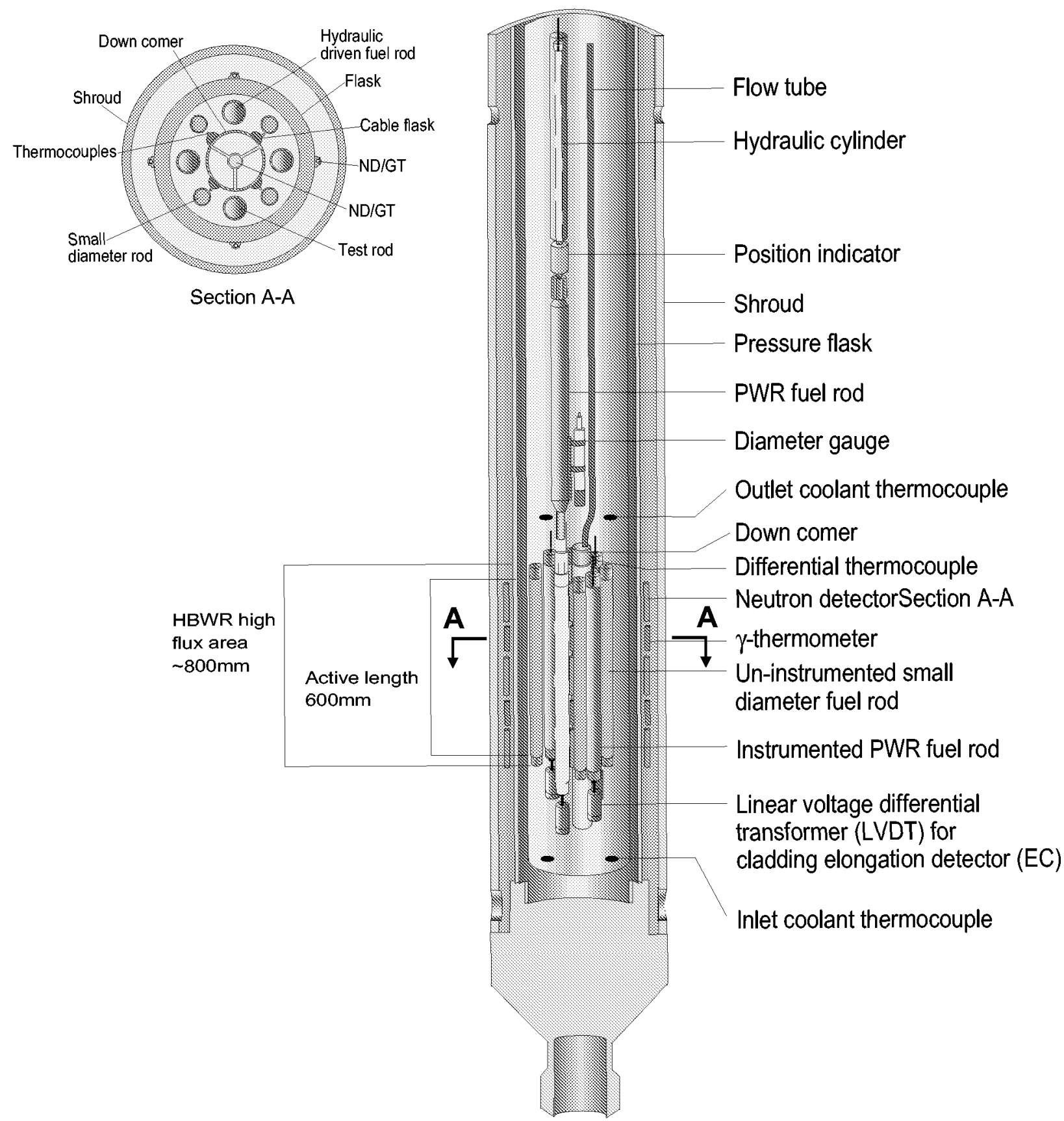

Figure 2-1

Schematic of test rig 
Table 2-1

Description of test rods

\begin{tabular}{|c|c|c|c|}
\hline & Large rod & $\begin{array}{l}\text { Large rods with } \\
\text { thermocouple }\end{array}$ & Small rods \\
\hline Number of rods & 1 & 3 & 4 \\
\hline Rod numbers & 1 & $2,3,4$ & $5,6,7,8$ \\
\hline Fuel length (mm) & \multicolumn{3}{|c|}{600} \\
\hline Clad OD (mm) & \multicolumn{2}{|c|}{9.50} & 7.25 \\
\hline Clad ID (mm) & \multicolumn{2}{|c|}{8.36} & 6.45 \\
\hline Fuel OD (mm) & \multicolumn{2}{|c|}{8.18} & 6.33 \\
\hline Fuel ID (mm) & - & $\begin{array}{l}1.8(300 \mathrm{~mm} \\
\text { length) }\end{array}$ & - \\
\hline $\begin{array}{l}\text { Fuel enrichment (wt\% U-235) in upper } \\
\text { section }(201-600 \mathrm{~mm})\end{array}$ & \multicolumn{2}{|c|}{6.7} & 8.4 \\
\hline $\begin{array}{l}\text { Fuel enrichment (wt\% U-235) in lower } \\
\text { section }(0-200 \mathrm{~mm})\end{array}$ & \multicolumn{2}{|c|}{3.1} & 3.9 \\
\hline Fuel - clad diametral gap $(\mu \mathrm{m})$ & \multicolumn{2}{|c|}{180} & 120 \\
\hline Fuel mass (g) & 322 & 313 & 194 \\
\hline
\end{tabular}




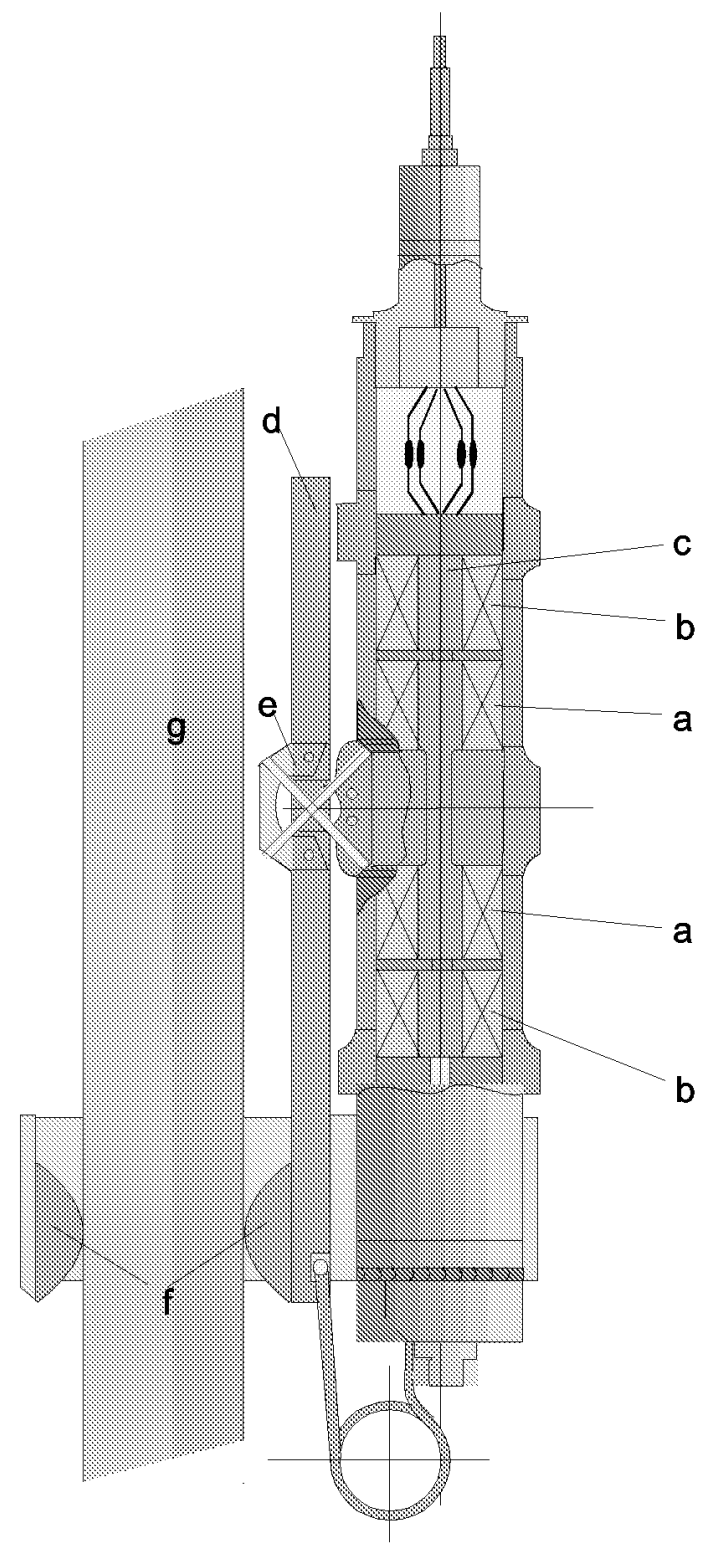
a: Primary coil
b: Secondary coil
c: Ferritic bobbin

d: Ferritic armature

e: Cross spring suspension

f: Feelers

g: Fuel rod

Figure 2-2

Schematic of diameter gauge 
All of the larger diameter fuel rods, with the exception of the rod to be analysed with the diameter gauge, were instrumented with fuel centre-line thermocouples. The four large diameter rods were also instrumented with cladding elongation detectors.

Instrumentation in the test rig consisted of 3 self-powered neutron detectors (NDs), 7 coolant thermocouples, and 16 differential coolant thermocouples. The NDs were positioned in the centre of the rig to measure the neutron flux at the centres of the lower, middle and top thirds of the fuel rods. The differential coolant thermocouples were arranged in four groups positioned at radial intervals of $45^{\circ}$, in which each group contained four thermocouples at different axial locations.

In addition, 12 neutron detectors were attached to the outside of the pressure flask. The NDs were arranged in three groups of four, positioned at radial intervals of $45^{\circ}$, and were located at the same axial heights as the corresponding instruments inside the pressure flask. The purpose of the pressure flask instrumentation was to allow detection of flux depression by investigation of the ratio of the signals in the inside and on the outside of the test rig.

The loop was constructed from AISI 316L stainless steel with a design pressure and temperature of 200 bar and $350^{\circ} \mathrm{C}$. The main flow circuit was constructed from $38 \mathrm{~mm}$ I.D. tubing with a volume of approximately 70 litres. The purification circuit added a further 29 litres. A diagram of the loop is shown in Figure 2-3.

Chemical control of the loop coolant was achieved by additions and by use of the purification plant. Soluble impurities were removed by a deep bed demineraliser saturated with respect to lithium and boric acid. Particulates were removed at the inlet and outlet of the purification plant by two $0.1 \mu \mathrm{m}$ porosity cartridge type filters. The outlet filter was employed mainly to prevent degraded resin entering the main loop circuit. Normal flow rate through the purification plant was $160 \mathrm{l} / \mathrm{h}$, and was controlled by a pneumatically operated valve.

The Li level in the loop, which tends to increase during operation, was controlled by intermittently passing water through an ion exchanger bed for lithium removal. Additionally, lithium was controlled by passing a very small and adjustable flow through a lithium removal ion exchanger in connection with the water analysis system (Figure 2-4).

The loop boron level was controlled by adjusting the temperature of the water passing through the purification line. A small electric heater was operated for this control. 


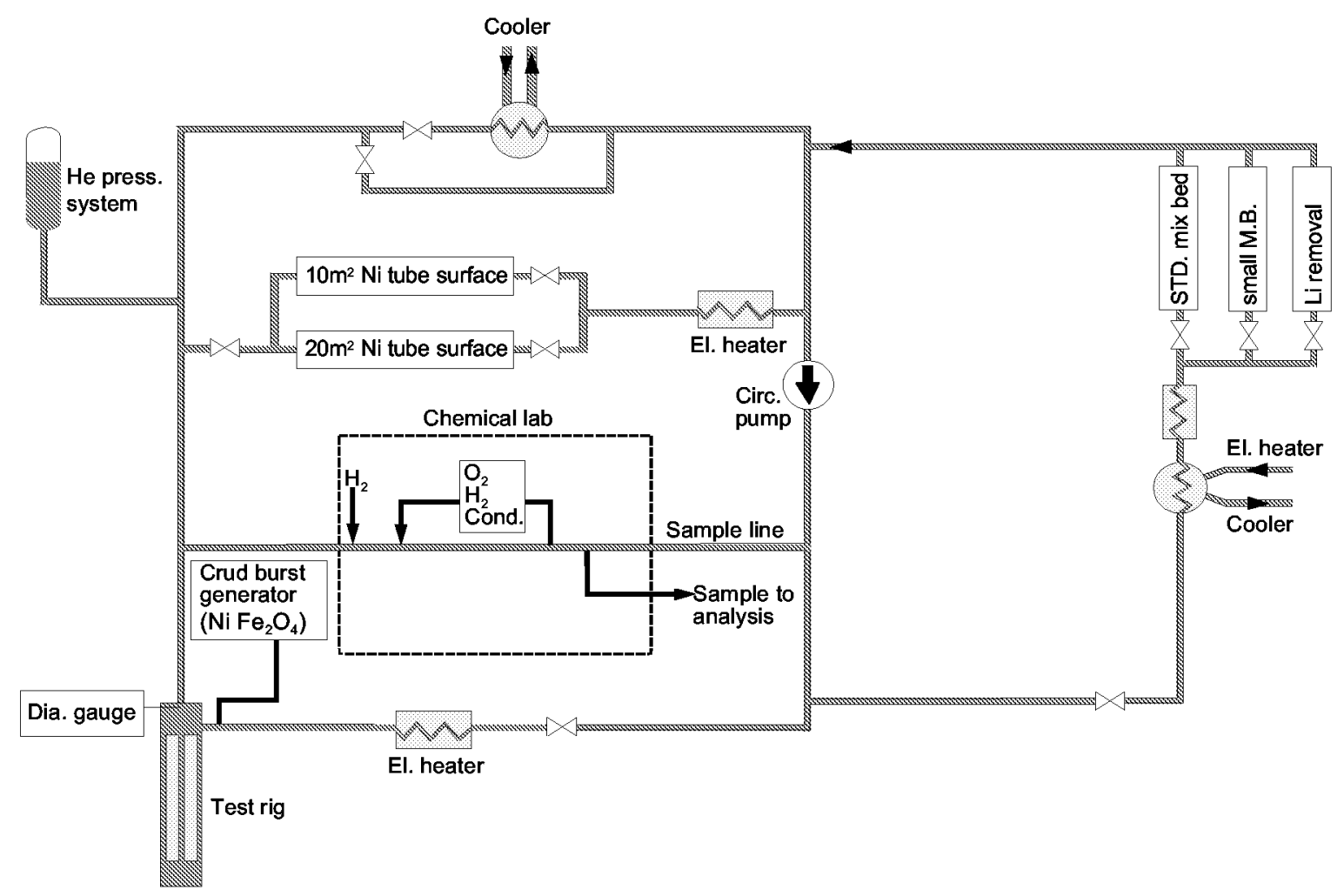

Figure 2-3

Schematic of test loop

The loop water sampling system, Figure 2-4, was a continuously flowing loop to an experimental laboratory outside the reactor hall. The flow rate was about $201 / \mathrm{h}$. A fraction of the water flow was cooled to approximately $25^{\circ} \mathrm{C}$ before the sample was taken. As described above, some of the sample line flow could be directed, by means of a flow control valve, through a lithium removal ion exchanger in order to keep the loop lithium level at a constant value.

A critical parameter for the formation of crud is the ratio of $\mathrm{Fe}$ and $\mathrm{Ni}$ in the coolant. The loop contained an autoclave containing small-bore nickel tubes such that the surface area ratio between stainless steel and nickel was similar to that in a PWR.

A "crud burst generator" was included to simulate a power transient and thereby accelerate the build-up of crud on the fuel cladding surface. The generator consisted of a tank (capacity 10 litres) containing a suspension of non-stoichiometric nickel ferrite $\left(\mathrm{Ni}_{x} \mathrm{Fe}_{y} \mathrm{O}_{4}\right)$ particles. The particles were supplied by AECL, Canada, and had an Fe:Ni ratio of 2.3. Each injection involved a volume in the range from 300 to $500 \mathrm{ml}$, using helium gas to force the slurry into the loop, via a $38 \mathrm{~mm}$ ID pipe, and was of duration from one to two minutes. The point of injection was as near to the test section as possible (about 10 metres); at this point, the loop water temperature was $289^{\circ} \mathrm{C}$. The temperature of the slurry was $50-60^{\circ} \mathrm{C}$. 


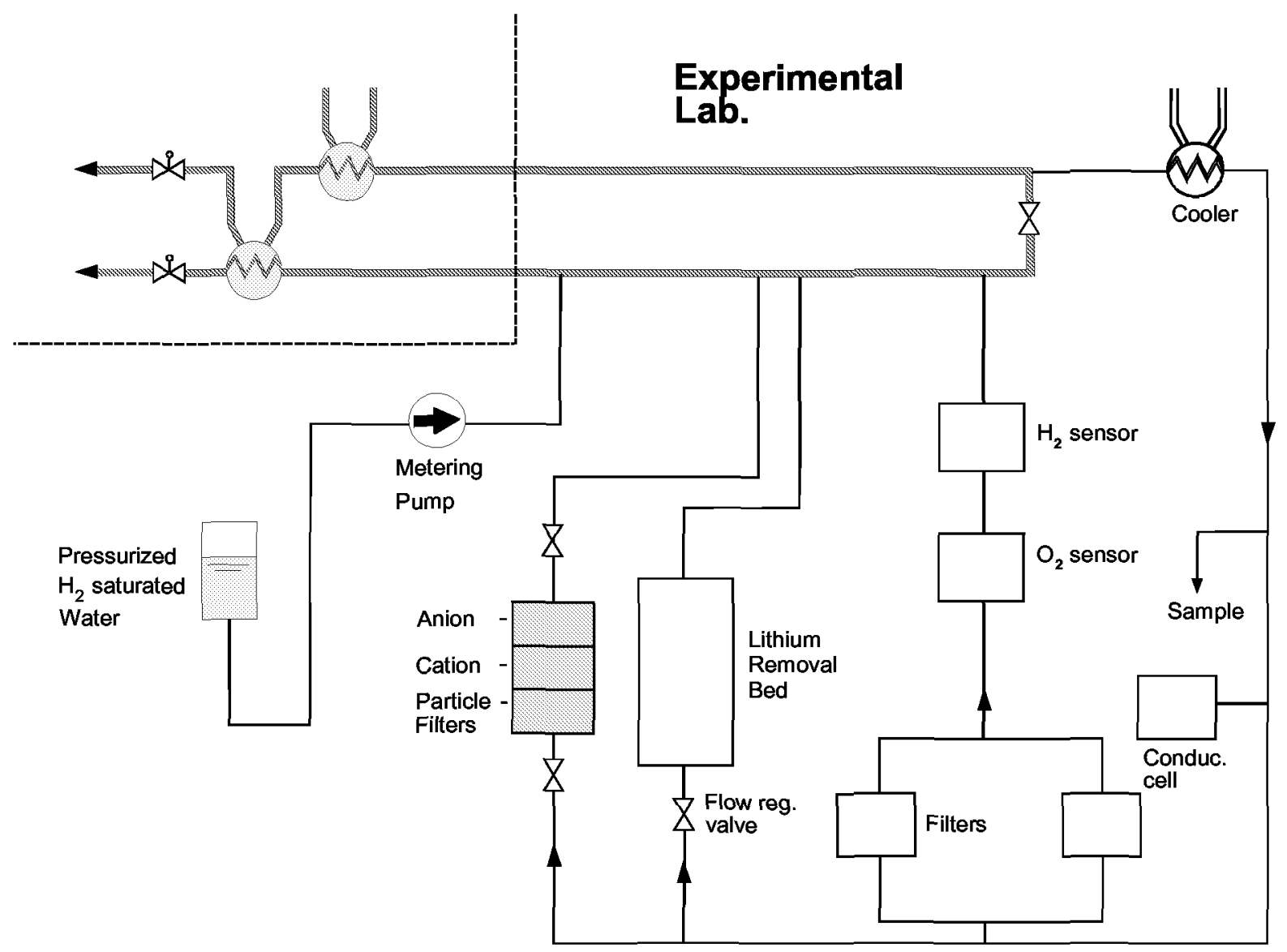

Figure 2-4

Schematic of water analysis system

The dissolved oxygen and hydrogen contents of the water were continuously monitored by Orbisphere detectors (MOCA 3600 instruments with the sensors 31240.01 for hydrogen and 31140.01 for oxygen). The loop conductivity was also monitored on-line, using a Yokogawa EXA SC402 instrument. Lithium and boron levels were controlled to obtain the desired $\mathrm{pH}$.

The coolant chemistry was characterised by both grab samples and integrated sampling. Grab samples, taken after a $0.45 \mu \mathrm{m}$ Millipore particle filter, were analysed for dissolved transition metals by ICP-MS (Inductively Coupled Plasma - Mass Spectrometry) (Perkin-Elmer, Elan 6000). Dissolved anions were measured with CE (Capillary Electrophoresis) (Waters Capillary Ion Analyser). The lithium and silicon contents were analysed by AAS (Atomic Absorption Spectroscopy) (Perkin-Elmer 1100), and boron by titration.

A filter package with $0.45 \mu \mathrm{m}$ pore size was used for integrated sampling, employing a Millipore particle filter and two Gelman ion exchanger filters. The filter packages were exposed for approximately 3 hours in the continuously flowing sampling line. The filters were analysed by EDXRF (Energy Dispersive X-Ray Fluorescence Spectroscopy) (Spectro X-lab 2000) and by gamma spectroscopy (Canberra GC1518-7500SL) with a germanium detector and Genie 2000 software. 



\section{3 \\ TEST SPECIFICATIONS: PHASE 1,TEST 1}

This chapter presents the specifications for the beginning of the test. As the test proceeded, changes were made to attempt to deposit crud. These changes are detailed in Chapters 4 and 5.

Initial operating conditions were chosen to represent as closely as possible those in operating PWRs that have experienced AOA. It was thus hoped to deposit the amount and type of crud associated with AOA.

\subsection{Water Chemistry Conditions}

The boron concentration in the coolant was $1400 \mathrm{ppm}$, with a ${ }^{10} \mathrm{~B}$ enrichment of 40 percent. This high level of ${ }^{10} \mathrm{~B}$ was chosen as a result of nuclear calculations (using the HELIOS lattice code [14]) in order that it would be possible to detect neutron flux depressions caused by deposited boron. For the calculations, it was assumed that an axial offset of 3 percent is caused by $8 \mathrm{mg} / \mathrm{dm}^{2}$ of natural boron deposited uniformly on the fuel surface [15]. The calculations showed that the neutron flux in the detectors in the centre of the test rig decreases with boron concentration, and that the rod power changes in a similar manner. Both effects change linearly with boron concentration (Figure 3-1). Hence, utilisation of enriched boron would facilitate the detection of the effects caused by boron incorporated in the crud. It was considered that the power changes that would be caused using natural boron $(\sim 20 \%)$ would be too small to be determined with confidence.

The coolant lithium concentration was $3.15 \mathrm{ppm}$, resulting in a $\mathrm{pH}_{300^{\circ} \mathrm{C}}$ value of 7.0. Dissolved hydrogen at $30-35 \mathrm{cc} / \mathrm{kg}$ was added to the water. Target total iron and nickel concentrations during normal operation (i.e. without crud bursts) were $7-9$ and 3 - 5 ppb, respectively. 


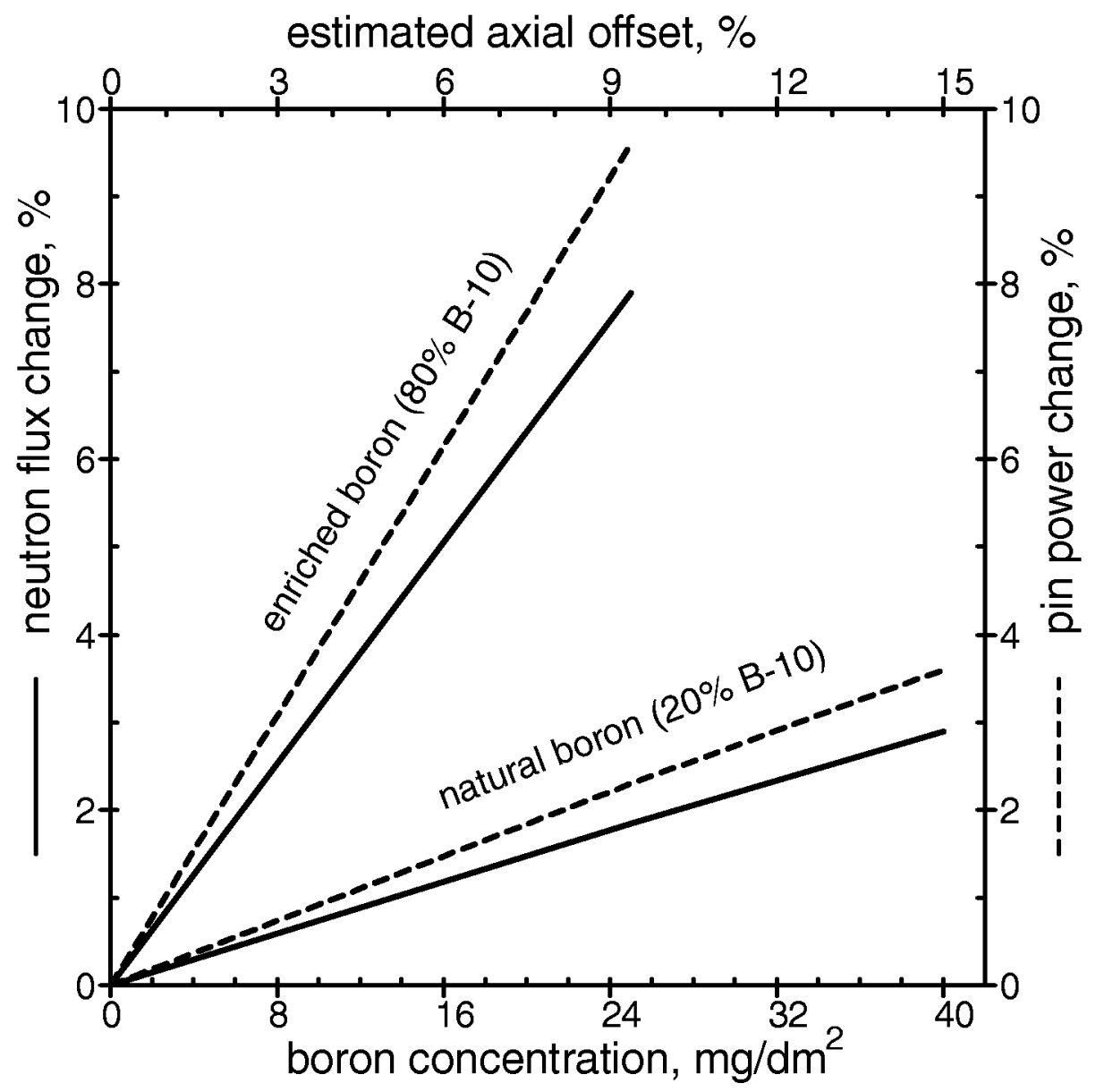

Figure 3-1

Nuclear calculations showing the effect of ${ }^{10} \mathrm{~B}$ enrichment on neutron flux and pin power changes

\subsection{Thermal-Hydraulic Conditions}

Thermal-hydraulic parameters for lead fuel assemblies in plants subject to AOA are listed below [15].

$T_{\text {in }}$

$T_{\text {out }}$

System pressure

Clad surface temperature

Flow velocity

Surface heat flux

Mass evaporation rate $293^{\circ} \mathrm{C}$

$338^{\circ} \mathrm{C}$

$15.5 \mathrm{MPa}$

$\sim 346^{\circ} \mathrm{C}$ (saturation temp)

$5.2 \mathrm{~m} \mathrm{~s}^{-1}$

$98 \mathrm{~W} \mathrm{~cm}^{-2}$

$980-2440 \mathrm{~kg} \mathrm{~h}^{-1} \mathrm{~m}^{-2}$ 
Recognising that it is not possible to duplicate all these parameters in a test reactor, emphasis was placed on the mass evaporation rate, with the specification that this should be achieved without steam at the exit to the test section, i.e., with zero steam quality. The thermal-hydraulic requirements for the test were:

- A mass evaporation rate in the range from 980 to $2440 \mathrm{~kg} \mathrm{~h}^{-1} \mathrm{~m}^{-2}$.

- An axial temperature increase along the fuel rods of $\geq 17^{\circ} \mathrm{C}$.

- Onset of boiling approximately halfway along the fuel rods.

To obtain all three of the above conditions it was necessary to have different linear heat rates (LHRs) in the lower and upper sections of the fuel rods: in the lower section, the LHR should be low enough to maintain single phase flow, while SNB should occur in the upper section. This was achieved by using fuel pellets with different enrichments in the lower third and upper two thirds of the fuel stack (see Section 2), and by careful positioning of the fuel with respect to the reactor's neutron flux profile (Figure 3-2).

The required test conditions were calculated using the Halden Project's in-house thermalhydraulics code, Vista:

- Coolant inlet temperature: $290^{\circ} \mathrm{C}$.

- Coolant inlet velocity: $1.8 \mathrm{~m} \mathrm{~s}^{-1}$.

- Fuel LHRs:

\begin{tabular}{|c|c|c|}
\hline \multirow{2}{*}{$\begin{array}{c}\text { Clad OD } \\
(\mathrm{mm})\end{array}$} & Lower section $(\mathbf{0}-\mathbf{2 0 0} \mathrm{mm})$ & Upper section $(201-600 \mathrm{~mm})$ \\
\cline { 2 - 3 } & 14 & 26 \\
\hline 7.25 & 18 & 34 \\
\hline 9.50 & $1 \mathrm{~kW} / \mathrm{m})$ \\
\hline
\end{tabular}

These conditions resulted in a calculated mass evaporation rate of $2333 \mathrm{~kg} / \mathrm{h} \mathrm{m} 2$. 
Test Specifications: Phase 1, Test 1

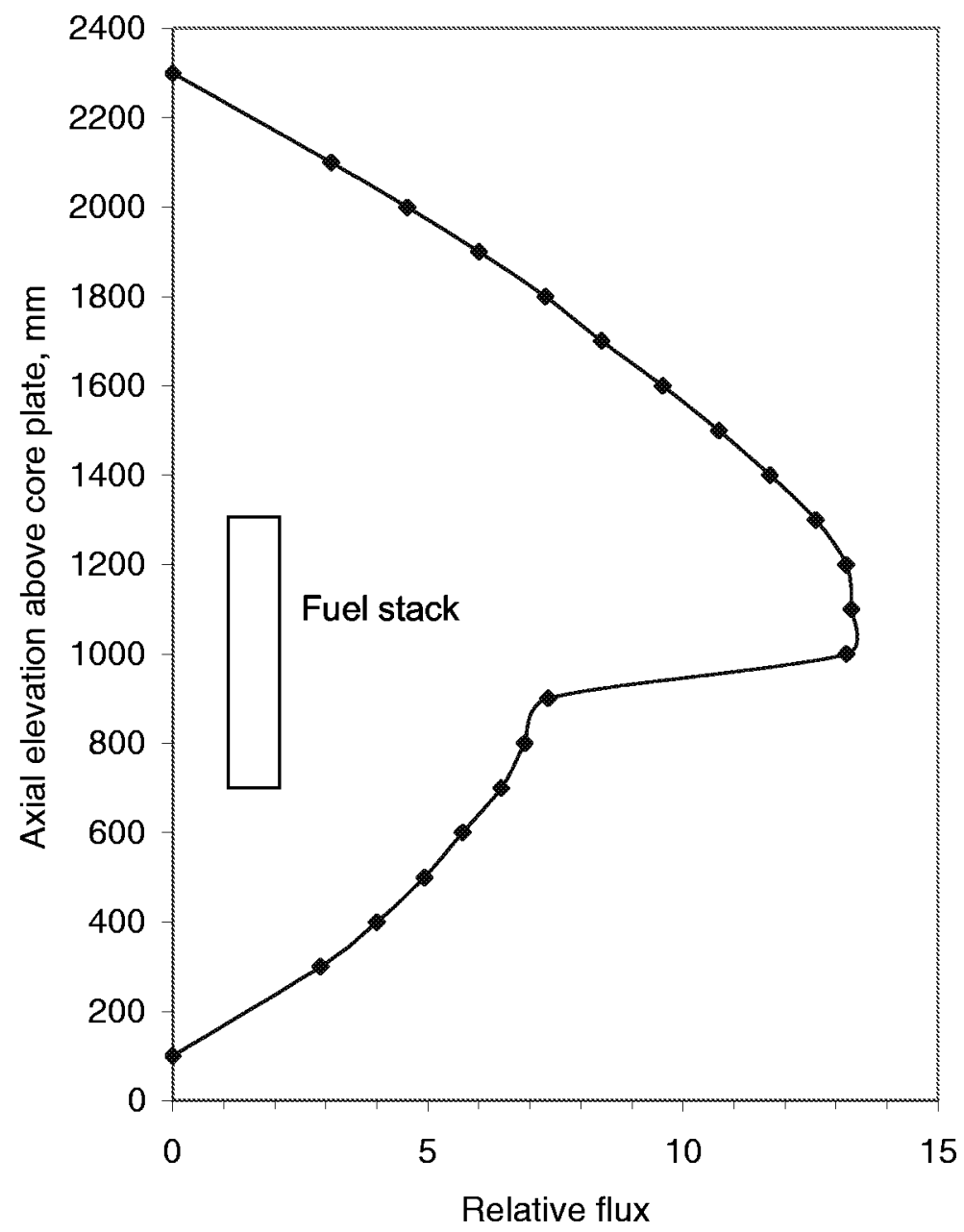

Figure 3-2

Flux / power profile to give required thermal-hydraulic conditions 


\section{4 \\ RESULTS: PHASE 1, TEST 1}

The test was divided into three separate periods: Phase 1, Test 1 was conducted over a period of 160 full power days (FPD) during the period from August 2002 to May 2003. Phase 1, Test 2 was loaded in January 2004 and operated for a further 97 FPD until May 2004. The third cycle commenced in July 2004 and operated for 88 FPD until October 2004. There were significant differences in the water chemistry conditions between the tests; hence the results from each are presented separately.

Test rig power and assembly burn-up during Phase 1, Test 1 are shown in Figure 4-1. The test rig was loaded in the latter period of a reactor cycle (before commencement of Test 1) and operated for approximately 25 days before reactor shutdown. The main purpose of this period was to perform a power calibration and to ensure that all instrumentation was functioning correctly. Test 1 commenced in December 2002 and continued until shutdown in May 2003. This period included several power transients and two short shutdowns, all of which were connected with operation of other test rigs in the reactor.

At the start of irradiation, test rigs in the Halden reactor are power calibrated. This is done by measuring the coolant temperature change between the bottom and top of the fuel section, which gives the enthalpy change in the rig. The product of the enthalpy change and coolant flowrate gives the thermal power of the assembly [16]. The purpose of the calibration is to provide the conversion factor between neutron detector signals and assembly power; so that power can be calculated over the lifetime of the experiment (i.e. fuel depletion can be accounted for). Measurement of the thermal power is essential in the current test as it is needed for calculation of the coolant mass evaporation rate on the fuel clad surface.

Until the calibration has been performed, a calculated value of this conversion factor (obtained from HELIOS calculations) is used. Subsequently, power is back-calculated using the experimentally-derived factor. It can be seen in Figure 4-1 that power during the first 25 days (i.e. when the calculated conversion factor was being used) was higher than in the remainder of the test. This was because the conversion factor obtained from the power calibration was significantly different from the calculated value. When the calibration data had been analysed, rig power was adjusted so that the required operational conditions were obtained. 

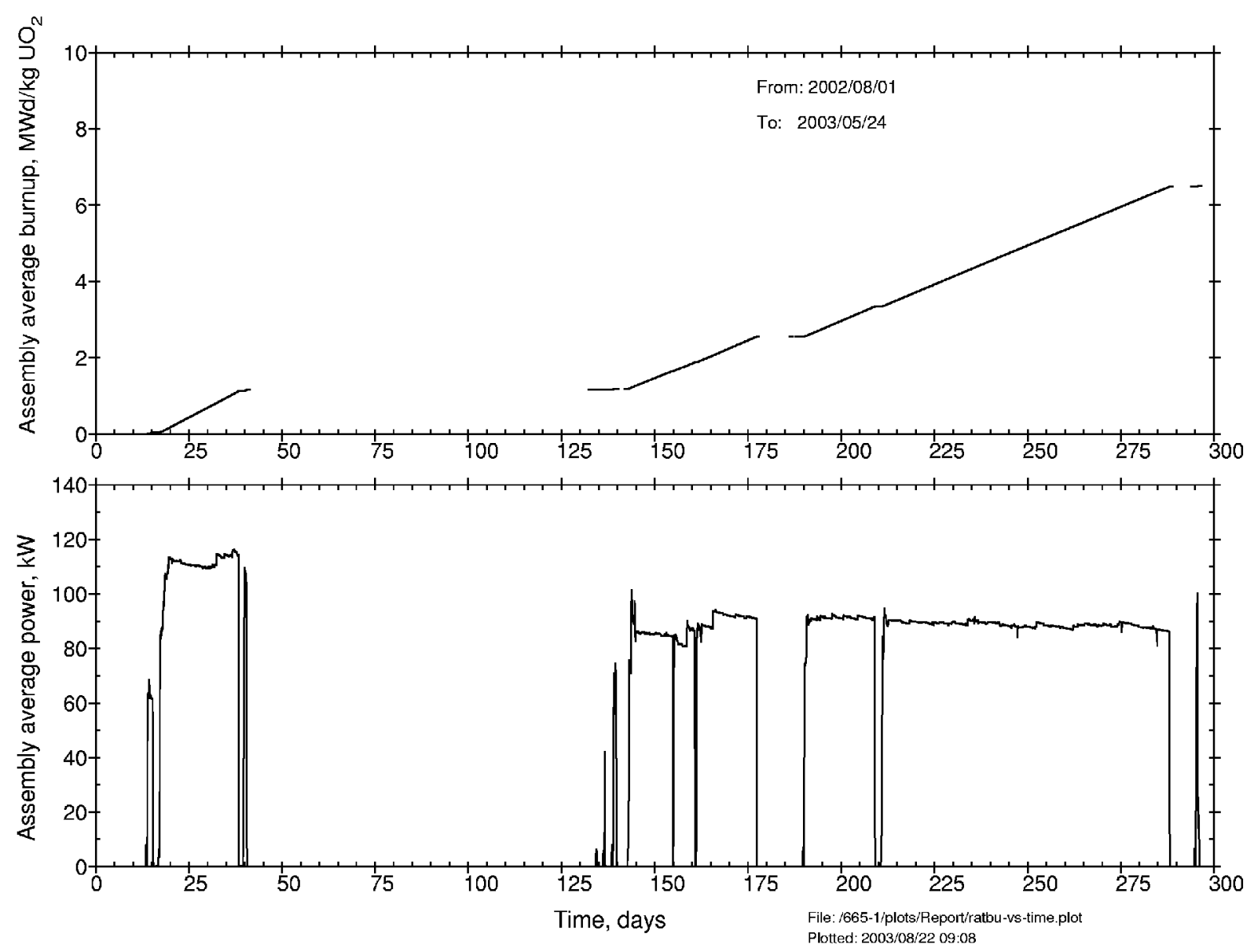

Figure 4-1

Assembly power and burn-up during Phase 1, Test 1

Bulk chemistry conditions are shown in Figure 4-2. Lithium, boron and hydrogen levels were maintained at specified levels, with the exceptions of short periods when the Li level was intentionally reduced during coolant $\mathrm{pH}$ transients (see below). The measured conductivity (approximately $50 \mu \mathrm{S} / \mathrm{cm}$ ) was higher than would be expected $(31.7 \mu \mathrm{S} / \mathrm{cm}$ ) and indicates that the monitor was not functioning correctly. However, it is considered that any trends in conductivity would be monitored correctly. 

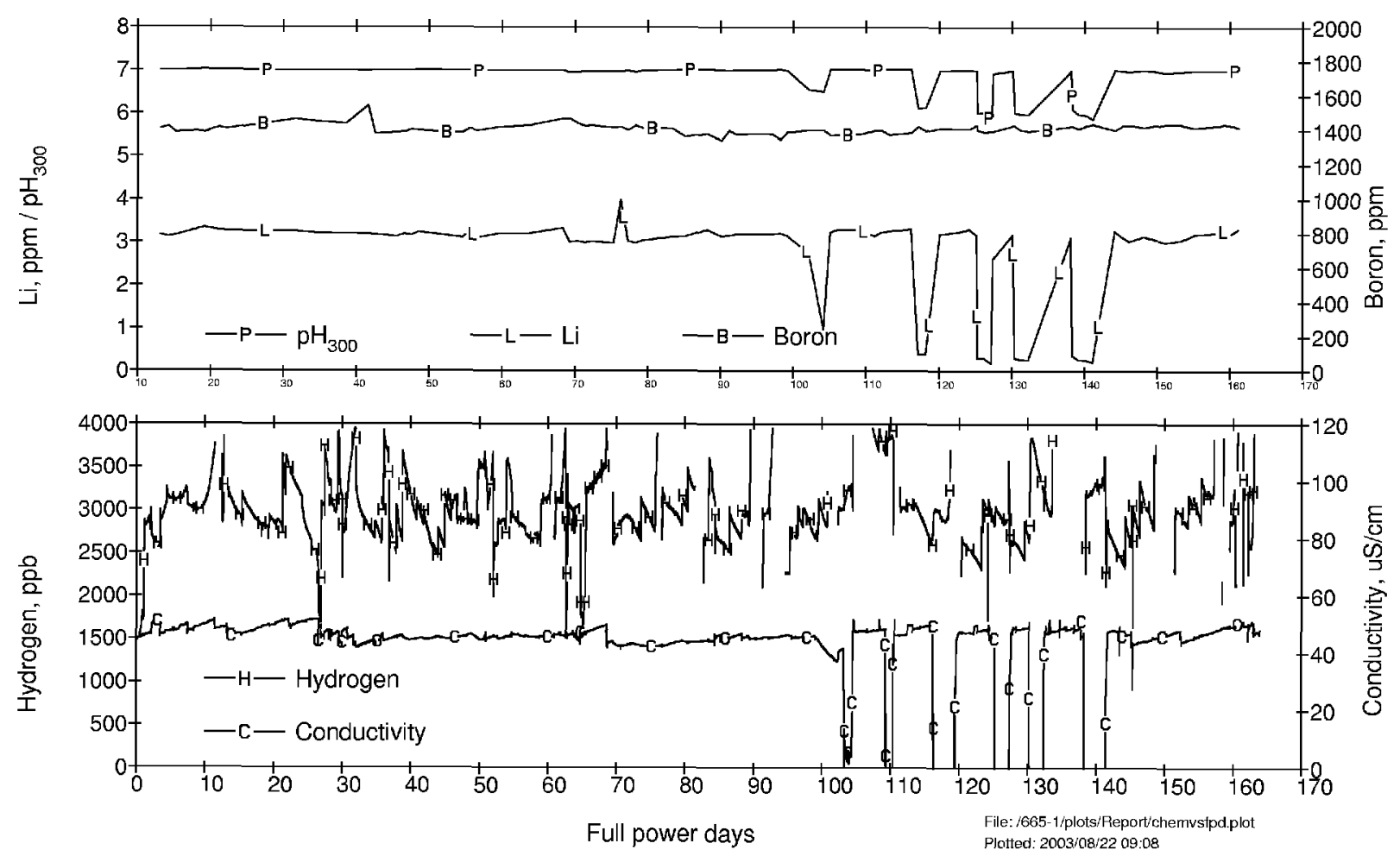

Figure 4-2

Water chemistry conditions during Phase 1, Test 1

Thermal-hydraulic conditions (coolant inlet temperature, temperature rise over the fuel bundle and inlet flowrate) are shown in Figure 4-3. At the start of the test, the maximum attainable flowrate was $1.05 \mathrm{~m} \mathrm{~s}^{-1}$, compared with the design value of $1.8 \mathrm{~m} \mathrm{~s}^{-1}$, which indicates that there was a flow restriction somewhere in the test rig. The reductions in flowrate seen after 110 FPD correlate with the coolant $\mathrm{pH}$ transients (see below).

Initially, when actual rig power was somewhat uncertain (i.e. until the power calibration had been performed), the rig inlet coolant temperature was set to $280^{\circ} \mathrm{C}$. This was done as a safety precaution against burn-out of the assembly. At the start of the second period, the temperature was reduced to $264^{\circ} \mathrm{C}$ for a period of two weeks. The purpose of this was to ensure that the maximum coolant temperature was less than $285^{\circ} \mathrm{C}$, which should promote formation of nickel ferrite on the fuel surface, which should encourage crud deposition due to its surface properties. (At higher temperatures, Halden thermodynamic calculations predicted formation of $\mathrm{NiO}$ ). The temperature was then raised to the design value of $290^{\circ} \mathrm{C}$. For the last 16 days of the test, inlet temperature was further raised to $294^{\circ} \mathrm{C}$ to increase the mass evaporation rate on the fuel surface. 

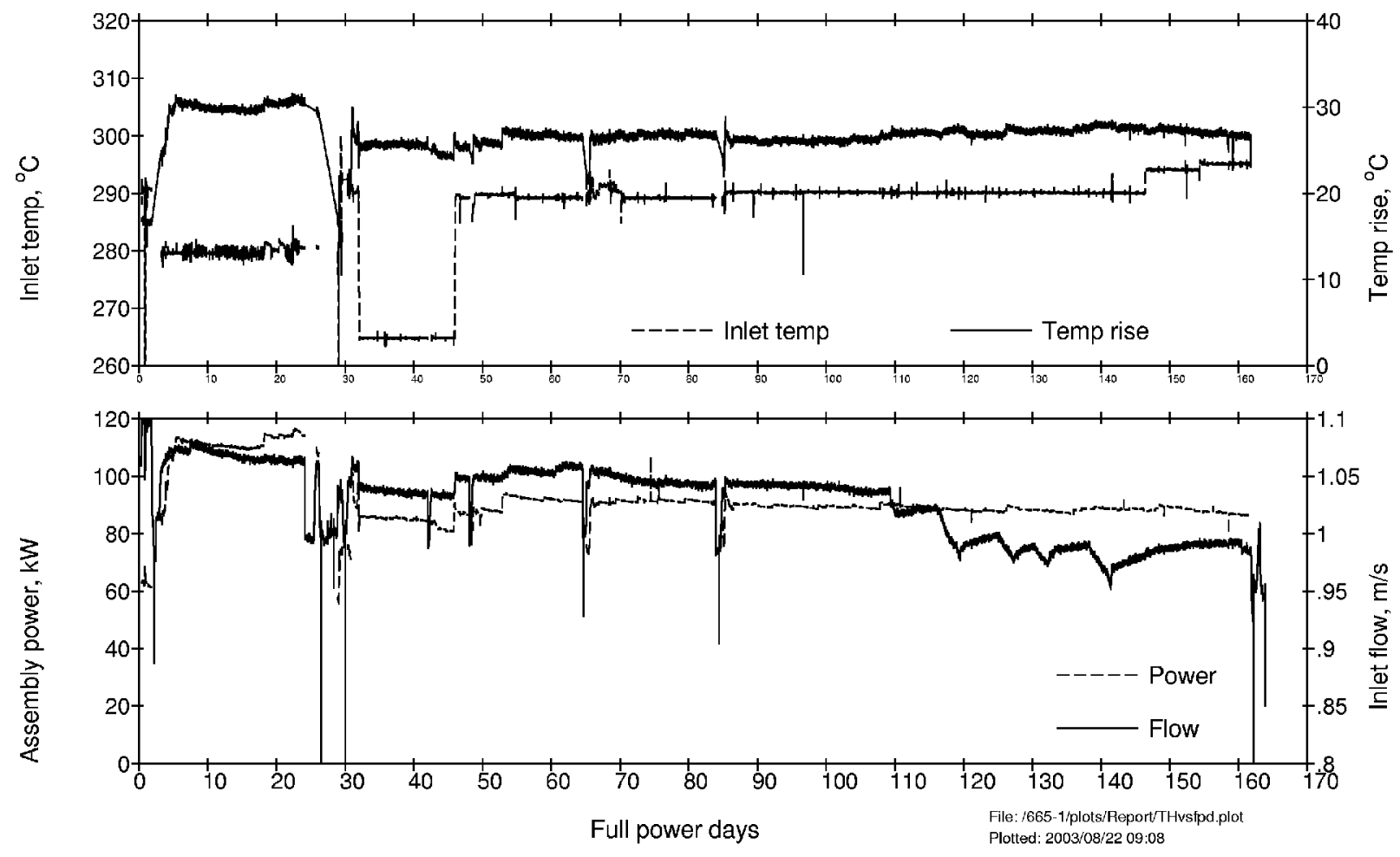

Figure 4-3

Thermal-hydraulic conditions during Phase 1, Test 1

Heat fluxes at the clad surface are shown in Figure 4-4. The $\mathrm{UO}_{2}$ enrichments for the two different rod diameters were chosen so that the heat fluxes would be similar. Values of approximately 500 and $850 \mathrm{~kW} \mathrm{~m}^{-2}$ were obtained for the lower $(200 \mathrm{~mm})$ and upper $(400 \mathrm{~mm})$ sections of the fuel, respectively.

The power profile along the fuel bundle and the resulting calculated thermal-hydraulic conditions during steady-state operation are shown in Figures 4-5 and 4-6. An axial temperature increase along the fuel rods of $20^{\circ} \mathrm{C}$ was calculated, with SNB commencing $200 \mathrm{~mm}$ from the bottom of the fuel stack. The calculated mass evaporation rate, $3200 \mathrm{~kg} \mathrm{~h}^{-1} \mathrm{~m}^{-2}$, was higher than the specification, which was due to the relatively low attainable flowrate (see above). However, calculations (by an outside organisation) using the VIPRE thermal-hydraulic code indicated that the mass evaporation rate was within specification. Since VIPRE has been used for calculations for plants subject to AOA, it is considered that the results from this code should be used in preference to Vista for mass evaporation rate analyses. 

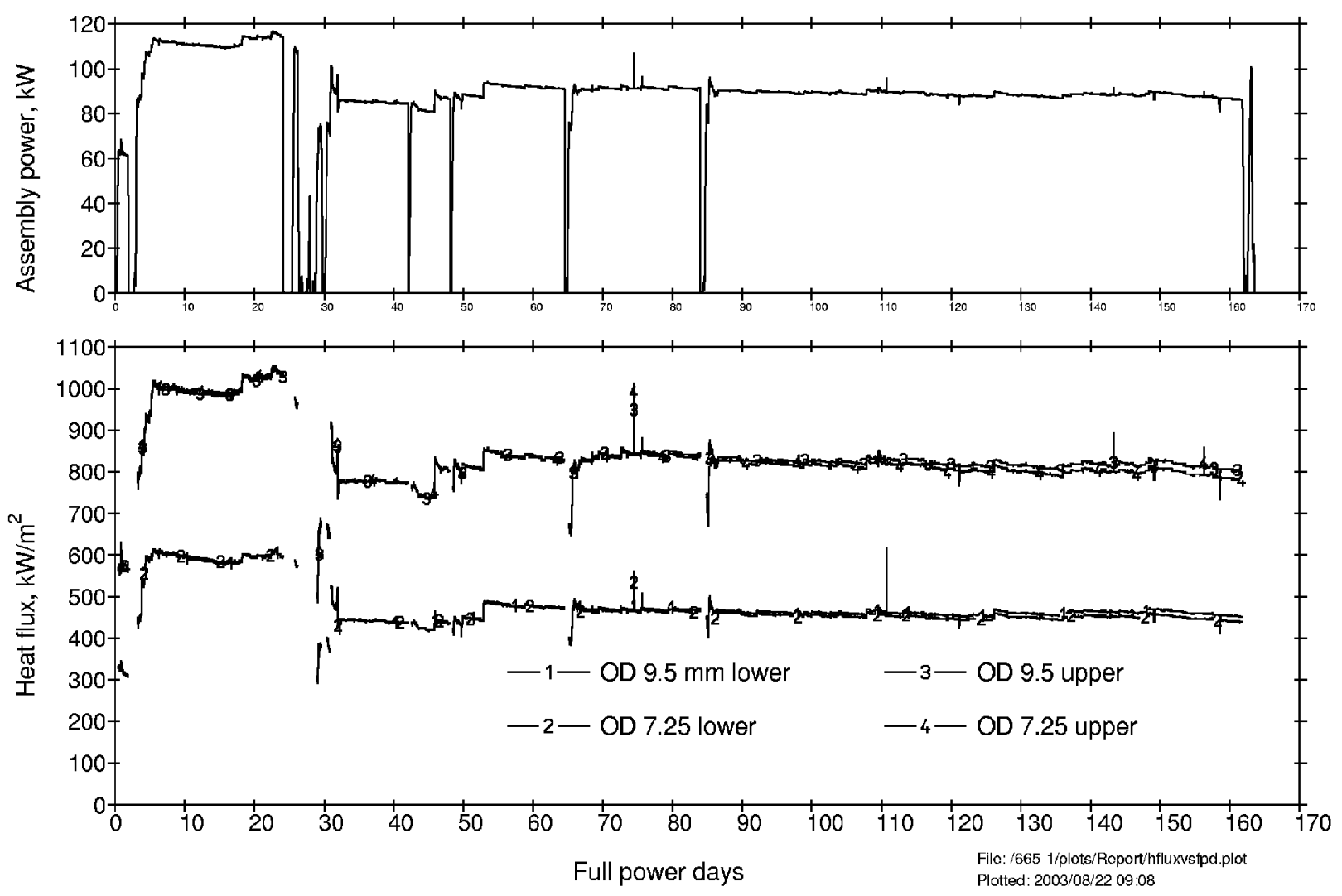

Figure 4-4

Heat fluxes at the clad surface during Phase 1, Test 1

During the test, three methods were used to attempt to deposit crud on the fuel rods:

- "crud burst" injections;

- coolant $\mathrm{pH}$ transients;

- oxygen additions to the coolant.

A summary of these events is given in Table 4-1, together with the diameter measurements taken. Several diameter measurements were also taken during the first month of operation, principally to check operation of the diameter gauge and reproducibility of the traces. 
Results: Phase 1, Test 1

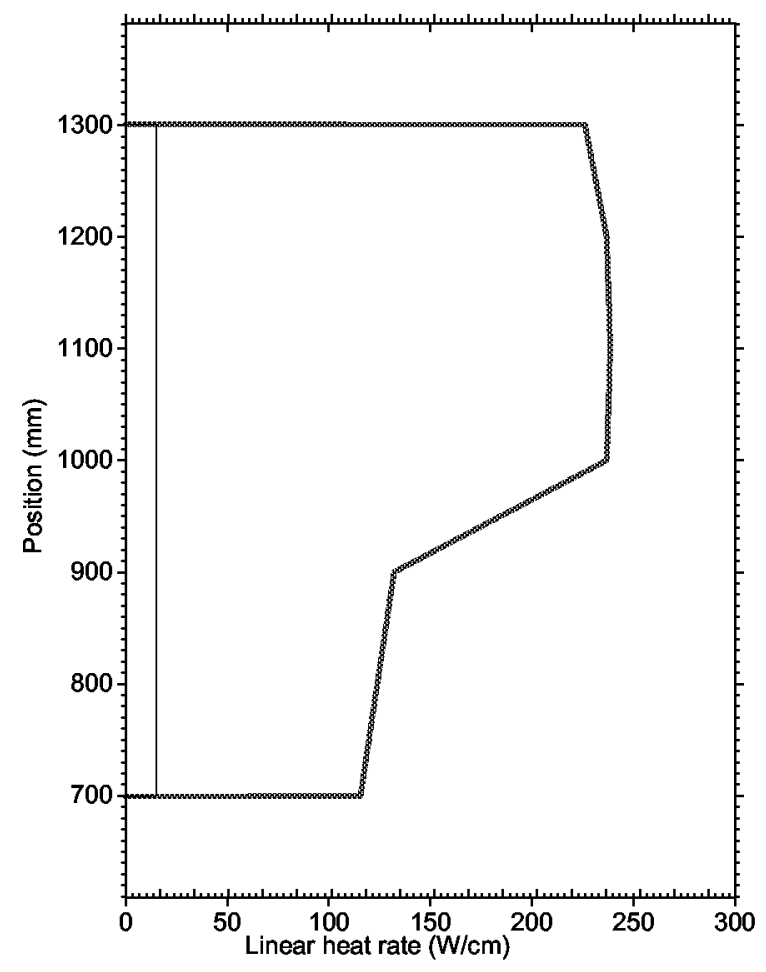

Figure 4-5

Axial power profile along fuel bundle

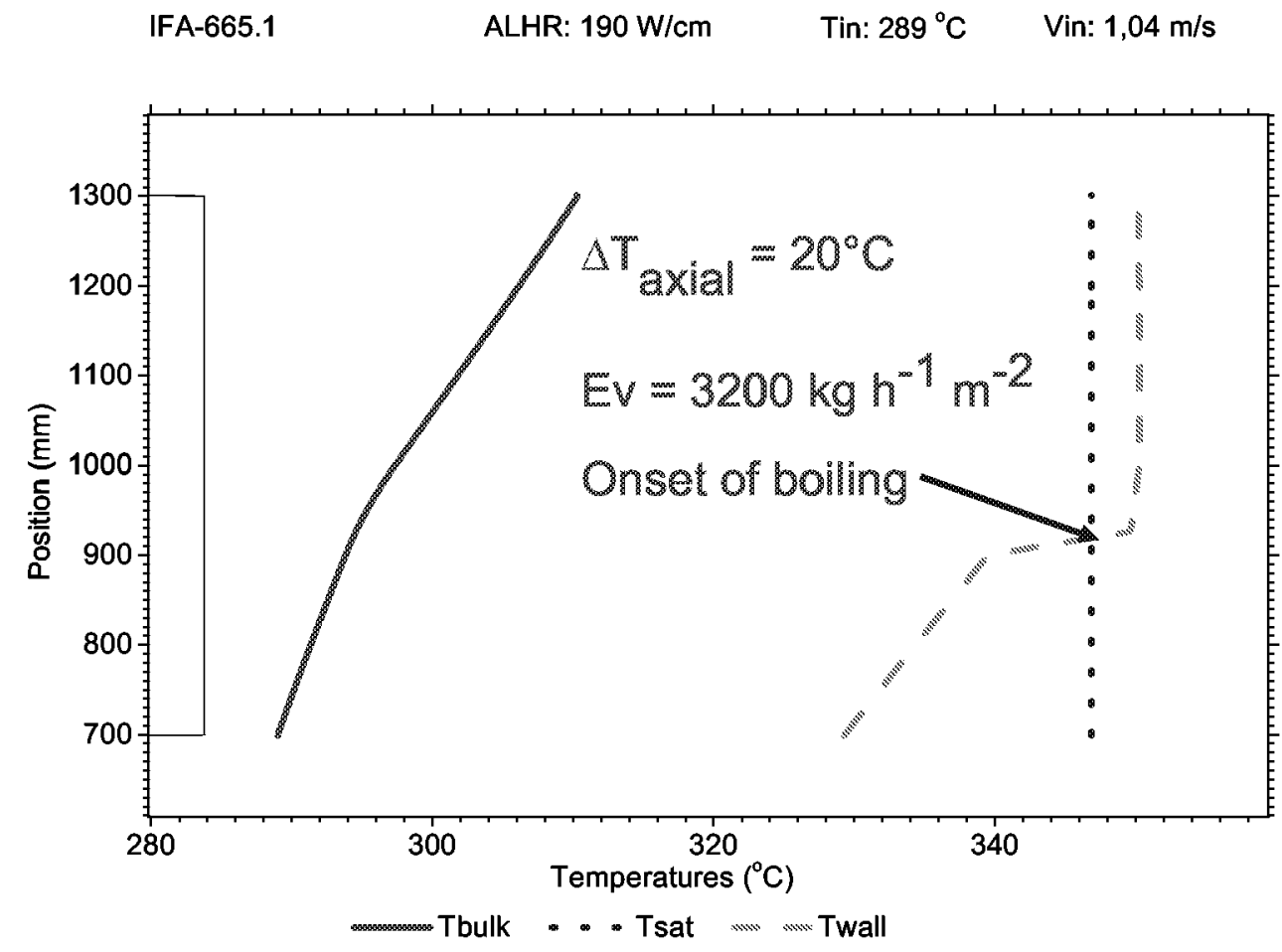

Figure 4-6

Thermal-hydraulic evaluation 
Table 4-1

Summary of diameter measurements, crud burst injections, $\mathrm{pH}$ transients and oxygen additions during Phase 1, Test 1

\begin{tabular}{|c|c|c|}
\hline Full Power Days & Event & Comments \\
\hline 32 & Diameter measurement. Inlet temperature $264^{\circ} \mathrm{C}$ & \\
\hline 46 & Inlet temperature $290^{\circ} \mathrm{C}$ & \\
\hline 52 & Diameter measurement & Baseline traces \\
\hline 53 & Crud burst injection \#1 & $300 \mathrm{mg}$ \\
\hline 60 & Crud burst injection \#2 & $300 \mathrm{mg}$ \\
\hline 61 & Crud burst injection \#3 & $300 \mathrm{mg}$ \\
\hline 63 & Diameter measurement & \\
\hline 70 & Diameter measurement & Following reactor shutdown/restart \\
\hline 76 & Crud burst injection \#4 & $300 \mathrm{mg}$ \\
\hline 83 & Crud burst injection \#5 & $300 \mathrm{mg}$ \\
\hline 89 & Crud burst injection \#6 & $300 \mathrm{mg}$ \\
\hline 90 & Crud burst injection \#7 & $50 \mathrm{mg}$ \\
\hline 95 & Diameter measurements & \\
\hline 96 & Crud burst injection \#8 & $300 \mathrm{mg}$ \\
\hline 103 & $\mathrm{pH}$ transient \#1 & $\mathrm{PH}_{300}=6.5$ for 24 hours \\
\hline 109 & $\mathrm{pH}$ transient \#2 & $\mathrm{PH}_{300}=6.0$ for 24 hours \\
\hline 116 & $\mathrm{pH}$ transient \#3 & $\mathrm{PH}_{300}=6.0$ for 48 hours \\
\hline 120 & Diameter measurements & \\
\hline 123 & Diameter measurements & \\
\hline 125 & $\mathrm{pH}$ transient \#4 & $\mathrm{PH}_{300}=6.0$ for 48 hours \\
\hline 130 & $\mathrm{pH}$ transient \#5 & $\mathrm{PH}_{300}=6.0$ for 48 hours \\
\hline 138 & Diameter measurements & \\
\hline 138 & $\mathrm{pH}$ transient \#6 & $\mathrm{PH}_{300}=6.0$ for 48 hours \\
\hline 144 & Diameter measurements & \\
\hline 146 & Inlet temperature raised to $294^{\circ} \mathrm{C}$ & \\
\hline 152 & Diameter measurements & \\
\hline 154 & $\mathrm{Ni}$ autoclave branch of loop temperature decreased by $20^{\circ} \mathrm{C}$ & \\
\hline 158 & Return to normal temperature in $\mathrm{Ni}$ autoclave branch & \\
\hline 159 & Diameter measurements & \\
\hline 159 & Oxygen addition test \#1 & 0.5 bar overpressure \\
\hline 160 & Oxygen addition test \#2 & 1.5 bar overpressure \\
\hline 160 & Oxygen addition test \#3 & 3.0 bar overpressure \\
\hline 160 & Oxygen addition test \#4 & 5.0 bar overpressure \\
\hline 161 & Diameter measurements & \\
\hline 161 & Oxygen addition test \#5 & 10 bar overpressure \\
\hline 161 & Diameter measurements & \\
\hline
\end{tabular}


During the period between 53 and 96 FPD, eight crud burst injections were performed, amounting to a total injected mass of $2.15 \mathrm{~g}$ of nickel ferrite. However, no evidence of crud deposition was found from diameter measurements taken after the injections. Scanning electron microscope (SEM) analyses of loop filter samples (Figure 4-7) revealed the presence of a homogeneous grey deposit, consisting of particles that were smaller than the injected $\mathrm{NiFe}_{2} \mathrm{O}_{4}$. Energy dispersive spectroscopy (EDS) analyses showed that the Fe:Ni ratio of the deposit was in the range from 2.9 to 3.1 , compared with a value of 2.3 for the injected particles. Significant quantities of carbon were also detected, the source of which was thought to be the graphite bearings of the injection system pump. Gamma spectroscopy analyses of particles from the coolant showed significant levels of ${ }^{95} \mathrm{Zr}$ and ${ }^{95} \mathrm{Nb}$, which most likely originated from the Zircaloy fuel clad. It was concluded that the injected particles were acting as an abrasive, scraping corrosion products off the loop surfaces, including the fuel rods. As a result, the decision was taken to cease the injections.

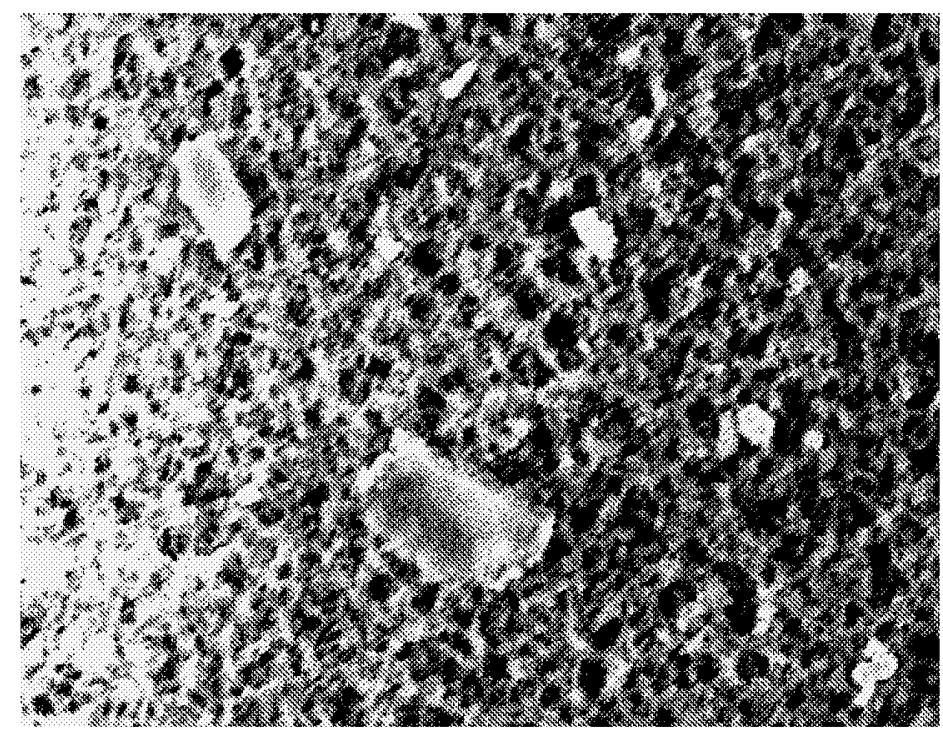

Figure 4-7 SEM micrograph of particles from coolant following a crud burst injection

Concentrations of $\mathrm{Fe}$ and $\mathrm{Ni}$ in the coolant covering the period up to the end of the crud burst injections are shown in Figure 4-8. The mean values for the dissolved ions (approximately $3.5 \mathrm{ppb} \mathrm{Fe}$ and $0.30 \mathrm{ppb} \mathrm{Ni}$ ) are as expected from the solubilities of the elements. Insoluble $\mathrm{Fe}$ and $\mathrm{Ni}$ were present at levels below 2 and $1 \mathrm{ppb}$ respectively. Iron:nickel ratios are shown in Figure 4-9. There was significant variation in the ratio for dissolved material, whereas that for particulates was mostly in the range from 2.3 to 3.3 , which is close to the theoretical value of 2 for nickel ferrite. Concentrations immediately before and for the six hours following a crud burst injection are shown in Figure 4-10. Maximum concentrations of insoluble Fe and Ni were 160 and $55 \mathrm{ppb}$ respectively, and were thus up to 80 times higher than the normal levels, while soluble levels were unaffected. 


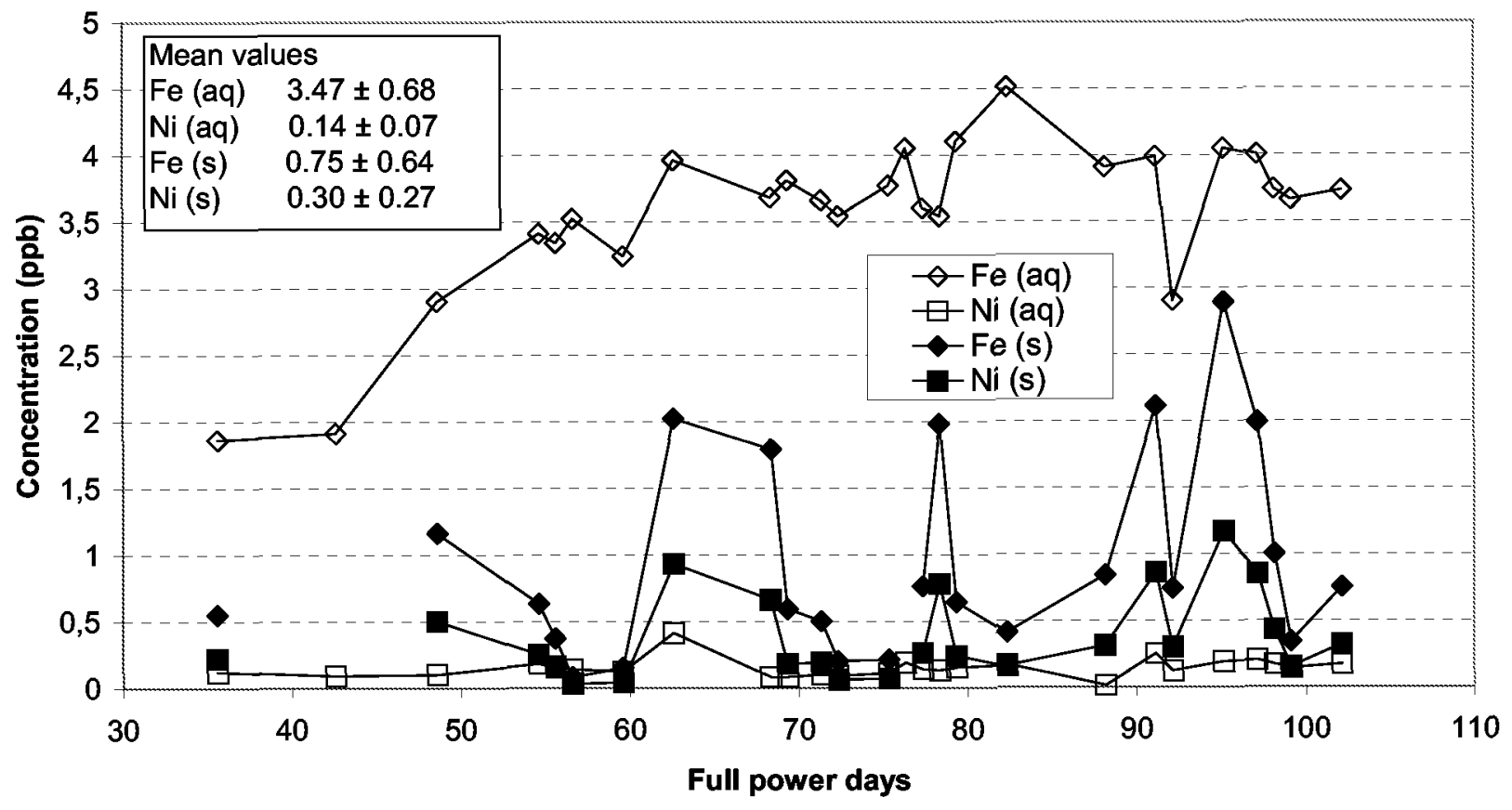

Figure 4-8

Coolant Fe and Ni concentrations during Phase 1, Test 1

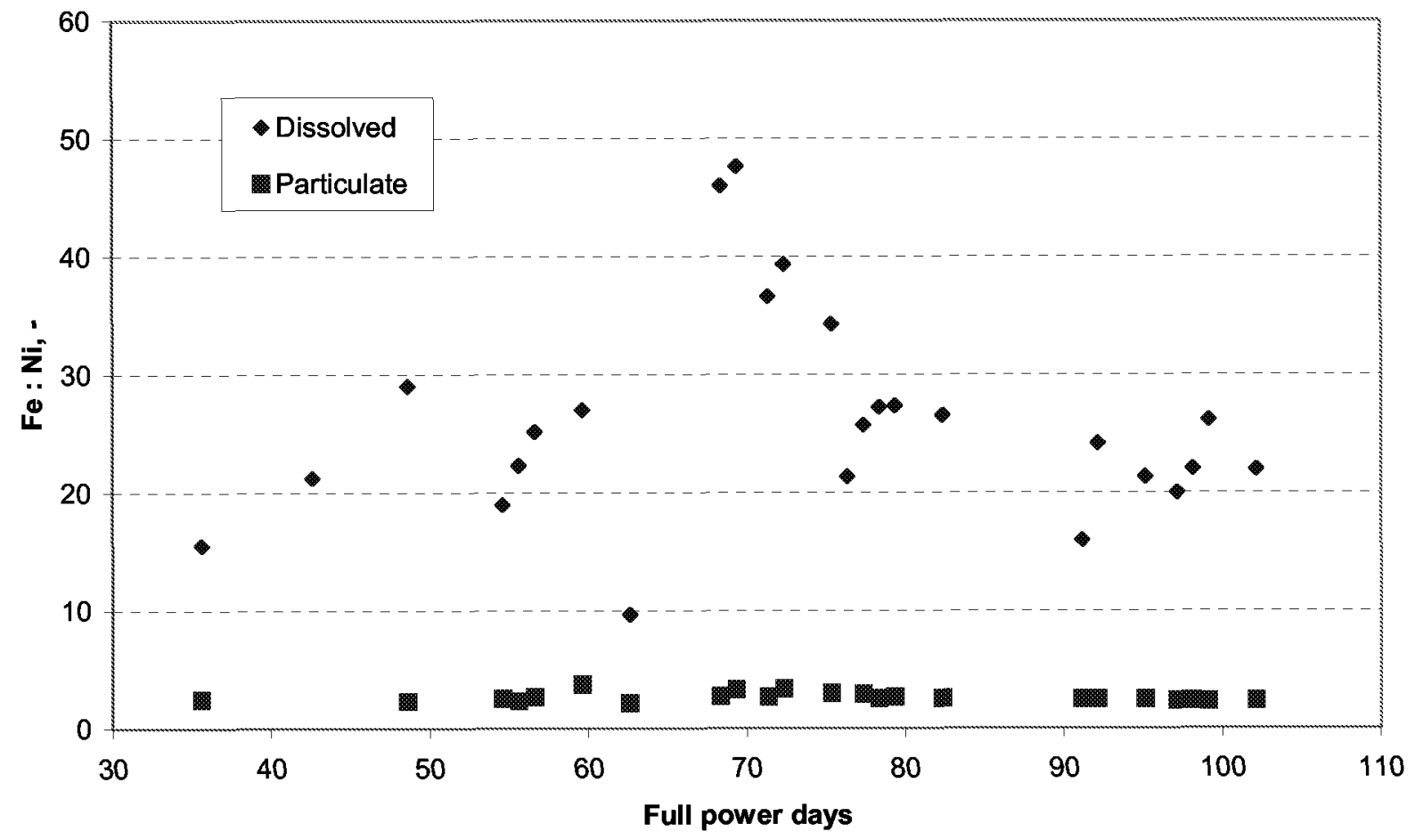

Figure 4-9

Fe:Ni ratios during Phase 1, Test 1 


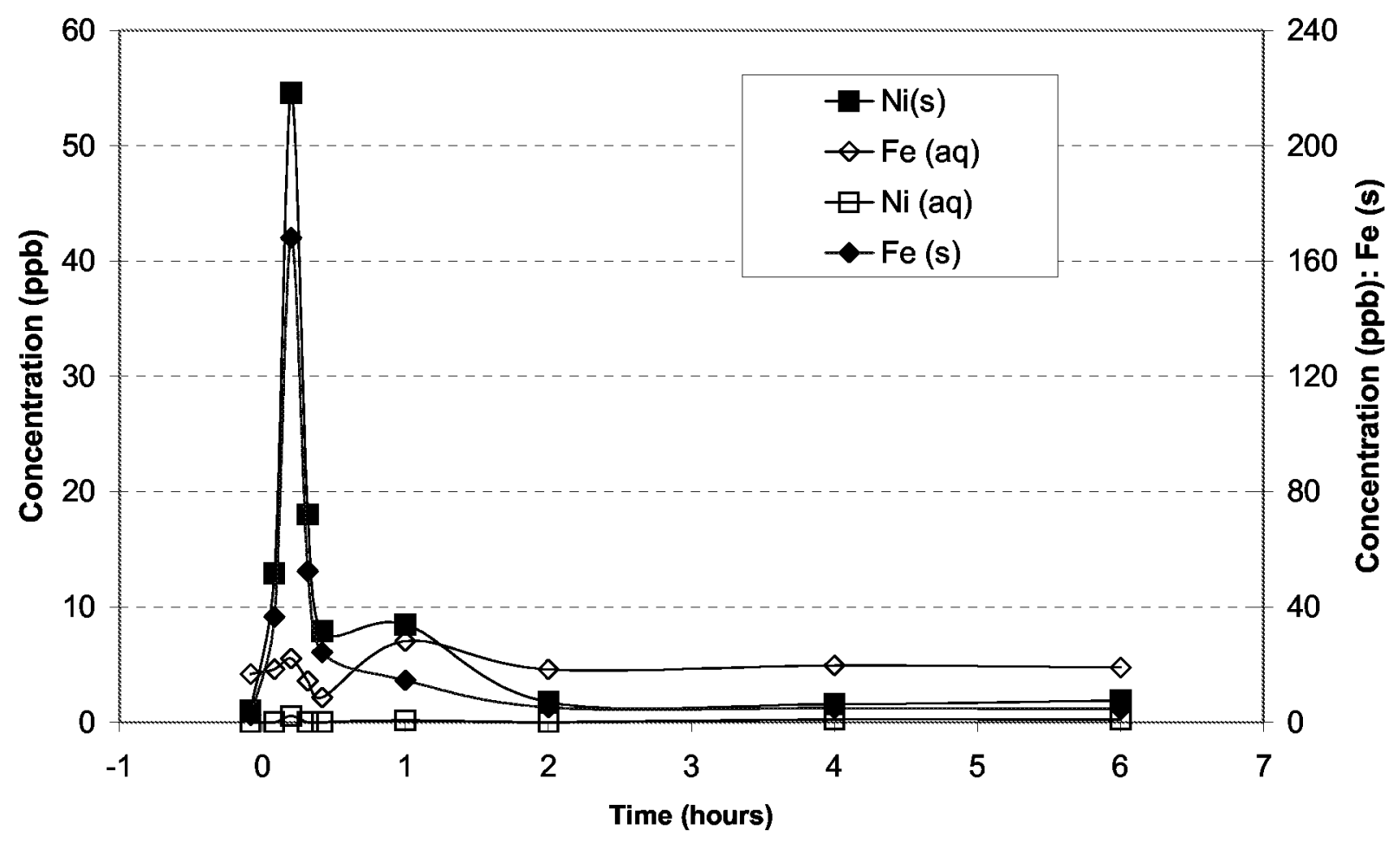

Figure 4-10

$\mathrm{Fe}$ and $\mathrm{Ni}$ concentrations after crud burst injection

In operating PWRs, changes to primary coolant chemistry are often caused by $\mathrm{pH}$ transients and oxygen ingress, which may boost corrosion product transport (and deposition) as speciation and solubilities are strongly affected by $\mathrm{pH}$ and electrochemical potential. Hence it was decided to simulate such transients in the current test after termination of the particle injections. A total of six $\mathrm{pH}$ transients were conducted during the period from 103 to $138 \mathrm{FPD}$. The first involved reducing $\mathrm{pH}_{300^{\circ} \mathrm{C}}$ (by removal of lithium) from 7.0 to 6.5 for a period of 24 hours; while in the second transient, also conducted over a period of 24 hours, $\mathrm{pH}$ was reduced to 6.0. The remaining four transients each involved a reduction to $\mathrm{pH} 6.0$ over a period of two days. With the exception of the first, each transient resulted in a reduction in coolant flowrate through the test rig (Figure 4-11), indicating deposition of crud somewhere in the rig; however, diameter measurements indicated that the deposit was not on the fuel clad surface. Iron and nickel concentrations during the $\mathrm{pH}$ transients are shown in Figures 4-12 (soluble) and 4-13 (insoluble material). The $\mathrm{pH}$ changes resulted in large releases and transport of corrosion products through the test rig and loop. Concentrations of soluble ions were up to six times higher than under steady-state operation, while peaks in the concentrations of insoluble material were over two hundred times higher. 


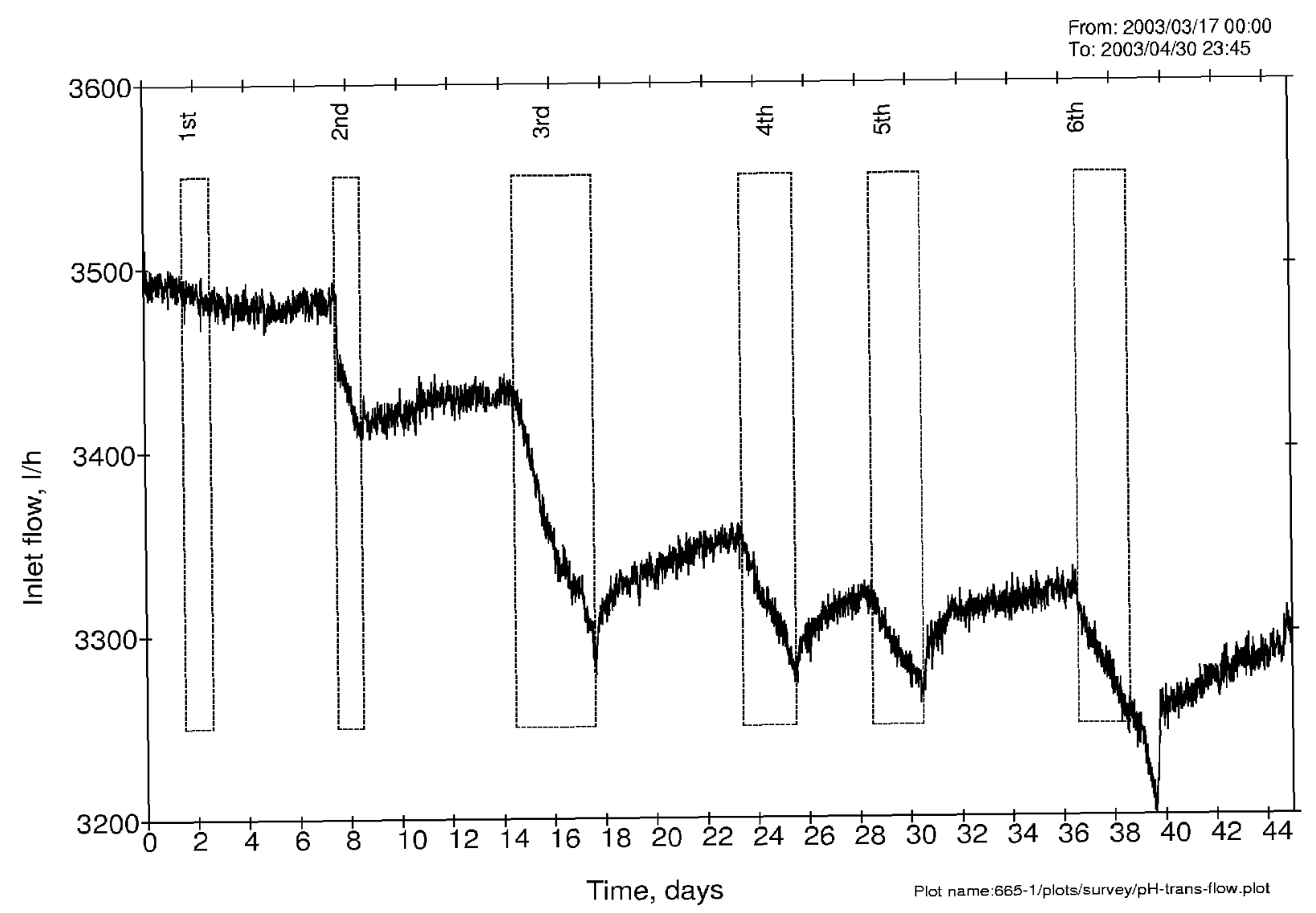

Figure 4-11

Coolant inlet flowrate during $\mathrm{pH}$ transients 
Results: Phase 1, Test 1

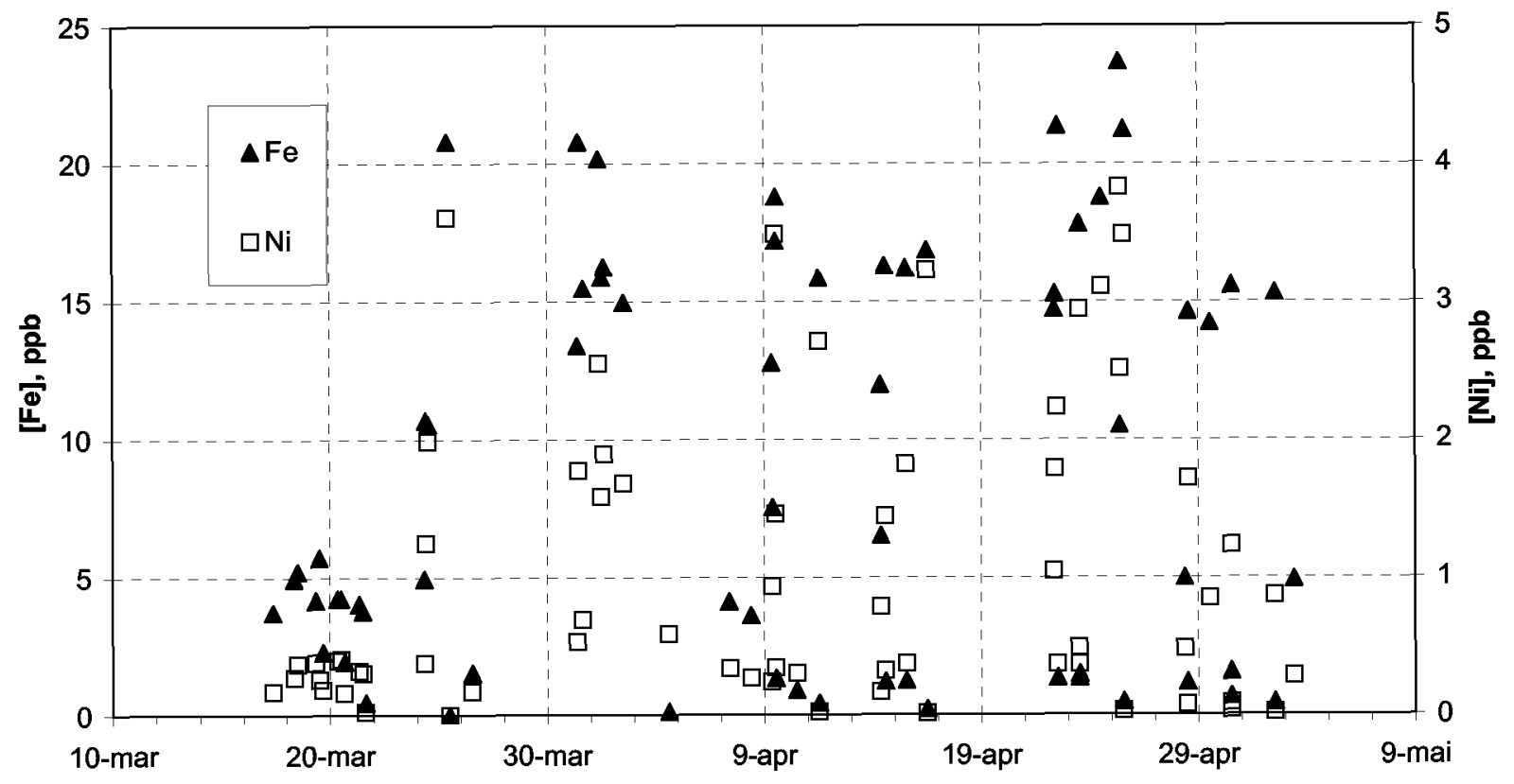

Figure 4-12

Soluble $\mathrm{Fe}$ and $\mathrm{Ni}$ concentrations during $\mathrm{pH}$ transients

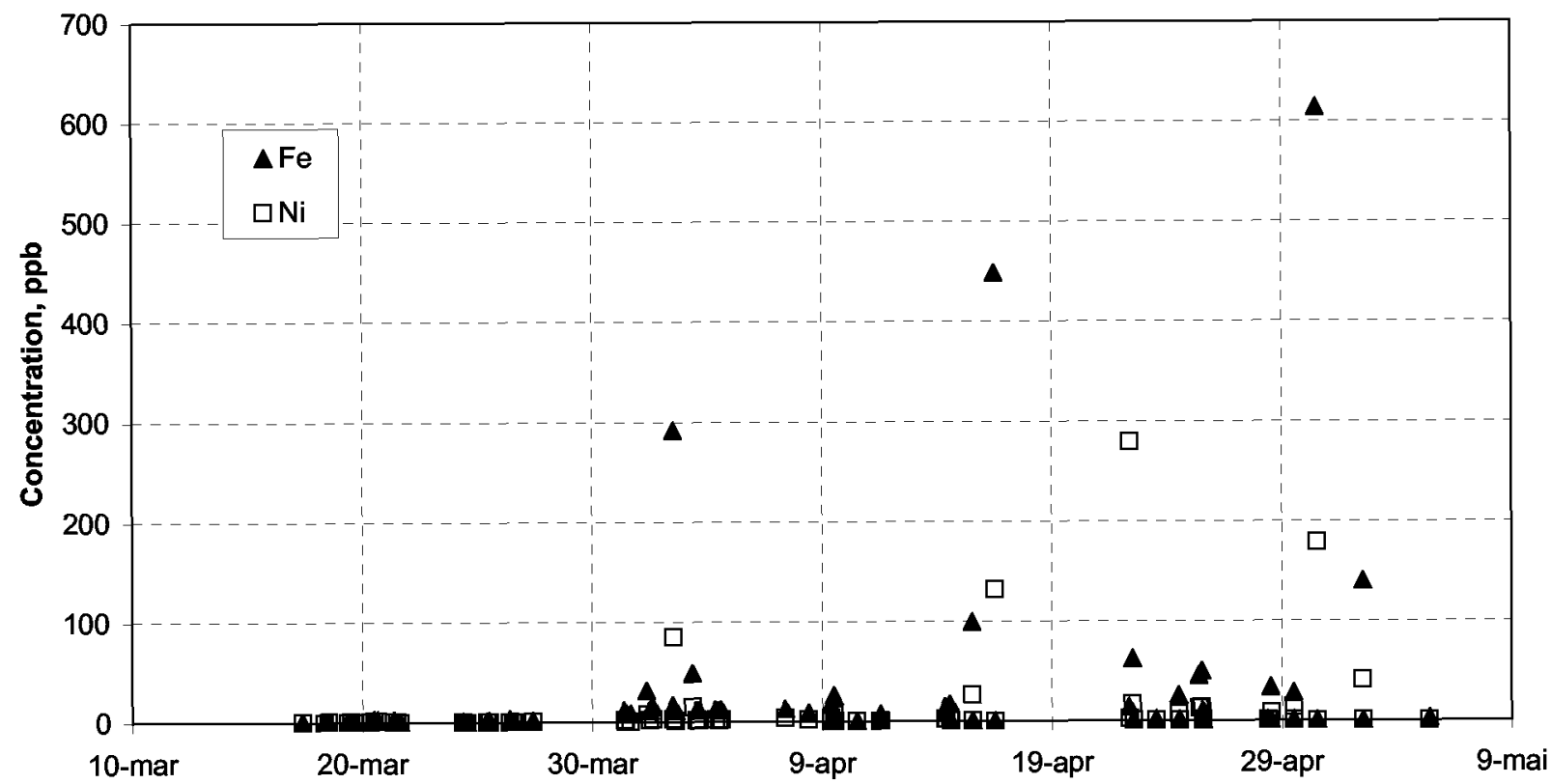

Figure 4-13

Insoluble $\mathrm{Fe}$ and $\mathrm{Ni}$ concentrations during $\mathrm{pH}$ transients 
Towards the end of the reactor cycle, five oxygen addition tests were conducted. These involved applying system overpressures (from an oxygen cylinder) of $0.5,1.5,3,5$ and 10 bar.

Overpressures of 1.5 and 3 bar resulted in temporary measured oxygen concentrations of 5 and $77 \mathrm{ppb}$, accompanied by small decreases in hydrogen levels (due to $\mathrm{H}_{2} / \mathrm{O}_{2}$ recombination, Figure 4-14). The 5 and 10 bar transients resulted in measured oxygen concentrations of 1.8 and $2.8 \mathrm{ppm}$, and hydrogen had to be injected to maintain specified levels (Figure 4-15). Grab samples were taken to determine the concentrations of particulate iron and nickel. A small volume, $0.5 \mathrm{~L}$, was filtered through a $0.45 \mu \mathrm{m}$ particle filter in the laboratory and subsequently analysed by XRF. The uncertainties were high due to the small sample volumes. Iron levels were similar in the first three tests, at $8-11,8-11$ and $8-12 \mathrm{ppb}$. The corresponding nickel contents were $0.8-2.0,0.3-0.5$ and $0.4-0.5 \mathrm{ppb}$. Hence, the injected oxygen had negligible effect on the concentrations of particles $(>0.45 \mu \mathrm{m})$ in the loop. Cation exchange filters, which were not used in these campaigns, may have shown larger variations than the particle filters. Again, no increase in clad diameter was observed following the oxygen additions.

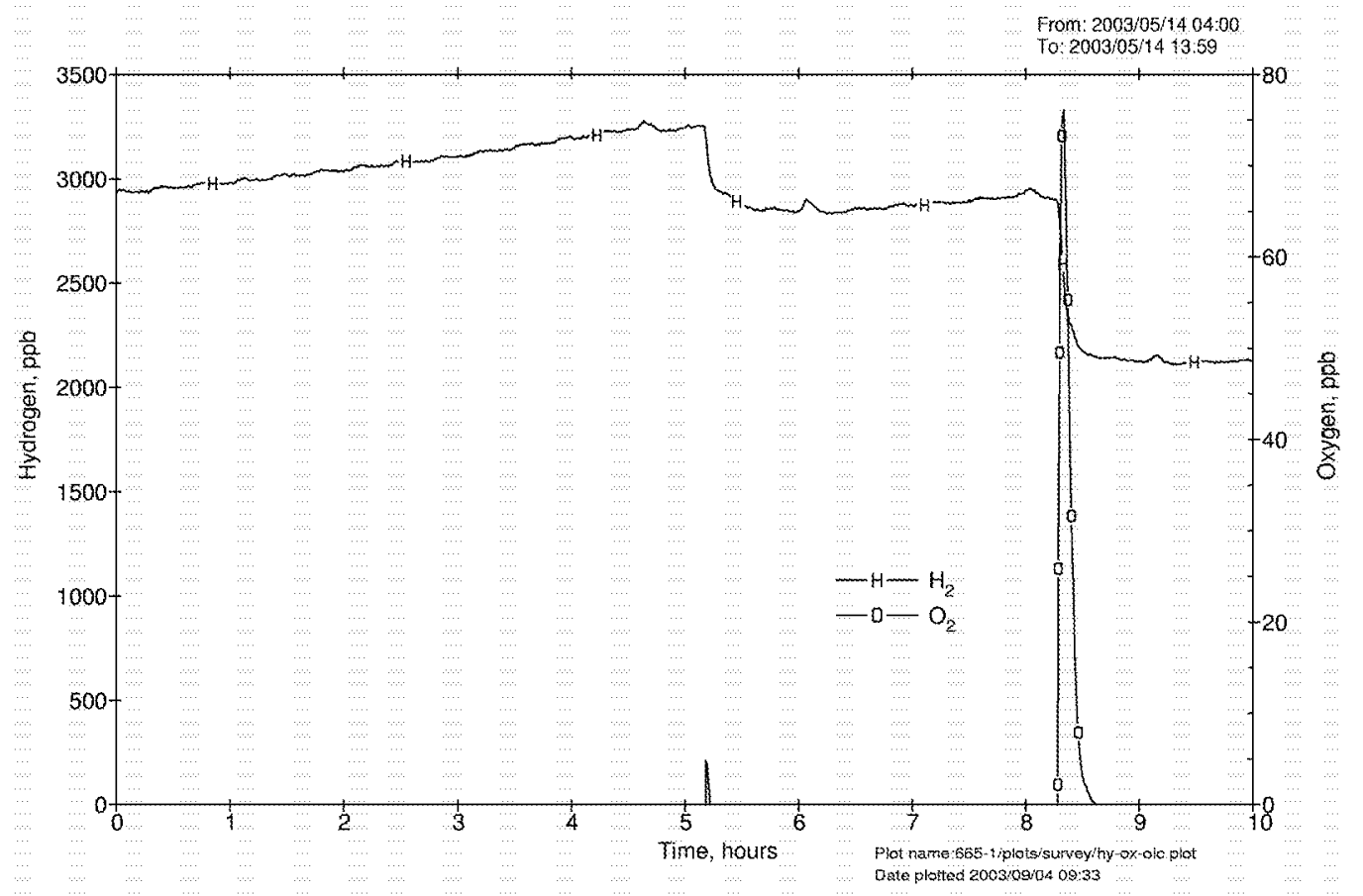

Figure 4-14

Hydrogen and oxygen concentrations during oxygen injections 2 and 3 (1.5 and 3 bar) 


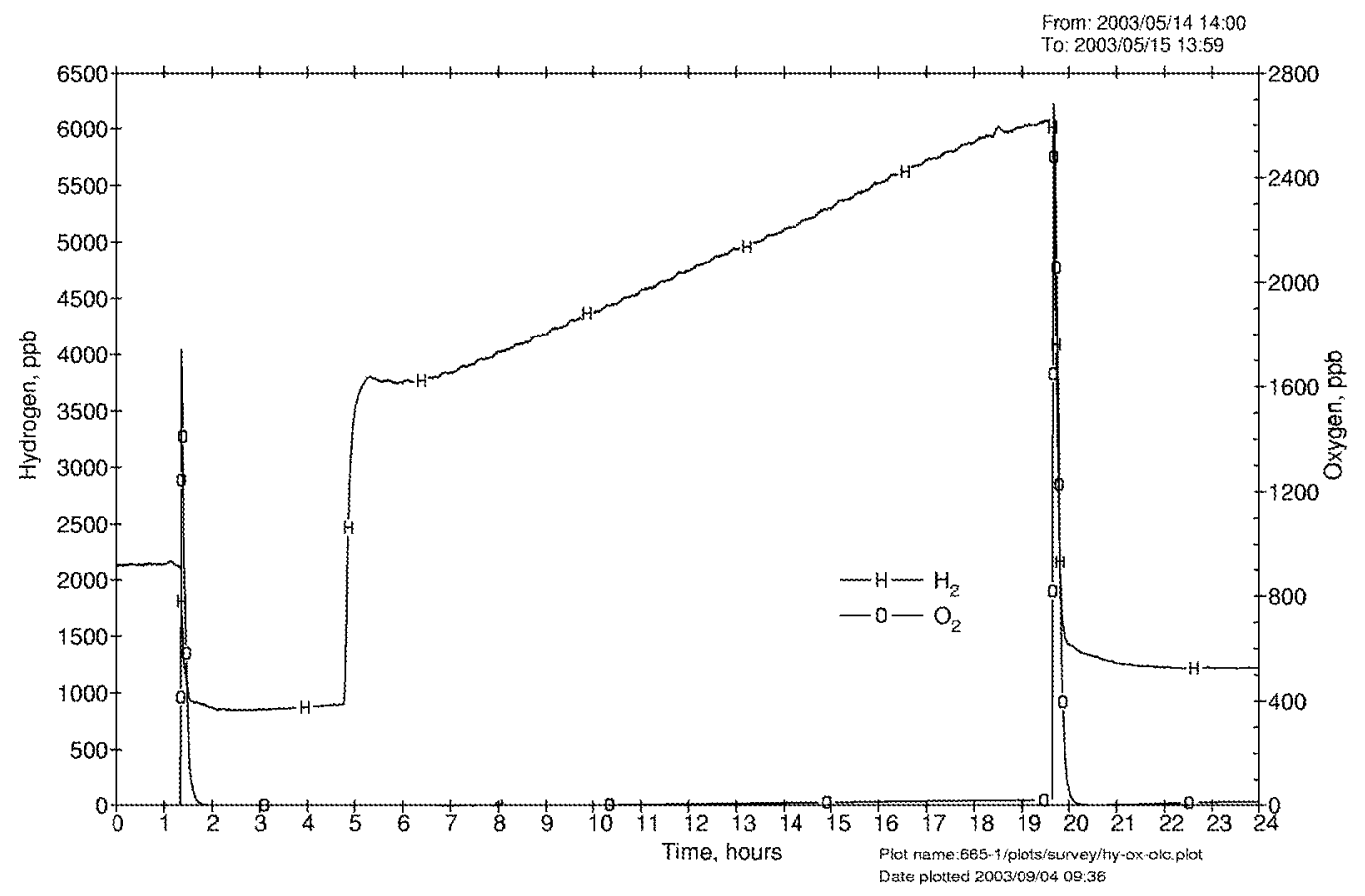

Figure 4-15

Hydrogen and oxygen concentrations during oxygen injections 4 and 5 ( 5 and 10 bar)

As shown in Table 4-1, between 154 and 158 FPD the temperature in the nickel autoclaves was decreased by $20^{\circ} \mathrm{C}$, in an attempt to increase the Ni concentration in the loop water by increasing its solubility. Grab samples were taken (from the loop sample line) to determine the concentrations of particulate iron and nickel. A small volume, $0.5 \mathrm{~L}$, was filtered through a 0.45 $\mu \mathrm{m}$ particle filter in the laboratory and subsequently analysed by XRF. The uncertainties were high due to the small sample volumes. With the temperature decrease, the nickel concentration increased from 0.3 to $2.2 \mathrm{ppb}$, and then decreased to $1.8 \mathrm{ppb}$. Iron concentrations were not affected. Cation exchange filters, which were not used in these campaigns, may have shown an increase in the level of dissolved nickel. However, any increase would probably not have been detected, as the Ni would have been consumed on the surfaces of the loop pipework before reaching the analysis line.

Results from gamma spectrometry analyses of coolant samples throughout the cycle are shown in Figures 4-16 $\left({ }^{51} \mathrm{Cr}\right), 4-17\left({ }^{54} \mathrm{Mn}\right.$ and $\left.{ }^{59} \mathrm{Fe}\right)$ and $4-18\left({ }^{58} \mathrm{Co}\right.$ and $\left.{ }^{60} \mathrm{Co}\right)$. Activities of both particulates and dissolved species are shown. The activities of particulate ${ }^{51} \mathrm{Cr}$ were usually higher than those of ${ }^{50} \mathrm{Fe}$, while ${ }^{54} \mathrm{Mn}$ was not detected, i.e. the activity level was below the Minimum Detection Activity (MDA). The MDA is a threshold value that depends on the background level, interference of energies of surrounding isotopes and energy values used in the detection analysis. The MDA value varies from sample to sample. The activity of aqueous ${ }^{51} \mathrm{Cr}$ was also very low: it was detected on only two occasions. Concentrations of aqueous ${ }^{59} \mathrm{Fe}$ were generally stable. The activities of aqueous radiocobalt isotopes were higher than those of particulates. 
In the first cycle of the test, the loop was new and had been preconditioned by formation of surface oxides with minimum defect contents. The release rates from the surfaces were low, and therefore the formation rates of neutron activated "corrosion products" were also low. The activities of dissolved species of ${ }^{54} \mathrm{Mn},{ }^{58} \mathrm{Co},{ }^{59} \mathrm{Fe}$, and ${ }^{60} \mathrm{Co}$ were fairly stable, with a few exceptions that are considered as artifacts. The levels of dissolved species show that the condition in the loop was stable with low release rates from the surfaces. However, the activity levels of the particles indicate less stable conditions. Particles containing ${ }^{54} \mathrm{Mn}$ were not detected during the cycle, which is in agreement with low release rates of particles from the surfaces. The activity curves for particles of the isotopes of iron and radiocobalt are in good agreement with each other, but there are variations in the data. Due to the low levels of particles in the loop, the data can vary. At these low levels of activity, minor differences in the sampling can make large differences in the derived activity levels. The variations in activities are considered to be a sampling effect, and not due to general variations of the physiochemical environment in the loop.

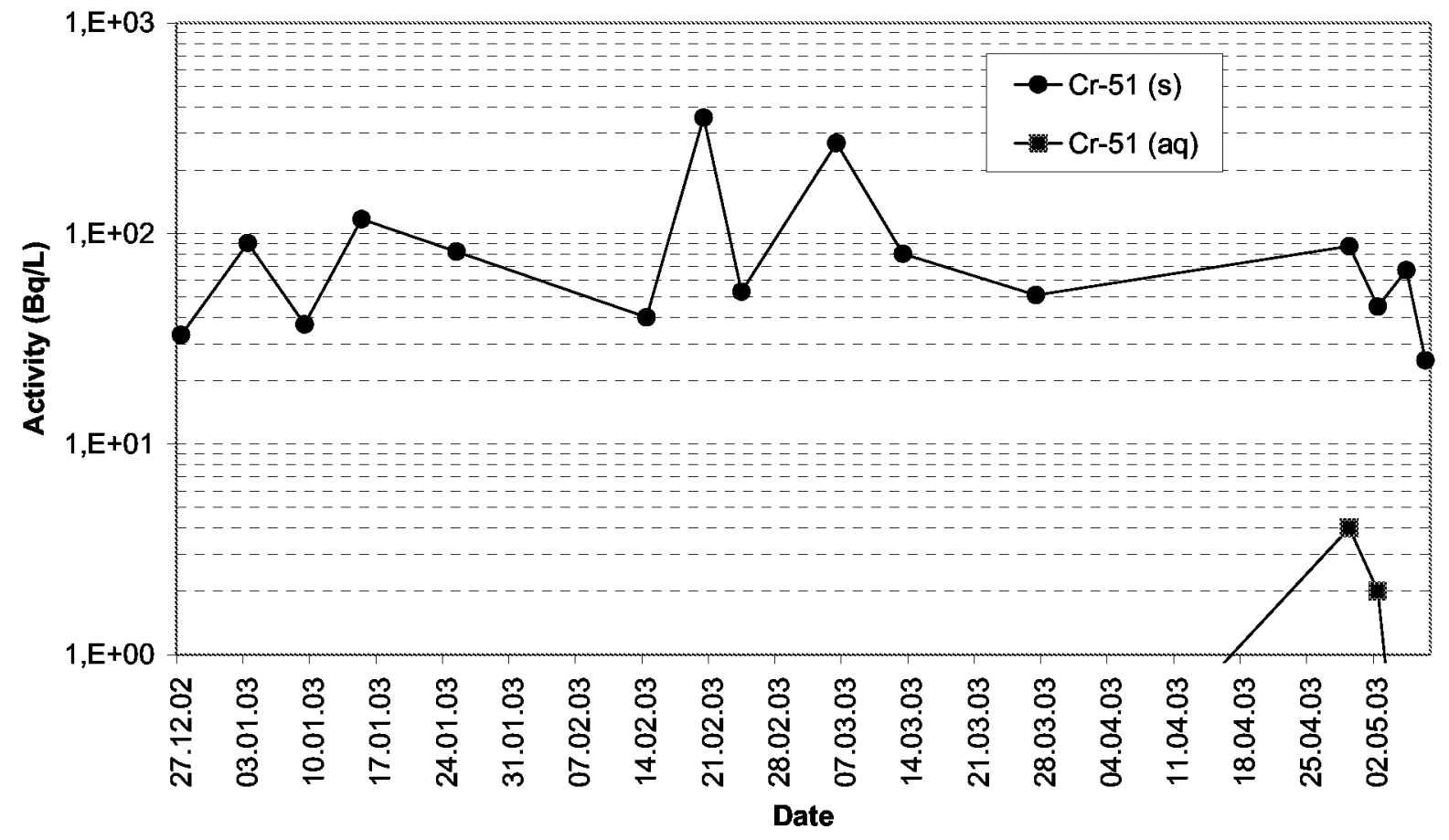

Figure 4-16

Activities of ${ }^{51} \mathrm{Cr}$ during Phase 1, Test 1 
Results: Phase 1, Test 1

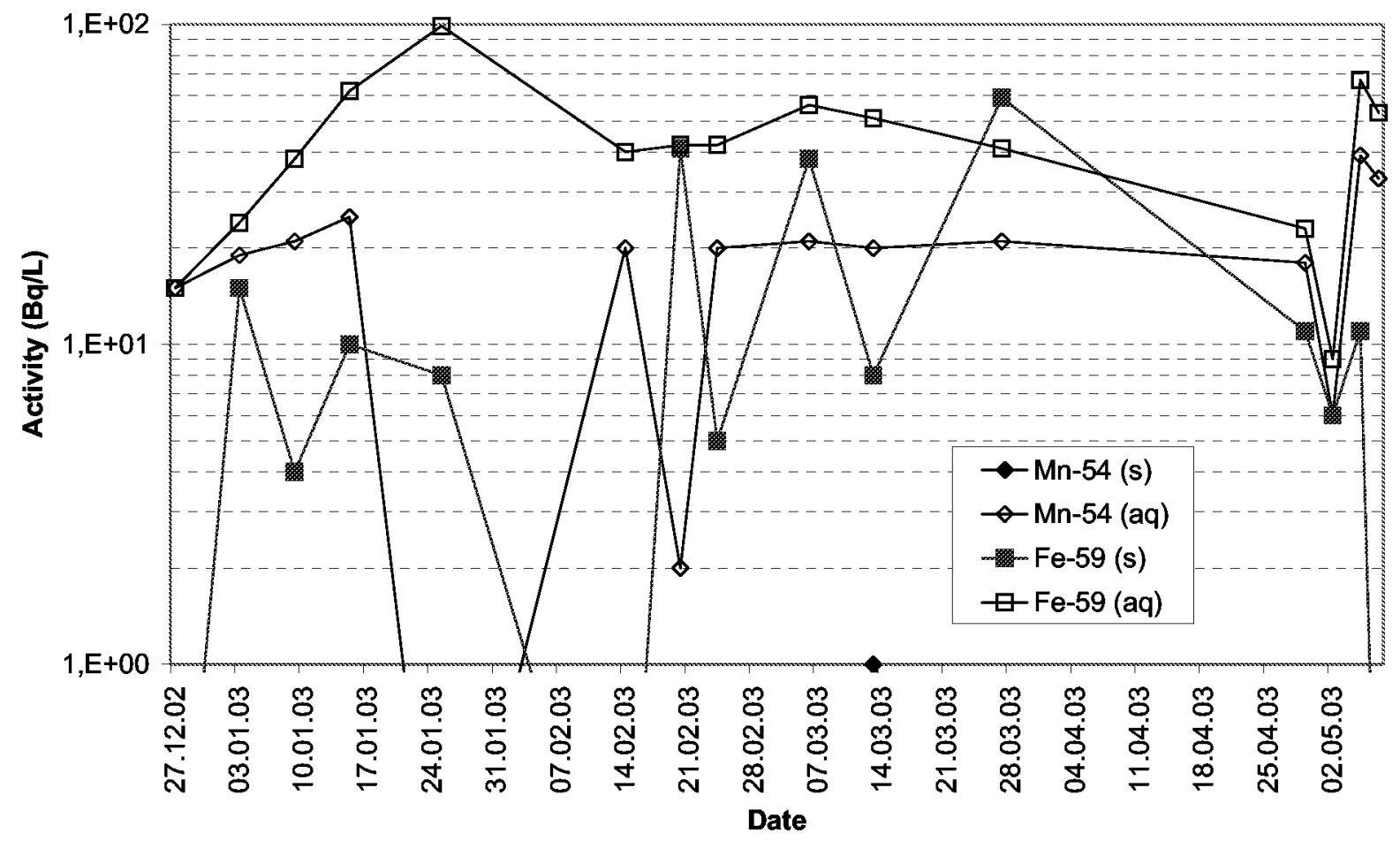

Figure 4-17

Activities of ${ }^{54} \mathrm{Mn}$ and ${ }^{59} \mathrm{Fe}$ during Phase 1, Test 1

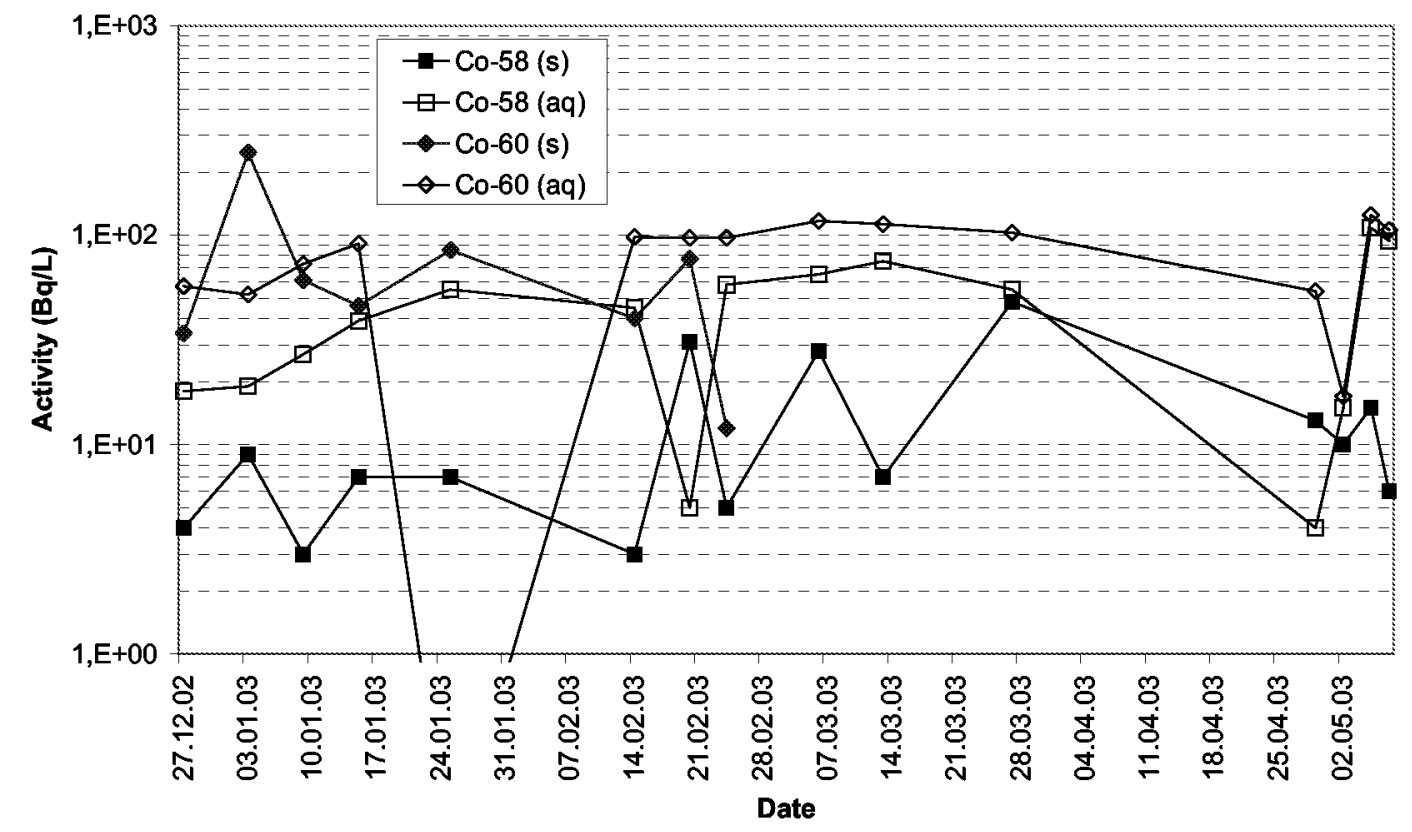

Figure 4-18

Activities of ${ }^{58} \mathrm{Co}$ and ${ }^{60} \mathrm{Co}$ during Phase 1, Test 1 
Two examples of diameter traces are shown in Figure 4-19. The first (Run 7275) was taken at the start of the test, after less than one day at full power. The three $50 \mu \mathrm{m}$ calibration steps at the top of the rod can be seen on the left hand side of the trace. As expected, the trace is flat in profile, indicating a constant diameter. The second trace (Run 7606) was taken at the end of the cycle, after 161 FPD. The profile has moved downwards on the diameter axis, indicating that the clad diameter has decreased. The diameter of the upper section (from approximately 300 to $700 \mathrm{~mm}$ on the position scale) has decreased more than that of the lower section $(700$ to $900 \mathrm{~mm})$. This decrease in diameter was due to creepdown of the clad. Creep is a common phenomenon caused by the pressure differential across the clad, which was approximately 130 bar in the current test. The fuel-clad gap was $180 \mu \mathrm{m}$, which with the addition of fuel densification, gives scope for a large decrease in the clad diameter before fuel-clad interaction takes place. The magnitude of creep is affected by the stress, clad microstructure, fast fluence and temperature. Creep was greater in the high-enrichment section of the fuel rod, due to the higher clad temperature and fast flux.

Diameter measurements throughout the cycle are summarised in Figure 4-20. A steady decrease in diameter was observed. The data show both primary creep (decreasing rate) followed by secondary creep (constant rate).

The diameter gauge measurements showed no evidence of crud deposition. There would be two main ways of identifying the presence of a deposit on the fuel clad:

- significant differences between the rod diameter profiles from successive traces. In the current test, the profile along the lower, non-boiling section, where crud is not expected, should not change significantly. Conversely, deposits on the upper, boiling section, would result in a change to the profile;

- a decrease in the secondary creep rate. 
Results: Phase 1, Test I

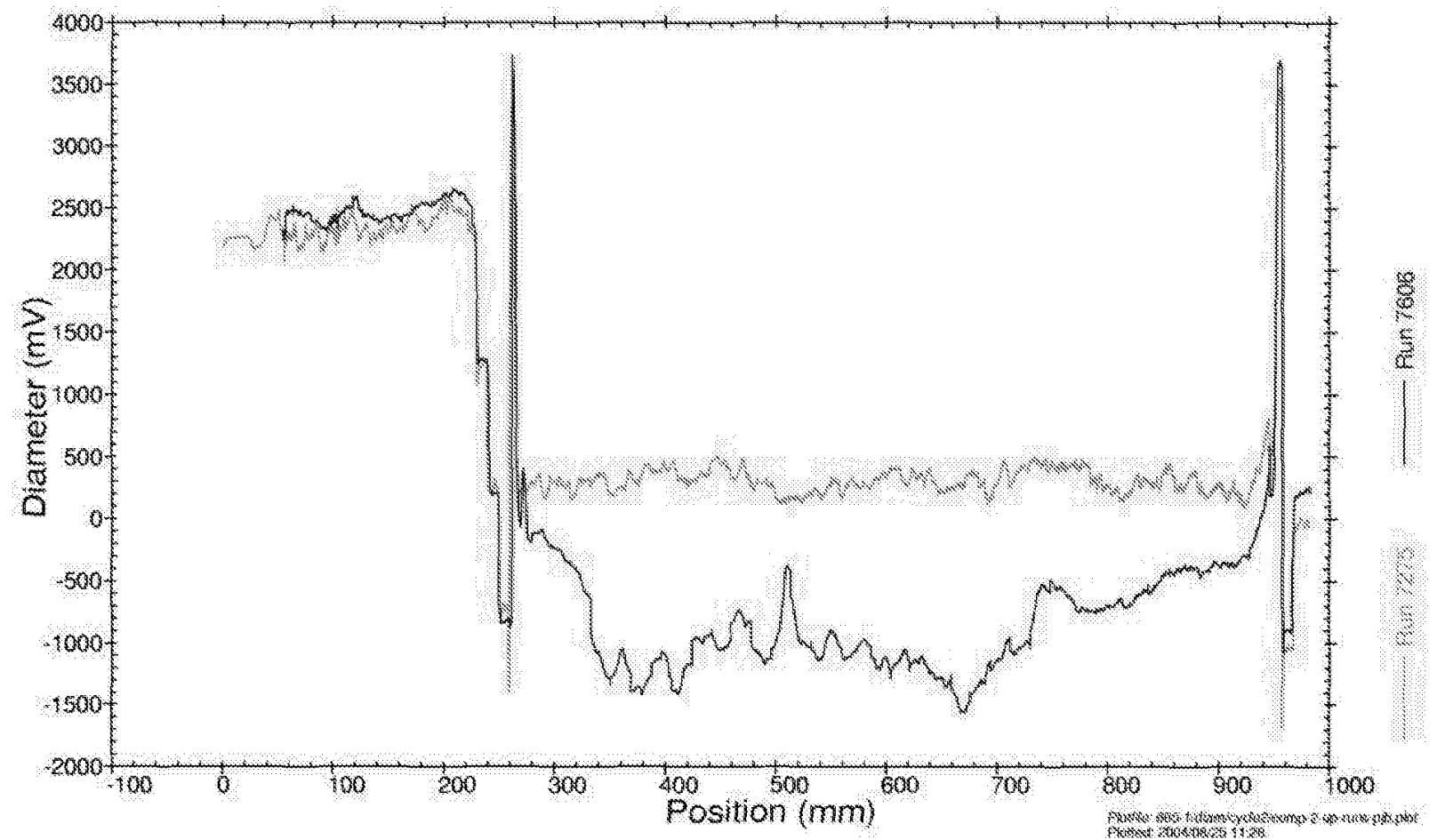

Figure 4-19

Diameter traces taken at 0.2 (Run 7275) and 161 (Run 7606) FPD

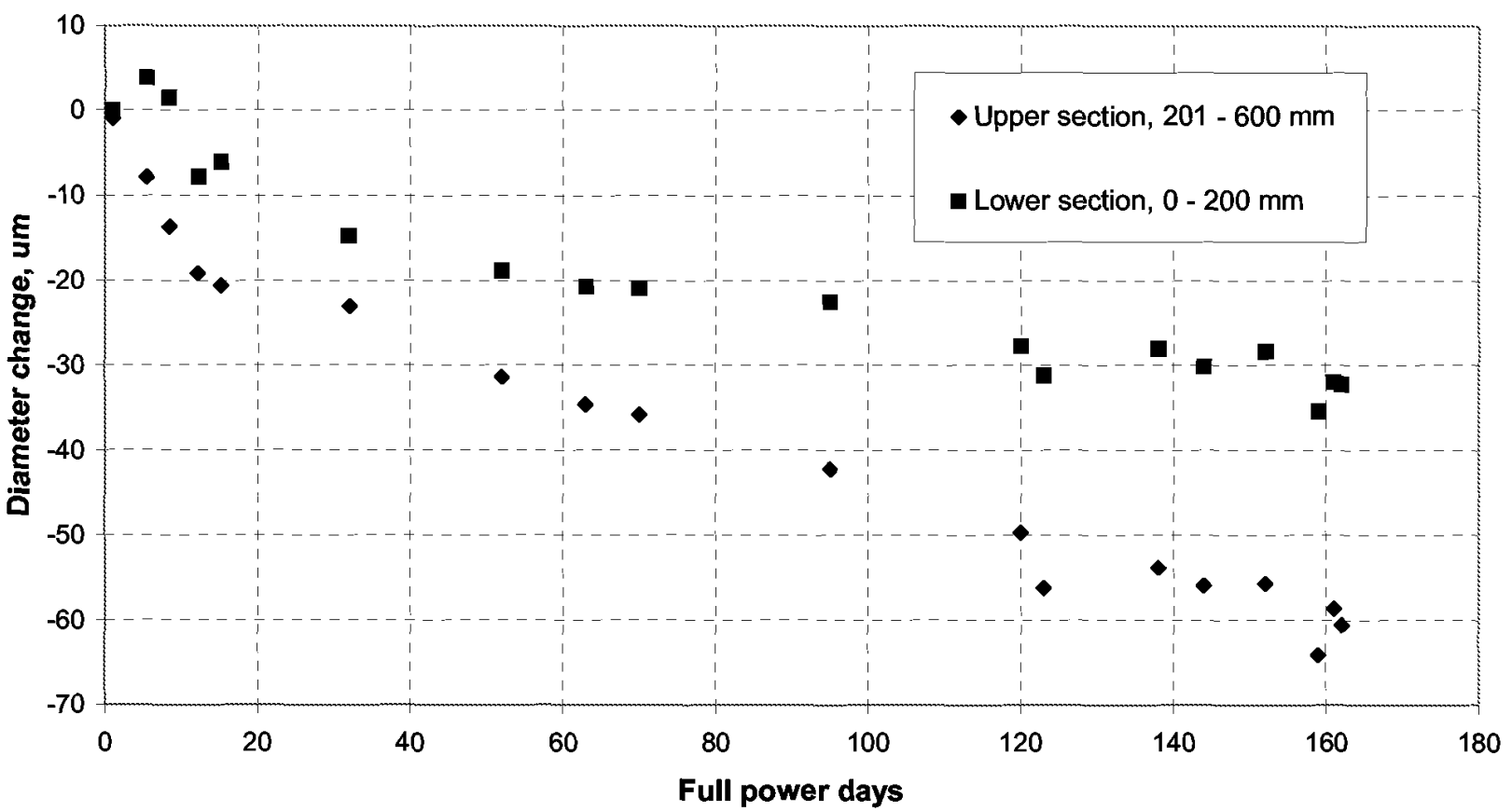

Figure 4-20

Diameter measurements during Phase 1, Test 1 
A visual inspection of the fuel rods at the end of the cycle confirmed the absence of any significant crud deposits. Thus, the instrumentation included to measure power changes due to incorporation of boron into a crud deposit showed no significant changes over the duration of the test. Figure 4-21 shows the ratios of the neutron detector signals on the outside of the pressure flask to those in the centre of the test rod at the three axial levels along the fuel bundle. It will be recalled that there was one-phase flow along the bottom third of the fuel, and hence that crud deposition would not be expected. Hence the ND ratio for this section can be used as a reference against which can be plotted the equivalent ratios for the upper two thirds of the fuel bundle. A power reduction in the latter region would result in lower ND signals from the centre of the test rig, whilst the NDs on the pressure flask would not be affected, and hence the ratios would increase. Similarly, the differential coolant thermocouples (Figure 4-22) would provide an independent check on power reductions along the upper two thirds of the fuel section. While the temperature increase along the bottom third of the fuel would be unaffected, those along the upper two thirds would be reduced as a consequence of the lower power. Finally, no changes in fuel centreline temperature or cladding elongation were recorded (Figure 4-23).
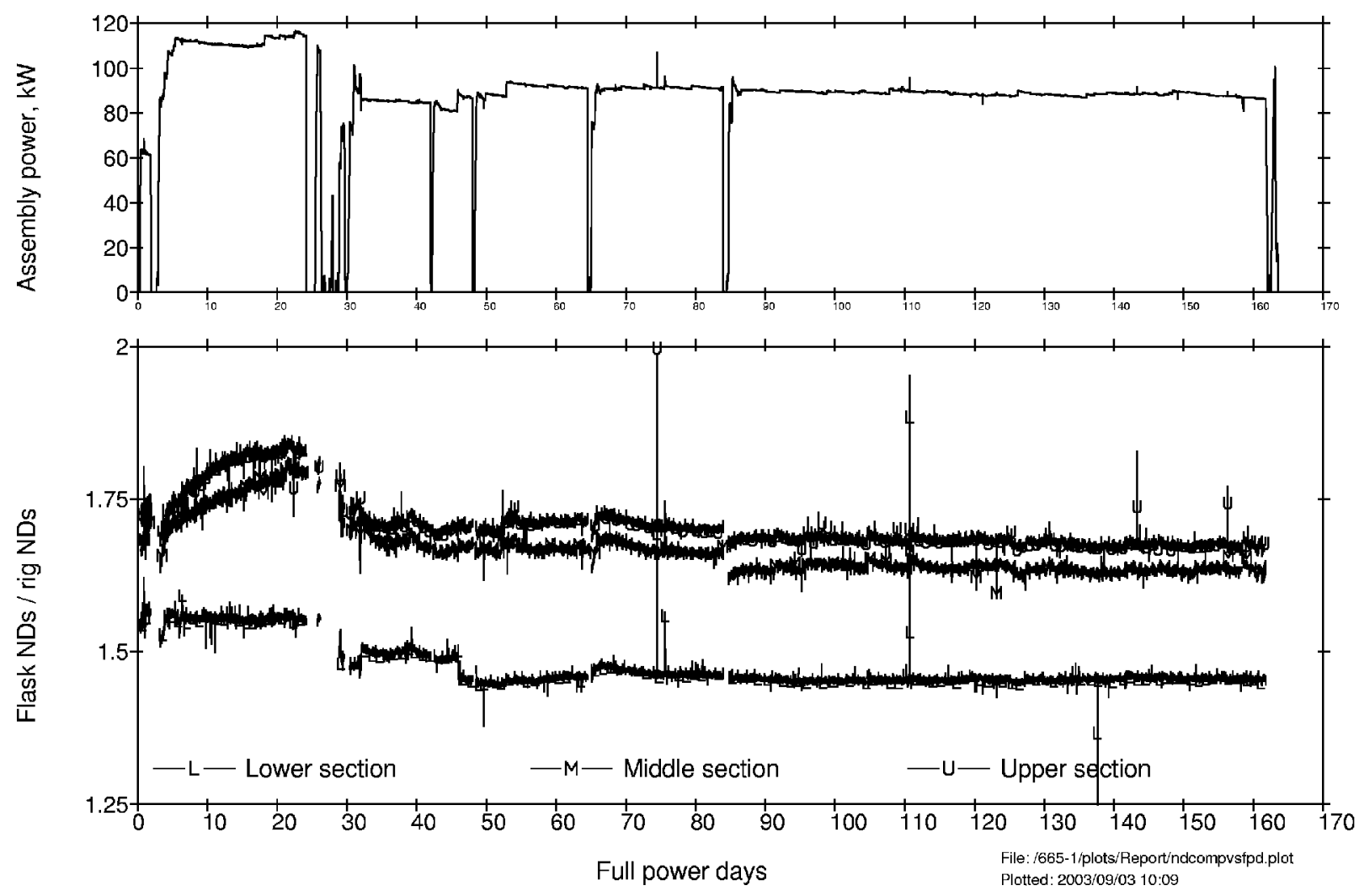

Figure 4-21

Ratios of neutron detector signals on outside of pressure flask to those inside test rig, over lower $(0-200 \mathrm{~mm})$, middle $(201-400 \mathrm{~mm})$ and upper $(401-600 \mathrm{~mm})$ sections of the fuel bundle 
Results: Phase 1, Test 1
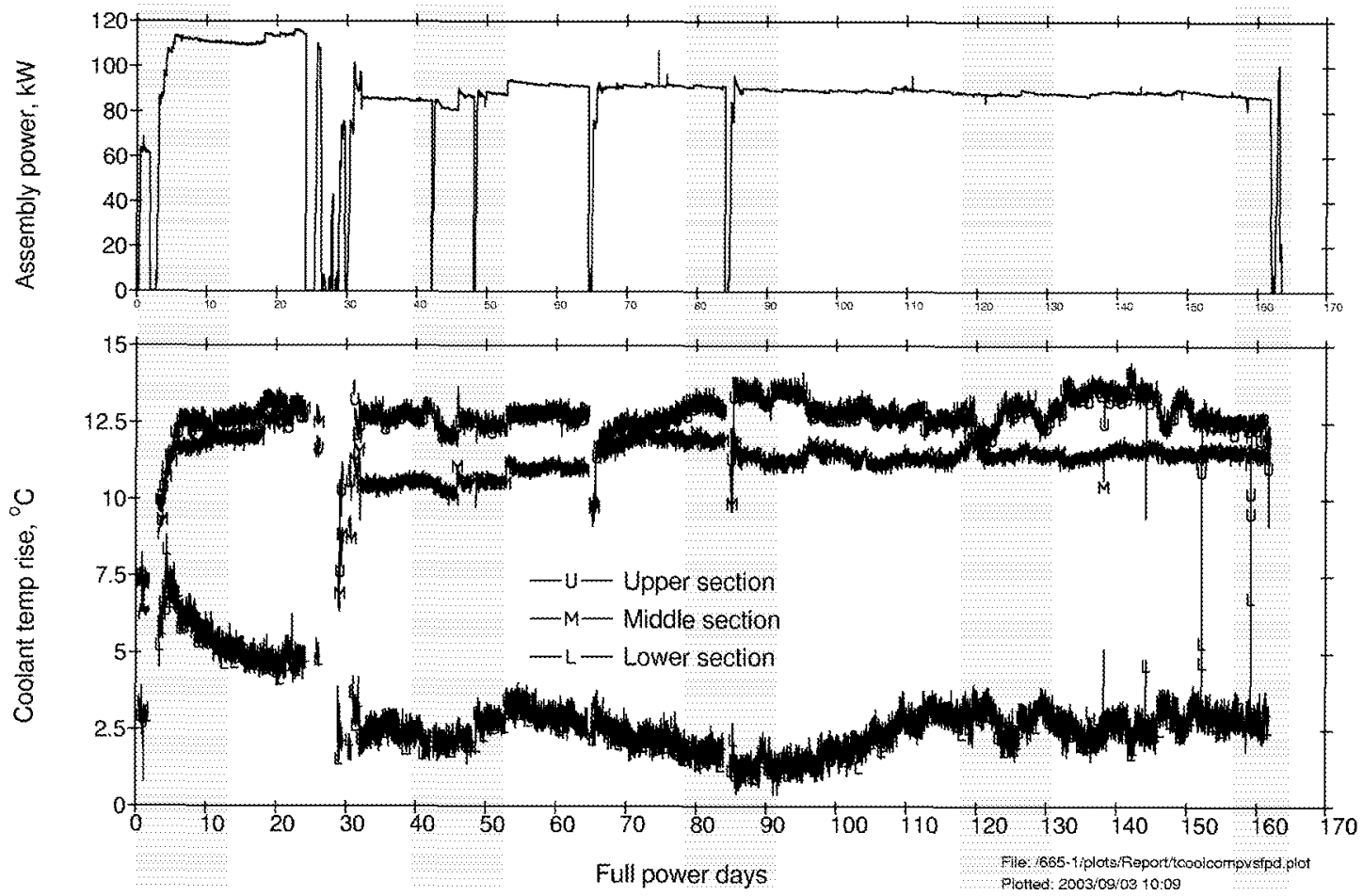

Figure 4-22

Increase in coolant temperature over lower $(0-200 \mathrm{~mm})$, middle $(201-400 \mathrm{~mm})$ and upper (401-600 $\mathrm{mm}$ ) sections of the fuel bundle

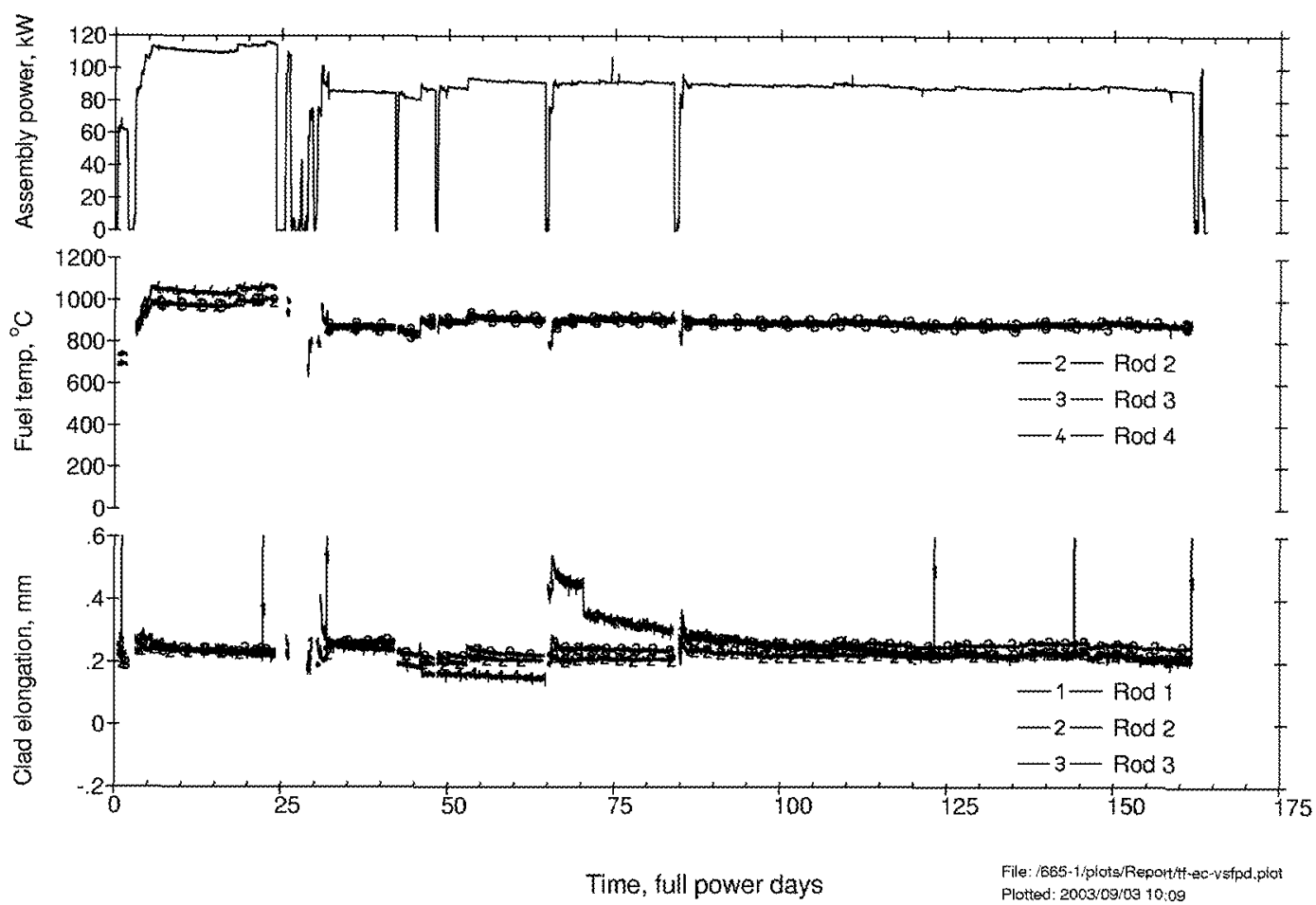

Figure 4-23

Fuel temperature and cladding elongation measurements during Phase 1, Test 1 


\section{5 \\ DISCUSSION: PHASE 1, TEST 1}

In a PWR, approximately 75 percent of the surface area of the coolant circuit (i.e. the reactor pressure vessel and steam generators) is fabricated from Ni-based alloys, compared with approximately 5 percent from stainless steels [17]. This results in approximately 96 percent of the corrosion products being initially formed from steam generator materials. The loop systems in the Halden reactor are fabricated from stainless steel, and hence there would be differences between the corrosion products formed in a PWR and a Halden test. Among the objectives of IFA-665 was that any crud formed should be representative of that in a PWR, and for this reason a representative relative surface area of $\mathrm{Ni}$-based material was included by installing two autoclaves containing a large number of small-bore nickel tubes (see Chapter 2). By varying the flow and temperature in these autoclaves, it was hoped that the nickel content in the coolant, and thereby the iron/nickel ratio, could be varied. The solubility of a metal is controlled by both thermodynamic and kinetic factors. Although the thermodynamic solubility at $300^{\circ} \mathrm{C}$ of nickel is low, it was hoped that high flow rates with turbulent flow would force the system into nonequilibrium conditions. If this was not sufficient, the autoclave temperature could be decreased to increase the solubility. However, sufficiently high flow rates could not be achieved. Higher solubilities were achieved by decreasing the temperature below the transformation temperature where nickel oxide is no longer thermodynamically stable (its hydrated form, nickel hydroxide, becomes stable). The measured nickel concentrations agreed well with calculated solubilities [18]. However, it was not possible to operate the main loop below the transformation temperature.

As described in Chapter 4, the crud burst injections had a negative effect on in-pile deposition, and the $\mathrm{pH}$ and oxygen transients likewise failed to deposit crud. Among possible reasons for the lack of crud deposition are that more time is required to form crud, and/or that the concentrations of Fe and $\mathrm{Ni}$ in the loop were simply too low (and that short-term increases had no quantifiable effect). It is also believed that any added particulate material must have favourable physical properties. It was described in Chapter 4 that the $\mathrm{NiFe}_{2} \mathrm{O}_{4}$ particles measured after particle injections were coated with graphite - believed to have been picked up from the crud burst injector pump bearings. The carbon coating on the particles likely had a significant effect on the charge of the material. Hence, for the second cycle of the test, steps were taken to increase Fe and Ni concentrations. These are outlined in Chapter 6 below.

Another possibility for the lack of crud is that the heat flux is too low to promote deposition. Crud deposition has occurred in previous Halden tests carried out under PWR conditions; a comparison between the thermal-hydraulic parameters and water chemistry conditions in these tests and IFA-665 is given below.

IFA-585 was a Zircaloy creep test [19], which shared a loop with an experiment to assess the effects of $50 \mathrm{ppb}$ dissolved zinc ( $\mathrm{Zn}$ ) on fuel cladding corrosion [20]. In IFA-585, anomalous 
diameter increases were observed, which were correlated with short term spikes in the coolant $\mathrm{Zn}$ concentration (upwards of $200 \mathrm{ppb}$ ), and were attributed to formation of a thick crud layer on the outer surface of the Zircaloy fuel cladding. Once Zn levels stabilised at $50 \mathrm{ppb}$, no further substantial deposition was observed. The crud layer was hard and tenacious, and little affected by mechanical abrasion from repeated movement of the diameter gauges. The peak thickness of the crud layer was $50 \mu \mathrm{m}$. Analyses concluded that deposition was favoured by high thermal flux and the onset of nucleate boiling. It was also noted that the crud dissolved during the subsequent reactor shutdown, when coolant temperature was reduced to around $70-80^{\circ} \mathrm{C}$ [19].

Thermal hydraulic parameters in IFA-585 were:

- Coolant inlet temp: $310^{\circ} \mathrm{C}$

- Coolant outlet temp: $320^{\circ} \mathrm{C}$

- Inlet flow velocity: $0.28 \mathrm{~m} / \mathrm{s}$

- Pressure: 162 bar

- Void fraction: $\quad 0.12$ to 0.19 (surface void)

The mean heat flux was $1180 \mathrm{~kW} / \mathrm{m}^{2}$, which is higher than that in IFA-665 (approx $850 \mathrm{~kW} / \mathrm{m}^{2}$ in the upper two thirds of the fuel bundle).

More detailed analyses of the test [21] showed that the amount of crud deposition (D) was proportional to the fifth power of the heat rate:

$$
D \propto\left(\frac{L H R_{x}}{L H R_{\min }}\right)^{5}
$$

where $\mathrm{LHR}_{\mathrm{x}}$ is the local heat rate and $\mathrm{LHR}_{\text {min }}$ is the minimum heat rate needed to produce nucleate boiling. This implies that crud deposition is promoted by boiling, not by the magnitude of the heat flux. In this case, $\mathrm{LHR}_{\min }$ was $28 \mathrm{~kW} / \mathrm{m}$, which is equivalent to a heat flux of 830 $\mathrm{kW} / \mathrm{m}^{2}$.

Vista analyses of IFA-665 show that nucleate boiling commenced at a LHR of $16 \mathrm{~kW} / \mathrm{m}$, or a heat flux of $600 \mathrm{~kW} / \mathrm{m}^{2}$. Under steady operating conditions, the heat fluxes are as follows:

- Bottom section $(0-200 \mathrm{~mm}): 455 \mathrm{~kW} / \mathrm{m}^{2}$

- Middle section (201 - $400 \mathrm{~mm}): 855 \mathrm{~kW} / \mathrm{m}^{2}$

- Upper section (401 - $600 \mathrm{~mm}): 837 \mathrm{~kW} / \mathrm{m}^{2}$

Hence, the heat flux along the middle and upper sections of the fuel in IFA-665 were similar to those in IFA-585 under which crud deposition occurred.

In a PWR Zircaloy corrosion test (designated here as "Test 2"), anomalous crud build-up on the fuel was detected by out-of-pile eddy current measurements of oxide thickness. 
Thermal hydraulic parameters for the test were:

- Coolant inlet temp: $\quad 322^{\circ} \mathrm{C}$

- Coolant outlet temp: $\quad 326-329^{\circ} \mathrm{C}$

- Inlet flow velocity: $1.8 \mathrm{~m} / \mathrm{s}$

- Pressure: 150 bar

- Void fraction: $\quad 0.13$ (surface boiling)

- Steam quality: 0.02

As in IFA-665, the fuel rods had split U-235 enrichment, and the mean fluxes were $1181 \mathrm{~kW} / \mathrm{m}^{2}$ (lower section) and $894 \mathrm{~kW} / \mathrm{m}^{2}$ (upper section). The latter is only slightly higher than that in IFA-665 (approx $850 \mathrm{~kW} / \mathrm{m}^{2}$ in the upper two thirds of the fuel bundle).

Eddy current measurements were taken after 45 and 160 days at power. These measurements have the usual uncertainties on how representative they are of the crud that was formed at normal operating conditions.

After 45 days, a layer of (oxide + crud) of approximately $6 \mu \mathrm{m}$ was observed. There were no significant differences between the thickness on the lower and upper segments. After 160 days, the lower segment had a layer of approx $20 \mu \mathrm{m}$, while the layer on the upper segment was approximately $10 \mu \mathrm{m}$; i.e. the crud was thicker on the section with the higher heat flux. Heated and unheated axial zones were clearly distinguishable. In the non-heated region, the layer thickness was approximately $5 \mu \mathrm{m}$. In the heated regions, there were minima at pellet-pellet interfaces and maxima at the pellet centres. It was found that bulk boiling did not lead to a higher crud deposition than nucleate boiling.

In summary, it can be concluded that while the heat flux in the first cycle of IFA-665 was not too low to allow crud deposition, higher heat fluxes may have accelerated crud formation. In addition, a higher heat flux in combination with higher circulating corrosion products may have been necessary in the current test to promote deposition of a sufficiently thick crud layer that would allow measurable flux depression due to boron incorporation.

Comparison of the void fractions in the three tests shows that the boiling conditions were much more severe in IFA 585 and Test 2 (Table 5-1): the coolant conditions sustained strong nucleate boiling with voidage detached from the walls (i.e. flow quality $>0.0$ ). In contrast, in IFA-665, void fractions were a factor of 10 lower and there was no detached voidage. These relatively benign conditions in IFA-665, typical of commercial PWRs, may partly explain the lack of crud formation. 
Table 5-1

Void fractions and steam quality in IFAs 585 and 665 and Test 2

\begin{tabular}{|l|l|l|l|}
\hline \multicolumn{1}{|c|}{ Parameter } & \multicolumn{1}{c|}{ IFA-585 } & \multicolumn{1}{c|}{ Test 2 } & \multicolumn{1}{c|}{ IFA-665 } \\
\hline Void fraction & $0.12-0.19$ & 0.13 & 0.012 \\
\hline Steam quality & $>0$ & 0.02 & 0.0 \\
\hline Inlet temperature $\left({ }^{\circ} \mathrm{C}\right)$ & 310 & 322 & $290-294$ \\
\hline Outlet temperature $\left({ }^{\circ} \mathrm{C}\right)$ & 320 & $326-329$ & $310-314$ \\
\hline
\end{tabular}

Water chemistry conditions in the three tests are compared in Table 5-2 below.

Table 5-2

Water chemistry conditions in IFAs 585 and 665 and Test 2

\begin{tabular}{|l|l|l|l|}
\hline \multicolumn{1}{|c|}{ Parameter } & \multicolumn{1}{|c|}{ IFA-585 } & \multicolumn{1}{|c|}{ IFA-593 } & \multicolumn{1}{|c|}{ IFA-665 } \\
\hline LiOH, ppm & 2.2 or 4.0 & $3.2 / 2.2^{*}$ & 3.15 \\
\hline $\mathrm{B}, \mathrm{ppm}$ & 1000 & $992 / 290^{*}$ & 1400 \\
\hline $\mathrm{pH}_{300}$ & $6.9 / 7.2$ & $7.1 / 7.4$ & 7.0 \\
\hline Soluble $\mathrm{Fe}, \mathrm{ppb}$ & 7.0 & $0.1-27$ & 3.5 \\
\hline Soluble $\mathrm{Ni}, \mathrm{ppb}$ & 0.3 & $0-1.4$ & 0.3 \\
\hline Soluble $\mathrm{Zn}, \mathrm{ppb}$ & 50 & $<1$ & $<1$ \\
\hline
\end{tabular}

* Concentration linearly reduced with time

Soluble Fe concentrations were higher in IFA 585 and Test 2 than in IFA-665, but there were no "spikes" such as were introduced in the current test by way of the $\mathrm{pH}$ transients. Levels of insoluble Fe and Ni in IFA-585 were similar to those in IFA-665. When comparing the current test with Test 2, the higher soluble Fe levels in the latter may have aided crud deposition. A comparison of the effects of water chemistry on crud deposition between IFA-585 and the current test is difficult because of the high level of added zinc in the former. 


\section{TEST SPECIFICATIONS: PHASE 1,TEST 2}

For the second irradiation cycle, several steps were undertaken to attempt to deposit crud by increasing the concentrations of Fe and $\mathrm{Ni}$ in the coolant.

Firstly, the $\mathrm{pH}_{300^{\circ} \mathrm{C}}$ was lowered from 7.0 to 6.5 ( $\mathrm{LiOH}$ concentration reduced from 3.15 to 0.95 $\mathrm{ppm}$ ), as it has been observed in some PWRs that low $\mathrm{pH}$ leads to rapid crud formation. The intention was to raise $\mathrm{pH}_{300^{\circ} \mathrm{C}}$ to 7.0 once crud had deposited.

A Fe-Ni-EDTA (EDTA = Ethylene Diamine Tetra Acetic acid) solution was prepared for continuous injection to the coolant with the intention of maintaining a steady-state $(\mathrm{Fe}+\mathrm{Ni})$ concentration of $100 \mathrm{ppb}$. The solution was prepared by mixing solutions that were 15 percent in EDTA and 2.5 percent in either Fe or $\mathrm{Ni}$, and contained $31.25 \mathrm{ppm}$ each of Fe and Ni. The stability of the solution was tested in an autoclave by Westinghouse; the results obtained for iron stability are summarised in Table 6-1. The nickel complex was found to be stable at all temperatures studied.

Table 6-1

Half life of Fe-EDTA complex from autoclave testing

\begin{tabular}{|l|l|l|}
\hline Temperature $\left({ }^{\circ} \mathrm{C}\right)$ & \multicolumn{1}{|c|}{ Corresponding location in test rig } & Half life (min) \\
\hline 275 & Inlet to test rig & 630 \\
\hline 294 & Bottom of fuel stack & 84 \\
\hline 322 & Top of fuel stack & 24 \\
\hline
\end{tabular}

EDTA has a strong chelate effect and forms stable complexes with all transition elements, which are stable in solutions up to $250-260^{\circ} \mathrm{C}$. Thus, the EDTA complex should enable soluble Fe and $\mathrm{Ni}$ to be transported at high concentrations to the test rig. At higher temperatures, or in a gamma/neutron field, the complex decomposes and releases its central ion. Such a release of Fe and $\mathrm{Ni}$ in the in-core section of the test rig at concentrations above their solubilities should result in deposition on the fuel cladding, which is a highly effective filter. However, temperature cycling in the in-core section may weaken the complex, which could result in release of the central ion in other sections of the loop.

High temperature and radiation decomposes EDTA to $\mathrm{CO}_{2}$ and water in system in equilibrium. However, since the loop was not in equilibrium and also for kinetic reasons, other decomposition products would form, such as formate and acetate anions. 
An Fe/Ni colloid suspension, consisting of non-stoichiometric nickel ferrite, was prepared for injection from the crud burst generator, with two injections per day planned during the first 30 days of operation. The $(\mathrm{Fe}+\mathrm{Ni})$ concentration in the suspension was $0.25 \mathrm{~g} / \mathrm{l}$, with an $\mathrm{Ni}: \mathrm{Fe}$ ratio of 0.61 . Each injection of $100 \mathrm{ml}$ would result in a calculated instantaneous $(\mathrm{Fe}+\mathrm{Ni})$ concentration in the loop of $500 \mathrm{ppb}$. The EDTA solution and colloid suspension had been used previously in autoclave tests by Westinghouse, and had been successful in depositing crud on both heated and unheated surfaces.

The loop purification flow during Phase 1, Test 1 was large compared with operating PWRs (in the test loop, the ratio of system passes through the core to passes through the cleanup system was 17.6, which was 150 times lower than in a PWR), which reduced corrosion product concentrations in the coolant and hence the likelihood of crud deposition. Hence, for the second test it was decided to run the loop purification flow only to maintain anion concentrations within allowable limits $\left(\left[\mathrm{Cl}^{-}+\mathrm{F}+\mathrm{SO}_{4}^{2}\right]<150 \mathrm{ppb}\right)$. 


\section{RESULTS: PHASE 1, TEST 2}

During the last day of operation of Phase 1, Test 1, radioiodine was measured in the loop coolant. Analyses of fuel temperatures indicated that all three rods fitted with fuel thermocouples had suffered small failures, probably at the thermocouple penetrations. Hence, three replacement rods were loaded for Phase 1 , Test 2 . The rods were equipped with clad extensometers, however thermocouples were not fitted as it was not possible to connect them to signal cables.

Phase 1, Test 2 was loaded in January 2004 and operated for 97 FPD until May 2004. Test rig power and assembly burn-up are shown in Figure 7-1. The period included several power transients and short shutdowns, all of which were connected with other test rigs.
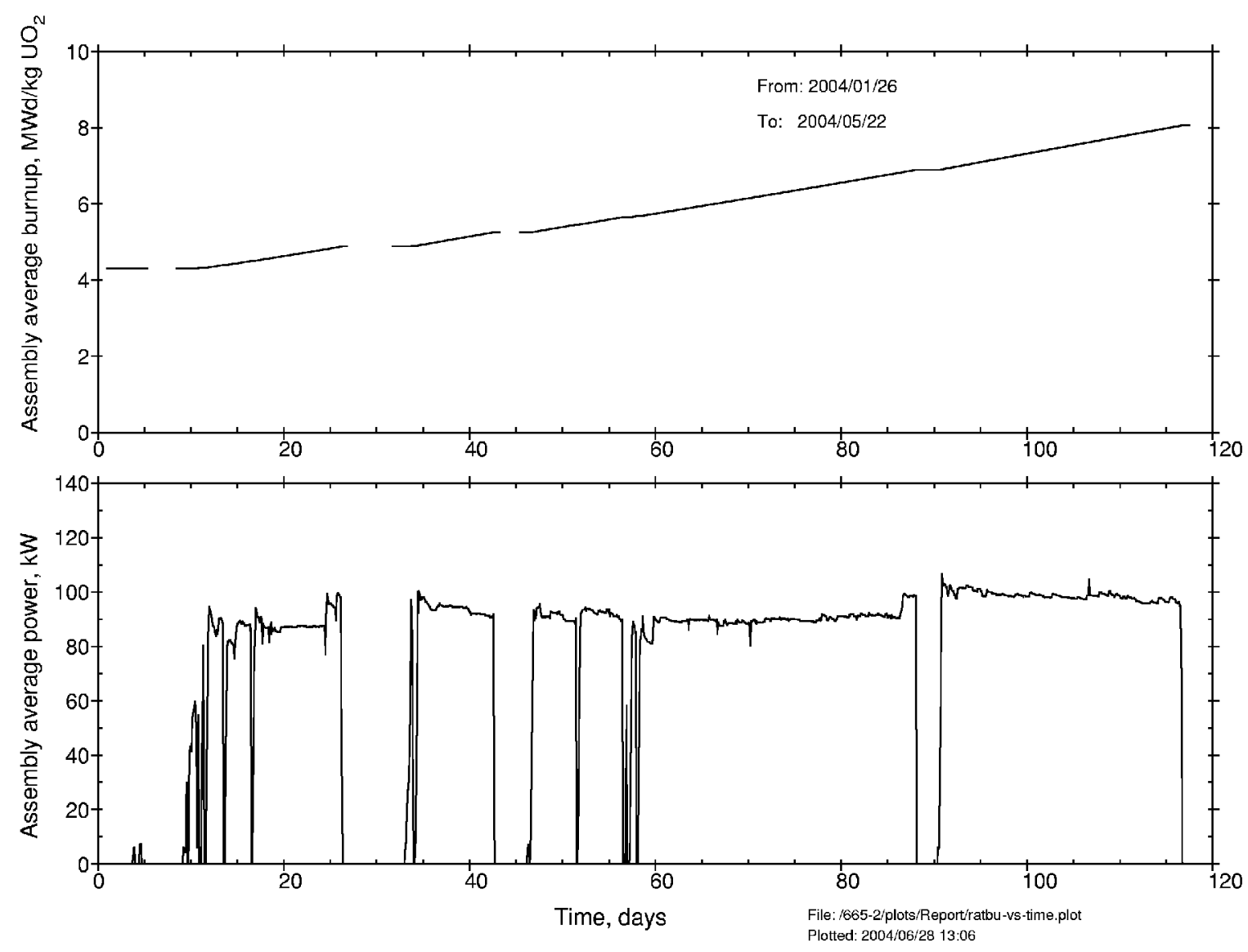

Figure 7-1

Assembly power and burn-up during Phase 1 Test 2 
Bulk chemistry conditions are shown in Figure 7-2. The low $\mathrm{pH}_{300}$ (6.5) was maintained until 225 FPD, after which the LiOH concentration was increased to $3.15 \mathrm{ppm}$ (i.e. the value in Phase 1, Test 1). Operation without purification resulted in increases in conductivity, which were primarily due to the breakdown products of EDTA (see below). The periods during which the purification system was in operation, to reduce anion levels, can be seen on the figure. After less than 20 days operation, measured hydrogen levels increased to the detection limit (10 ppm) of the $\mathrm{H}_{2}$ monitor. It is believed that this was due to decomposition of EDTA (see below).

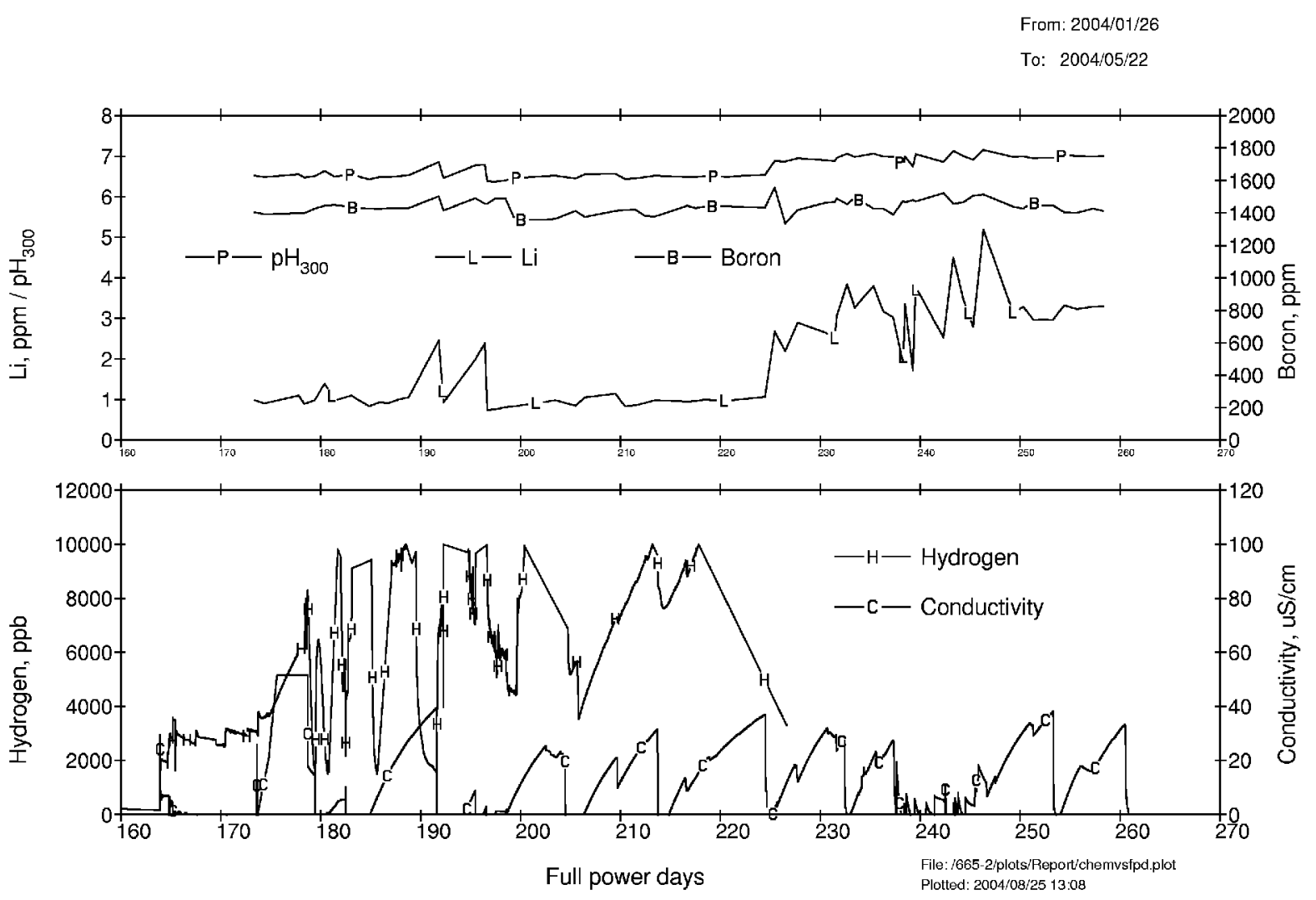

Figure 7-2

Water chemistry conditions during Phase 1 Test 2

Thermal-hydraulic conditions (coolant inlet temperature, temperature rise over the fuel bundle and inlet flowrate) are shown in Figure 7-3. At the start of the test, the inlet temperature was set to $290^{\circ} \mathrm{C}$, and the rig power was similar to that obtained during Phase 1, Test 1 (i.e. approximately $90 \mathrm{~kW}$ ). The temperature rise over the fuel showed a slow but steady increase over the duration of the test, which correlates with a reduction in coolant flowrate.

After 233 FPD (total from Test 1 and Test 2), despite additions of soluble and insoluble Fe and $\mathrm{Ni}$ (see below), there were still no signs of significant crud deposition. At this point, the inlet temperature was increased to $294^{\circ} \mathrm{C}$ and assembly power was increased by approximately 10 percent, by removal of a nearby control rod. These changes resulted in significant changes in the rig thermal-hydraulic conditions, as listed in Table 7-1. 
Table 7-1

Development of thermal-hydraulic conditions

\begin{tabular}{|l|l|l|l|}
\hline \multicolumn{1}{|c|}{ Full power days } & \multicolumn{1}{|c|}{$\begin{array}{c}\text { Inlet temperature } \\
\left({ }^{\circ} \mathbf{C}\right)\end{array}$} & \multicolumn{1}{|c|}{$\begin{array}{c}\text { Maximum heat flux } \\
\left(\mathbf{k W} / \mathbf{m}^{2}\right)\end{array}$} & $\begin{array}{c}\text { Mass evaporation rate } \\
\left(\mathbf{k g} / \mathbf{h} . \mathbf{~ m}^{\mathbf{2}}\right)\end{array}$ \\
\hline 178 & 290 & 860 & 2700 \\
\hline 234 & 294 & 980 & 5800 \\
\hline
\end{tabular}

Heat fluxes throughout the cycle are shown in Figure 7-4. In contrast to the first cycle, in which the fluxes were similar for the two clad diameters, the heat fluxes in the second cycle were higher in the $9.5 \mathrm{~mm}$ OD rods. This was due to the inclusion of the three new rods at the start of the second cycle; these rods, with fresh fuel, developed approximately six percent higher power than the other rods (Figure 7-5).

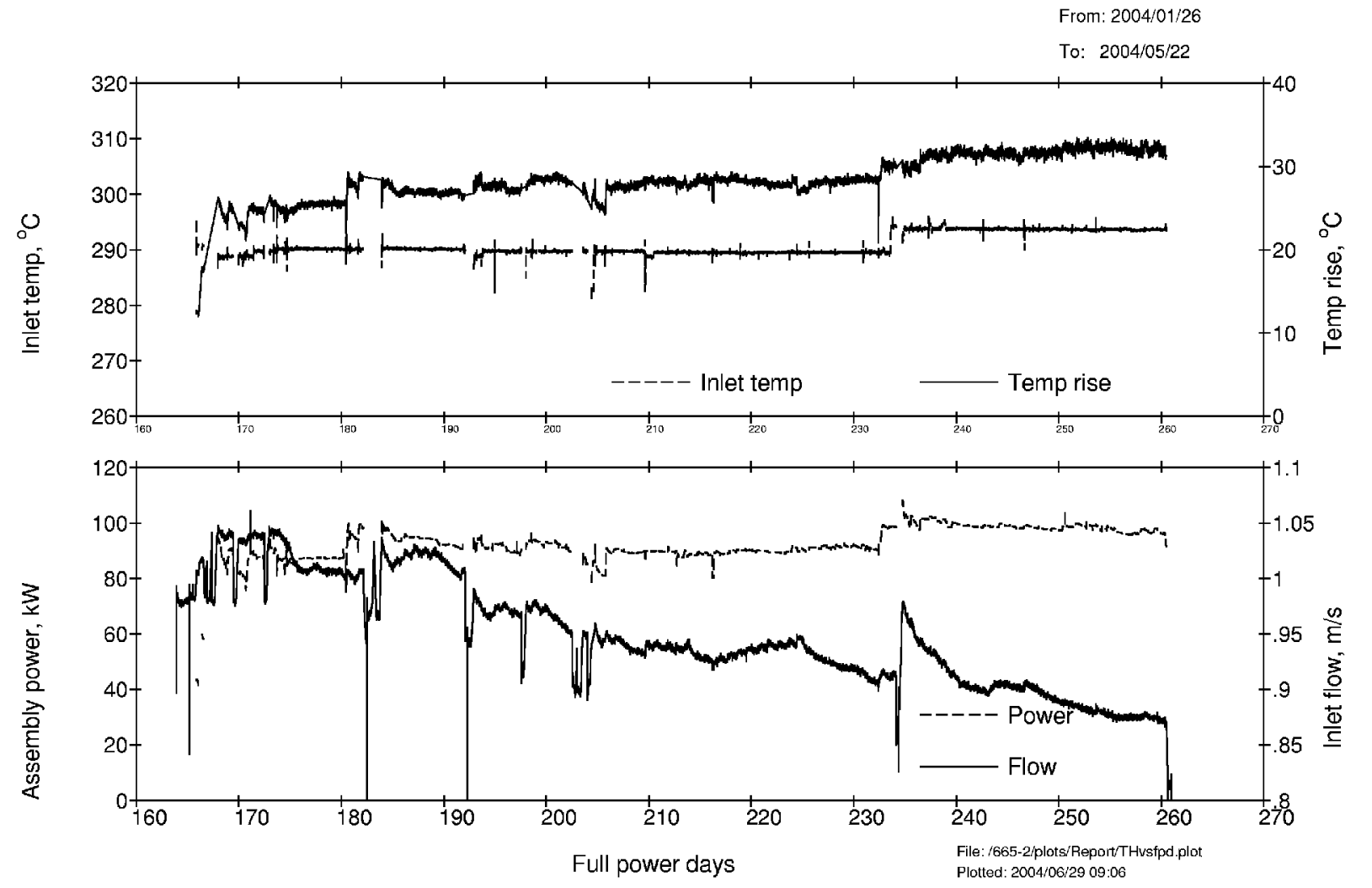

Figure 7-3

Thermal-hydraulic conditions during Phase 1 Test 2 


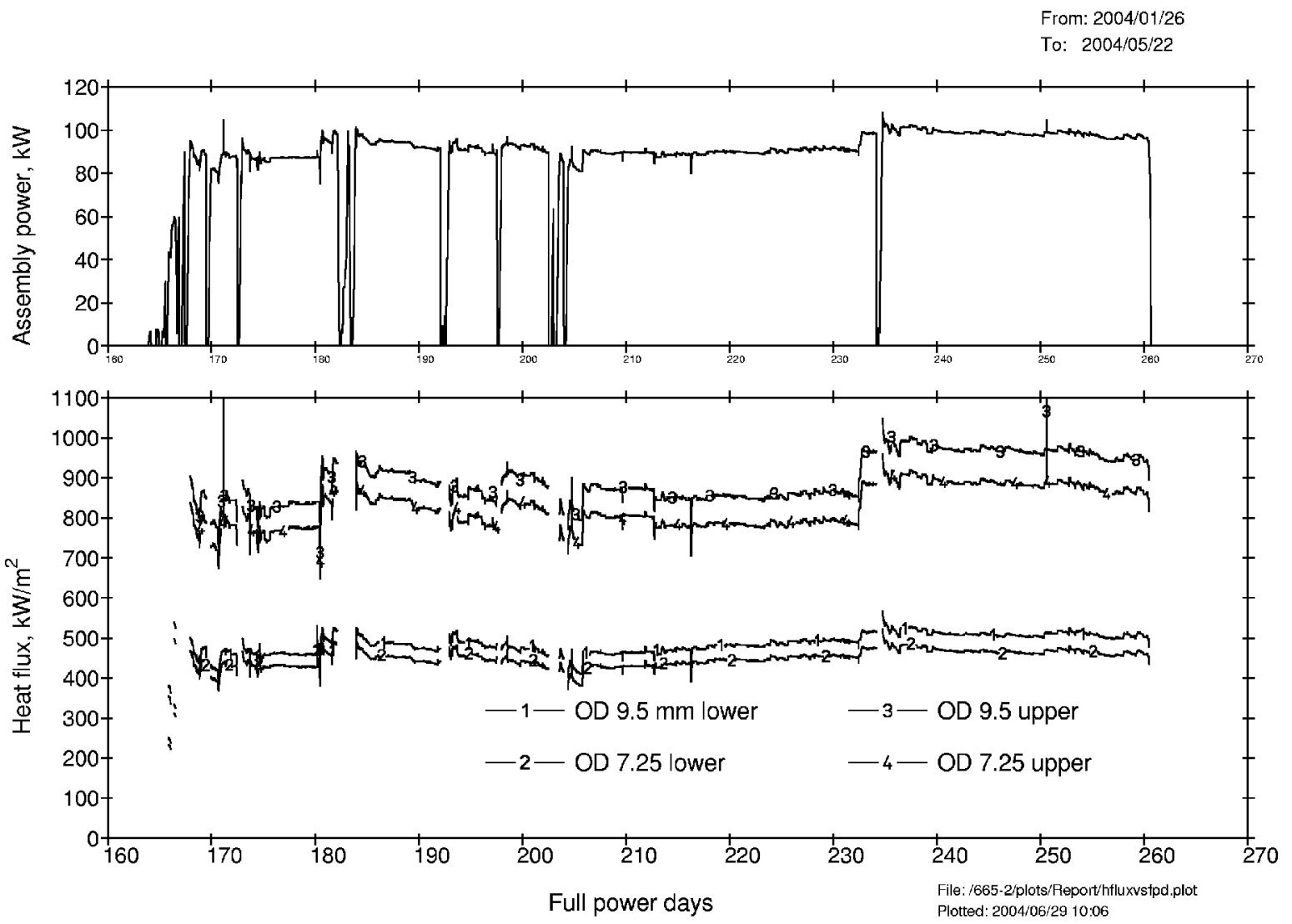

Figure 7-4

Heat flux at the clad surface during Phase 1, Test 2 


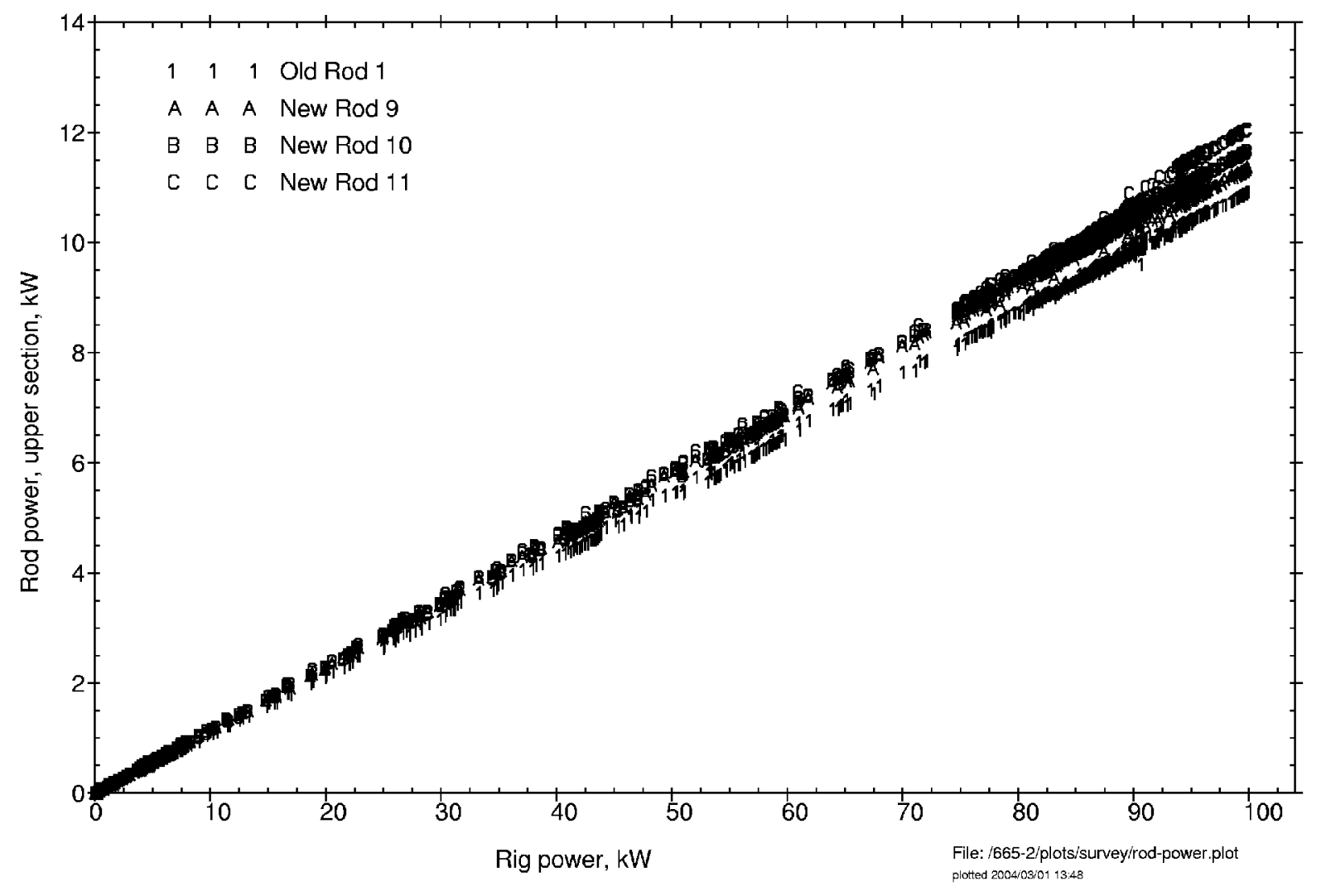

Figure 7-5

Increased power from fresh fuel rods installed for Phase 1 Test 2

After nine full power days (i.e. 173 FPD total), injection of the Fe-Ni-EDTA complex commenced. The injection rate was $70 \mathrm{ml} /$ hour. As measured concentrations of $\mathrm{Fe}$ and $\mathrm{Ni}$ remained low, the concentrations of these elements were increased from 31.25 to $62.5 \mathrm{ppm}$ after 175 FPD and to $125 \mathrm{ppm}$ after 181 FPD. Injection was maintained (except during shutdowns) until the end of the test. Figure 7-6 shows the masses of Fe and Ni injected, together with the concentrations that would have arisen if all of the injected material remained in the coolant. By the end of the cycle, over $10 \mathrm{~g}$ each of $\mathrm{Fe}$ and $\mathrm{Ni}$ had been injected, corresponding to a maximum concentration of $105 \mathrm{ppm}$. Figure 7-7 shows the theoretical crud thickness on the upper $40 \mathrm{~cm}$ of the fuel rods assuming deposition of different fractions of the injected material; a maximum crud thickness of over $130 \mu \mathrm{m}$ would have been possible. 
Results: Phase 1, Test 2

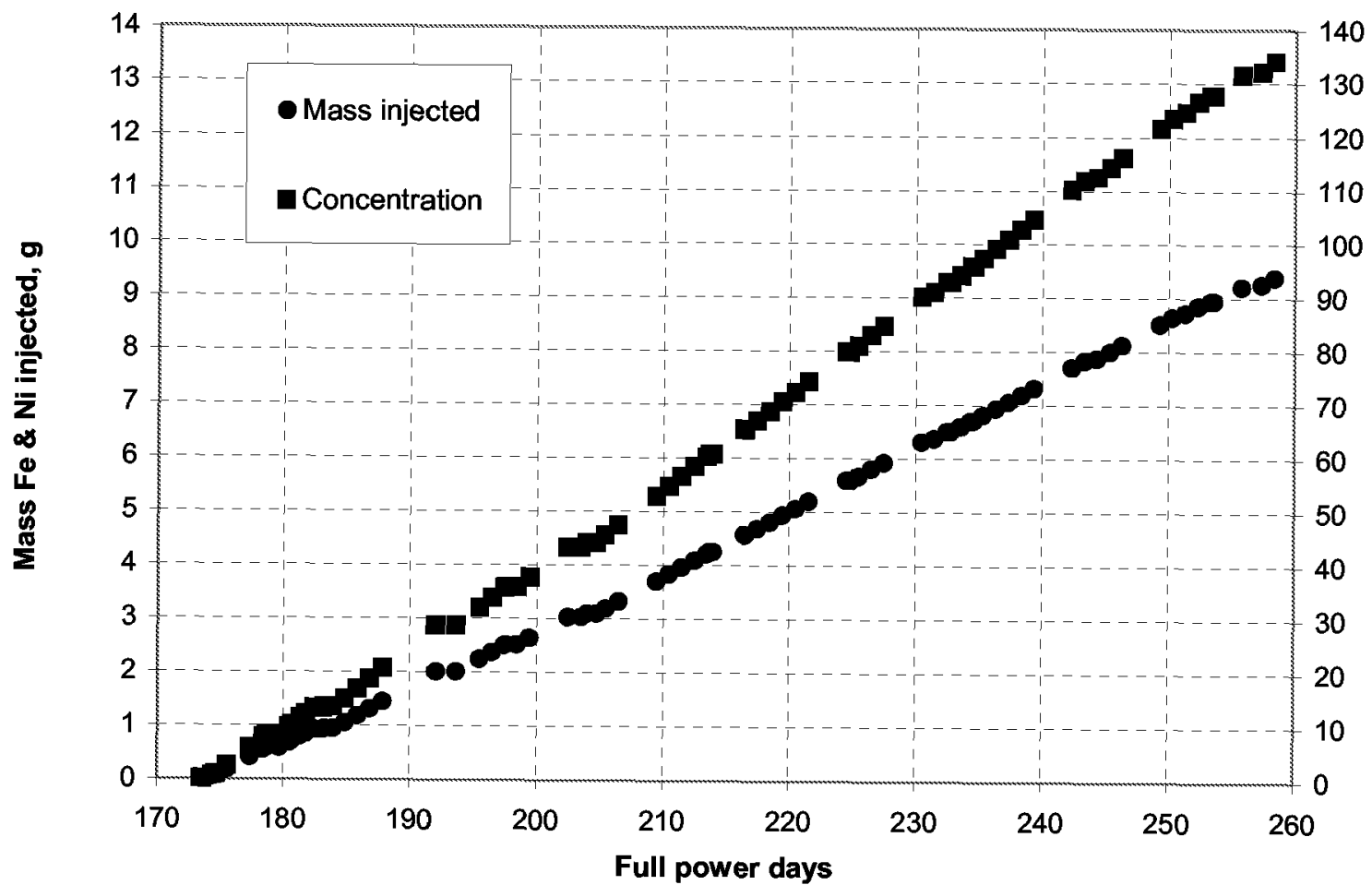

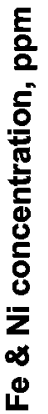

Figure 7-6

Details of injection of Fe-Ni-EDTA solution during Phase 1 Test 2

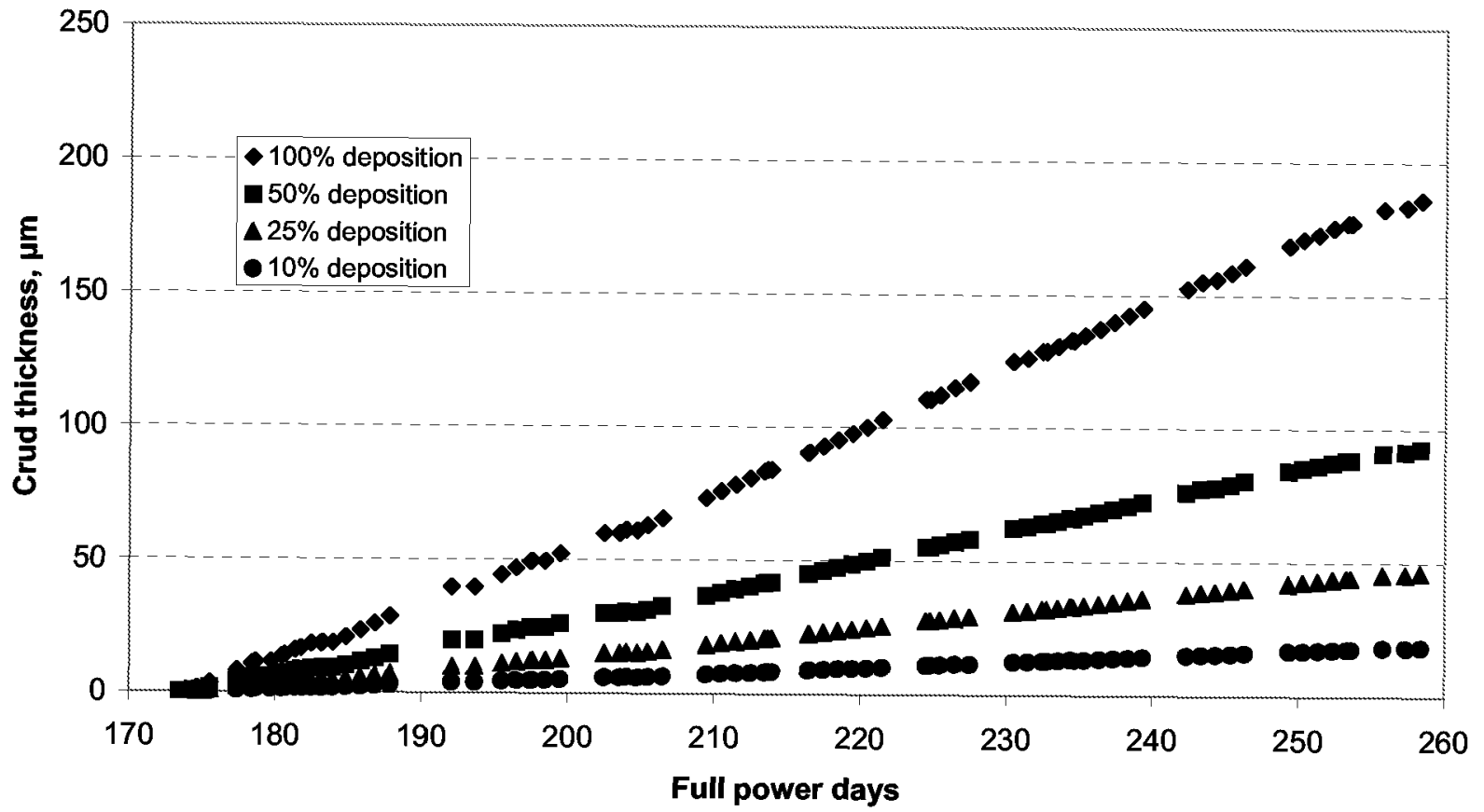

Figure 7-7

Theoretical crud thickness on upper $40 \mathrm{~cm}$ of fuel rods from injected $\mathrm{Fe}$ and $\mathrm{Ni}$ 
Colloid injections were started 17 FPD into the test. A total of 57 injections were done over the following 43 days (Figure 7-8), amounting to addition of a total of $1.54 \mathrm{~g}$ of $(\mathrm{Fe}+\mathrm{Ni})$. Initially, two injections were done each day, but from 218 FPD the frequency was increased to three per day. Over a period of one week with three colloidal injections per day, the flow rate showed a generally increasing trend, which is inconsistent with deposition of the colloids on the boiling fuel surfaces. There were perturbations in flow rate within this increasing trend, and the largest increases followed the addition of the colloids (Figure 7-9). Observations on the variation in flow rate also indicated that the periods of largest reduction were during weekends when no colloids were added. An interpretation of these data was that the addition of the colloids was causing removal of the deposits on system surfaces, and possibly also on the fuel surfaces. The high surface energy of the colloids may have caused clustering, and thereby formation of larger particles, and accelerated removal of deposits. Hence, the colloid injections were stopped.

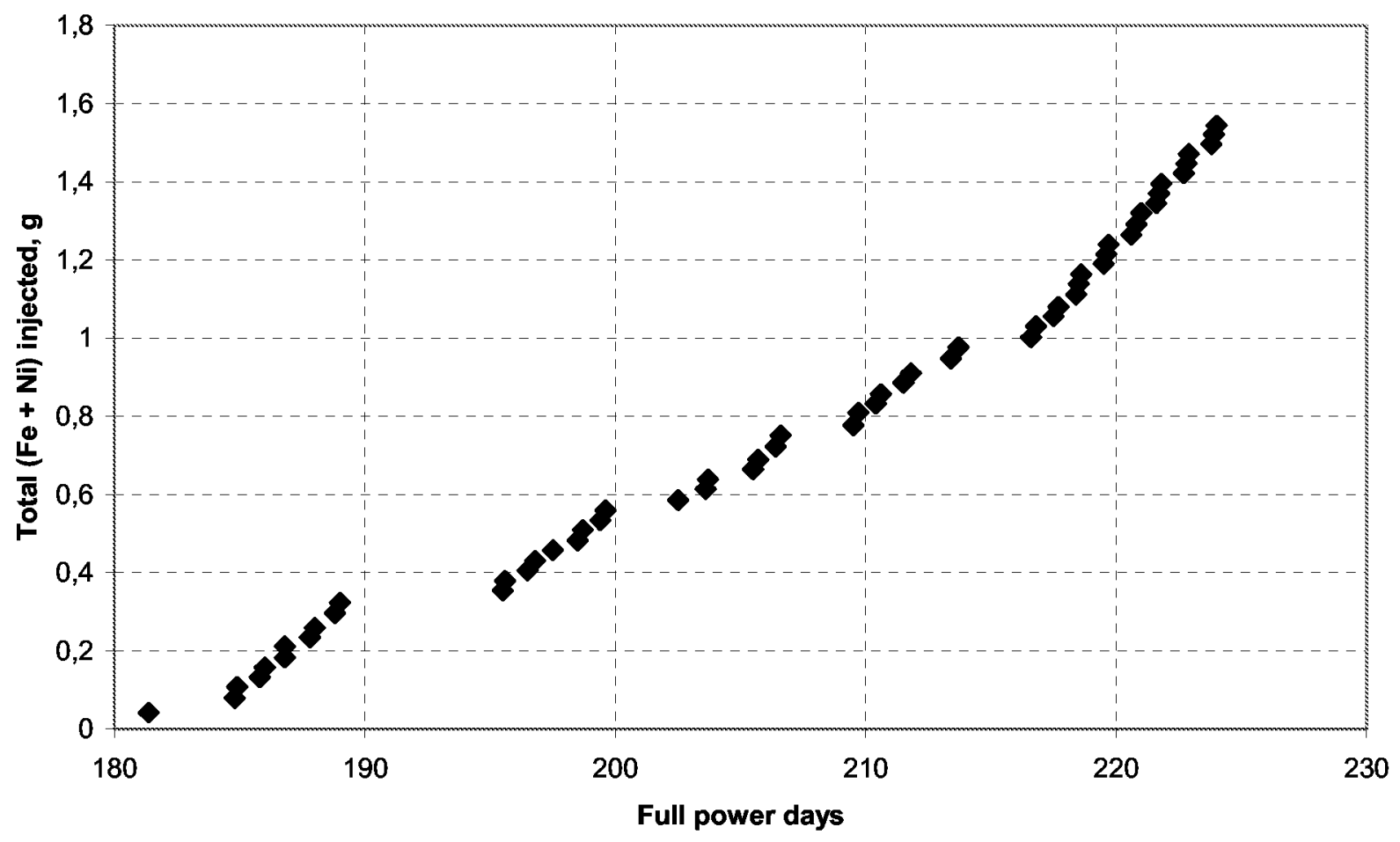

Figure 7-8

Injection of colloidal Fe and Ni during Phase 1 Test 2 


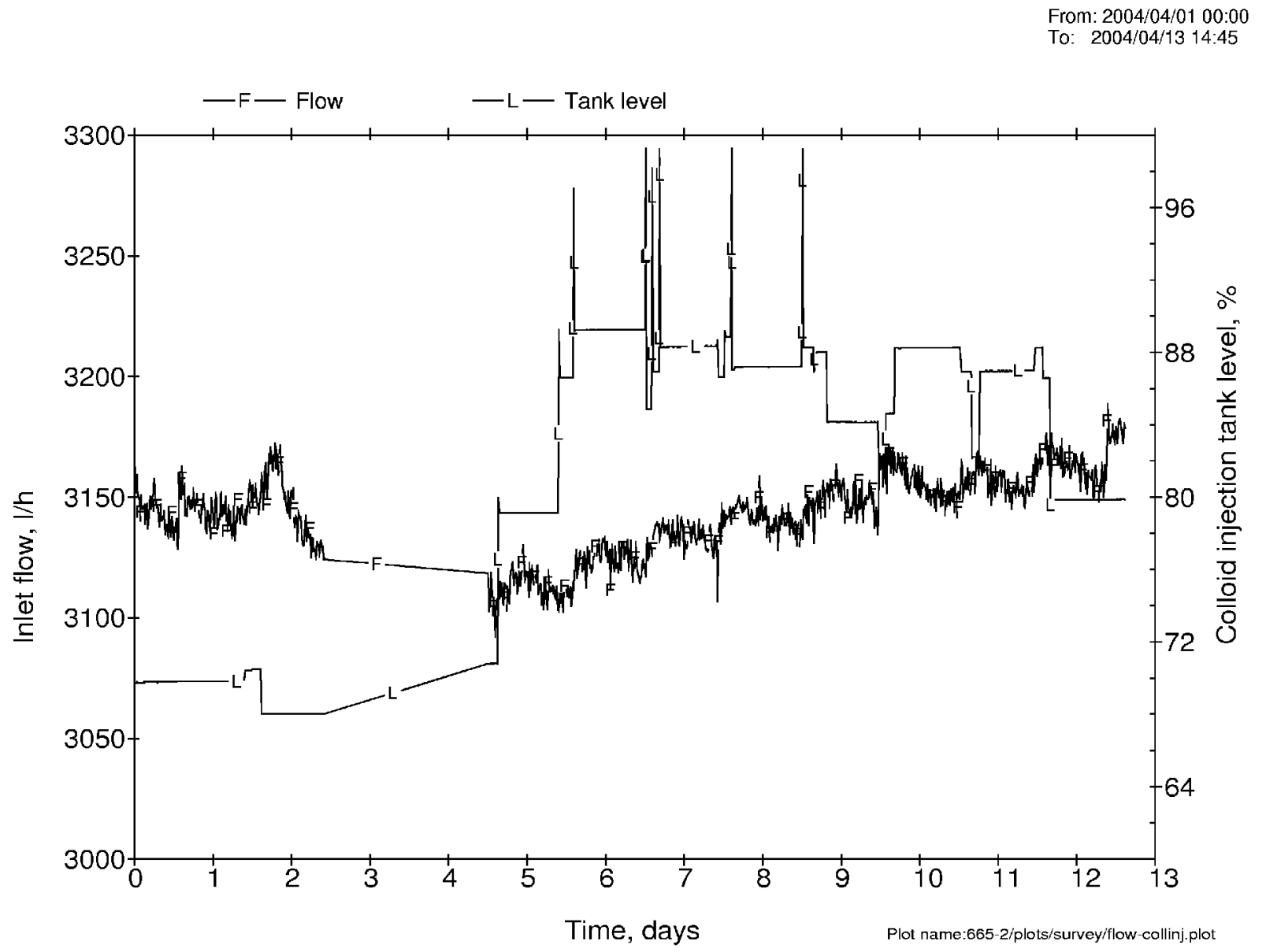

\section{Figure 7-9}

Increases in coolant flowrate due to colloid injections

(Colloid injections can be recognised from changes in the colloid injection tank level)

Measured concentrations of formate and acetate anions throughout the cycle are shown in Figure 7-10. The levels were in the ppm range, with acetate approximately an order of magnitude higher than formate. The levels decreased drastically during interruptions of the EDTA injections. Oxalate formed at high temperatures but only during non-nuclear operation. These byproducts of the decomposition of EDTA increased the coolant conductivity (Figure 7-2), and hence it was no longer possible to use this parameter as an on-line indication of boron and lithium concentrations. Since analysis of $\mathrm{Li}$ and B was done once per 24 hours, and the results used to calculate $\mathrm{pH}_{300^{\circ} \mathrm{C}}$, it was more difficult to control the coolant $\mathrm{pH}$ during the second cycle than during the first. 


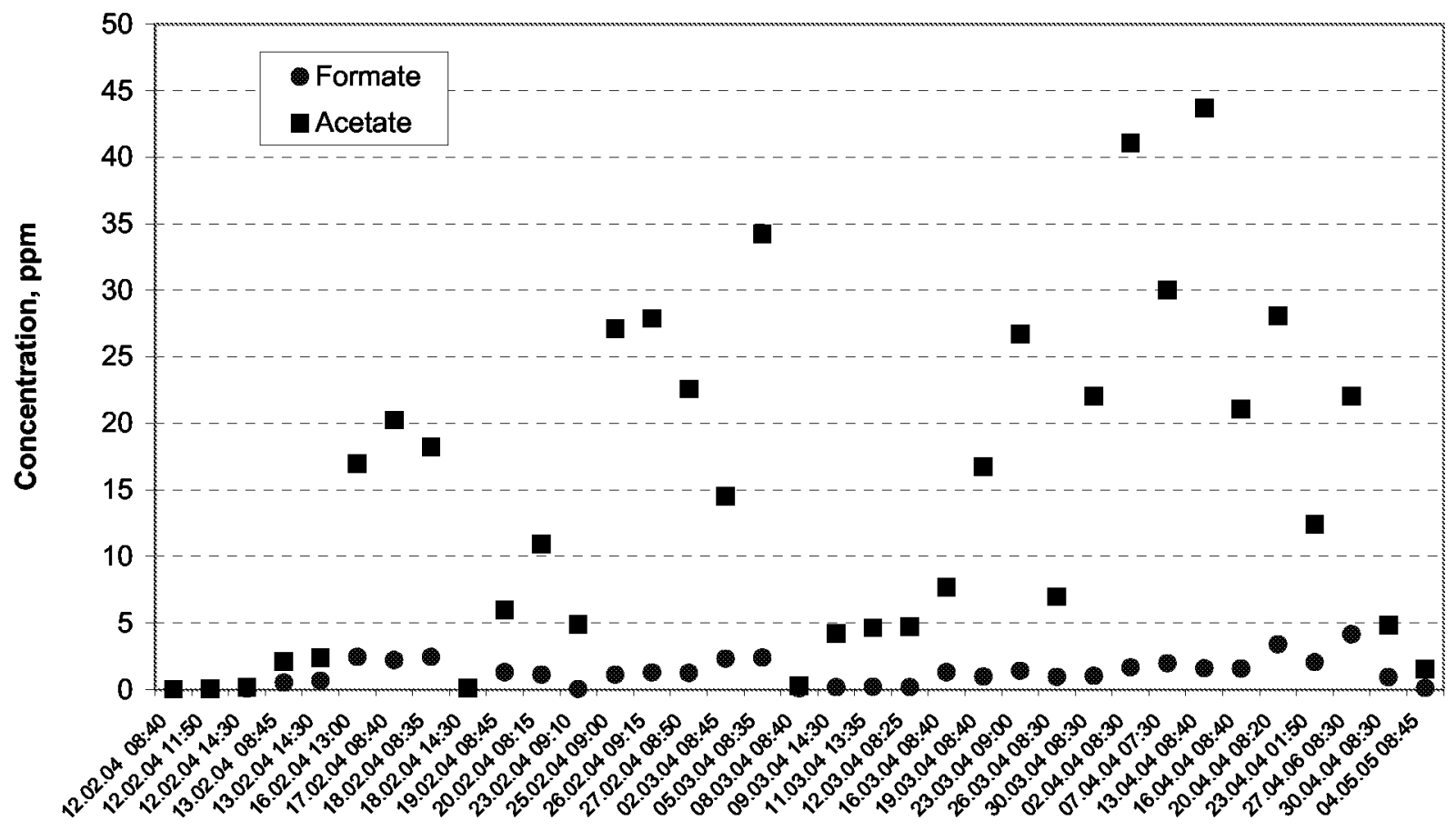

Date

Figure 7-10

Formate and acetate concentrations in the coolant during Phase 1 Test 2

The decomposition products also affected the signals from the $\mathrm{H}_{2}$ (Figure 7-2) and $\mathrm{O}_{2}$ monitors, which tended to increase over time. The measured increases in $\mathrm{H}_{2}$ concentrations were concluded to be real: hydrogen was probably formed from decomposition of EDTA, which electrochemically reacted to form atomic hydrogen that combined to form dissolved hydrogen gas. Formation of oxygen was discounted, as it was not expected to form in a reducing environment. The byproducts from EDTA decomposition may have poisoned the membrane in the oxygen sensor: similar increases in indicated oxygen levels were obtained, on several occasions, shortly after a new sensor was installed. The signals from new hydrogen sensors did not behave in this way: the signal increased continuously from the time of installation.

The silicon content in the coolant of the loop was $135-225 \mathrm{ppb}$, with an average just below 200 .

Iron and nickel concentrations in the loop coolant are shown in Figure 7-11, and the Fe:Ni ratios in Figure 7-12. Concentrations of dissolved iron were mostly in the range from 4 to $15 \mathrm{ppb}$, with an average of $8 \mathrm{ppb}$. Nickel levels were mostly between 0.4 and $2 \mathrm{ppb}$, with an average of 1.0 $\mathrm{ppb}$. These average $\mathrm{Fe}$ and Ni levels were two and eight times higher, respectively, than those in the first cycle, and show that the injection of the EDTA complex was successful in raising Fe and $\mathrm{Ni}$ concentrations, although the levels were significantly lower than the target of $100 \mathrm{ppb}(\mathrm{Fe}+$ $\mathrm{Ni}$ ). The iron and nickel must have been consumed in the system (as noted above, sufficient material was injected to result in a concentration of over $100 \mathrm{ppm}$ each of $\mathrm{Fe}$ and $\mathrm{Ni}$ ); this is in agreement with the high levels of acetate and formate in the coolant. The iron/nickel ratio of the dissolved species varied considerably, between $<5$ and 45 . 
Concentrations of particulate iron varied considerably during the reactor cycle, reflecting, in part, changes caused by the colloid injections. The particle filters usually exhibited a slightly greyish colour, indicating high iron levels. Some very high levels were measured (up to $1000 \mathrm{ppb}$; these values are not plotted for reasons of clarity); which were due to crud bursts caused by shutdowns. Nickel levels were generally less than $10 \mathrm{ppb}$. The iron/nickel ratios were mostly between two and five, which can be compared with the theoretical value of 2, assuming formation of stoichiometric nickel ferrite.

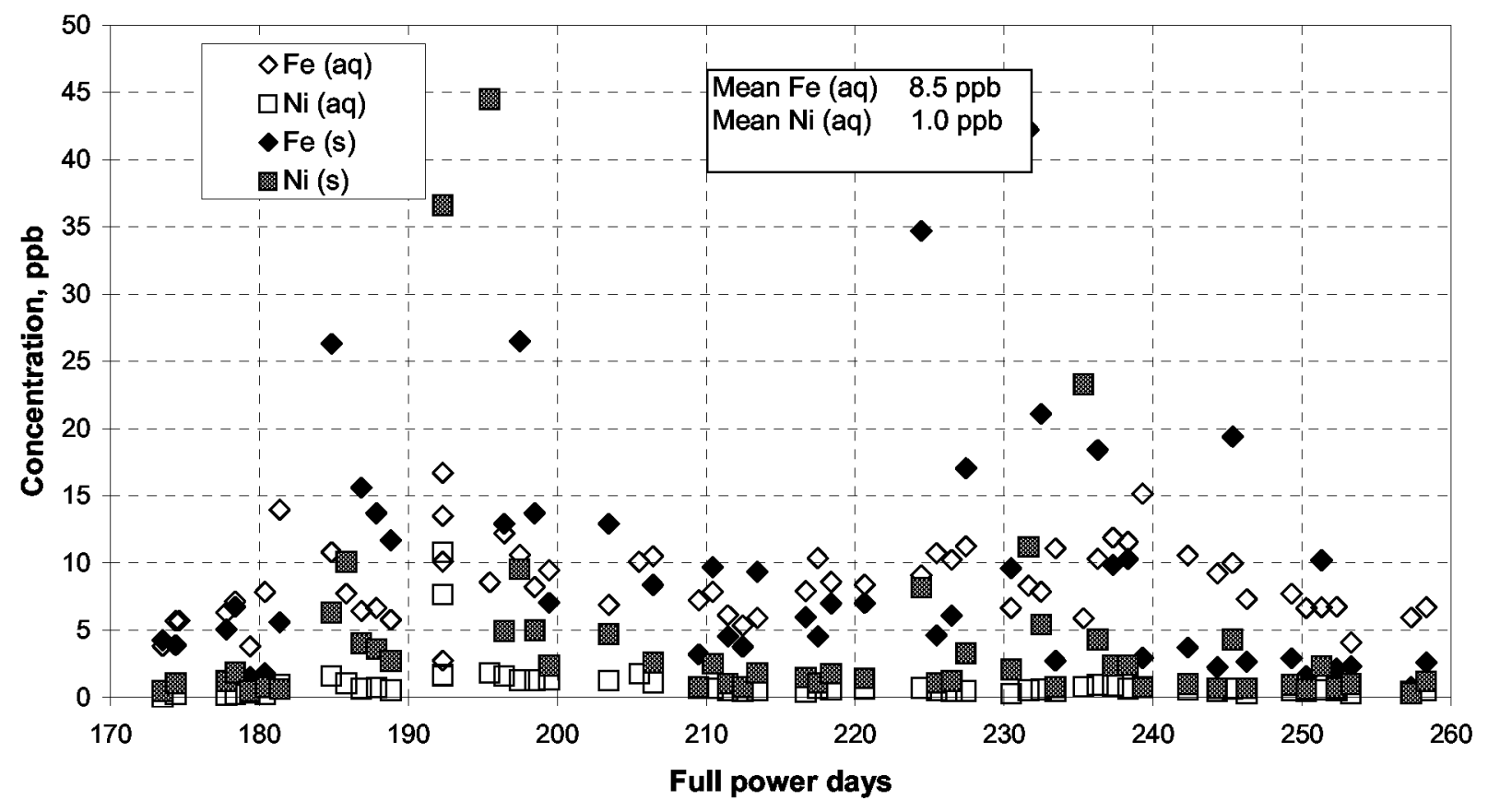

Figure 7-11

Coolant Fe and Ni concentrations during Phase 1 Test 2 


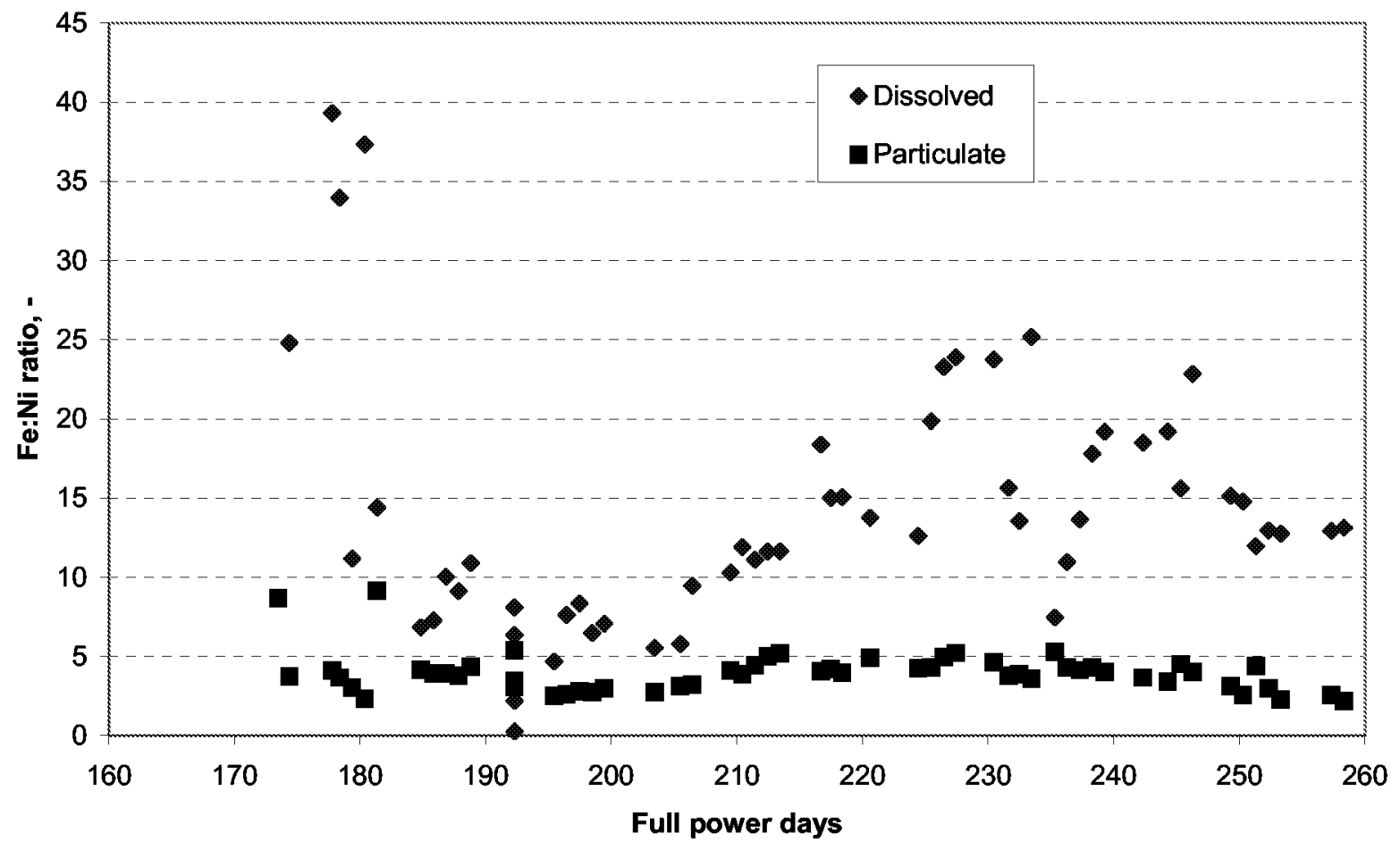

Figure 7-12

Fe:Ni ratios during Phase 1 Test 2

Following injection of colloids into the loop, maxima of $10 \mathrm{ppb}$ particulate iron were measured one to two hours after injection. This shows that the $500 \mathrm{ppb}$ of injected material was quickly consumed by the system surfaces.

Results from gamma spectrometry analyses of coolant samples throughout the cycle are shown in Figures 7-13 $\left({ }^{51} \mathrm{Cr}\right), 7-14\left({ }^{54} \mathrm{Mn}\right.$ and $\left.{ }^{59} \mathrm{Fe}\right)$ and 7-15 $\left({ }^{58} \mathrm{Co}\right.$ and $\left.{ }^{60} \mathrm{Co}\right)$. Activities of both particulate and dissolved species are shown. The activity of ${ }^{51} \mathrm{Cr}$ was mostly in particulate, rather than dissolved, material. The activities of ${ }^{54} \mathrm{Mn}$ and ${ }^{59} \mathrm{Fe}$ were also mostly in particulate form, and the curves are parallel, as expected. This parallel behaviour was also seen for the dissolved species. The activities of ${ }^{58} \mathrm{Co}$ and ${ }^{60} \mathrm{Co}$ in particulate and dissolved species also showed the same trends. 
Results: Phase 1, Test 2

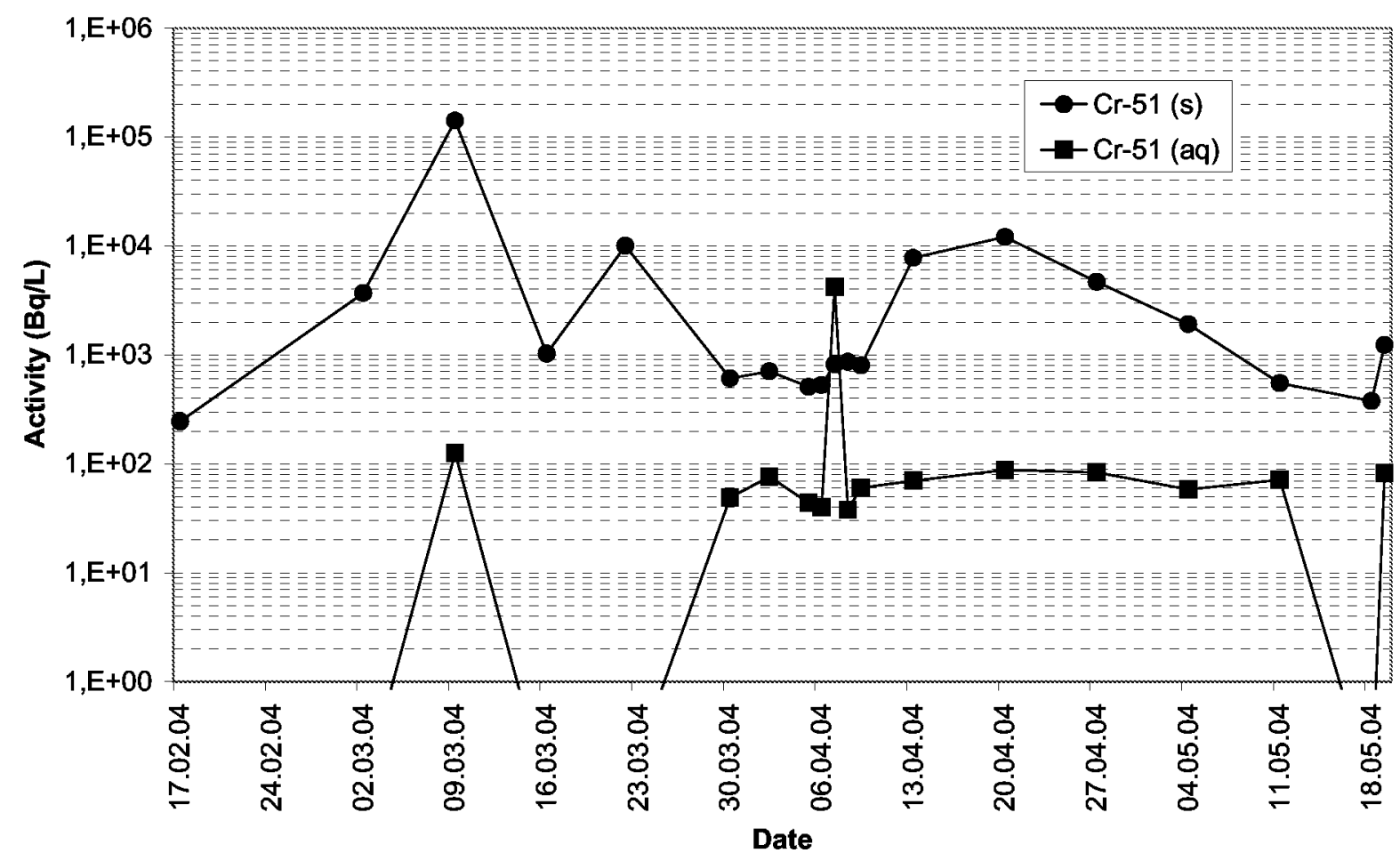

Figure 7-13

Activities of ${ }^{51} \mathrm{Cr}$ during Phase 1 Test 2

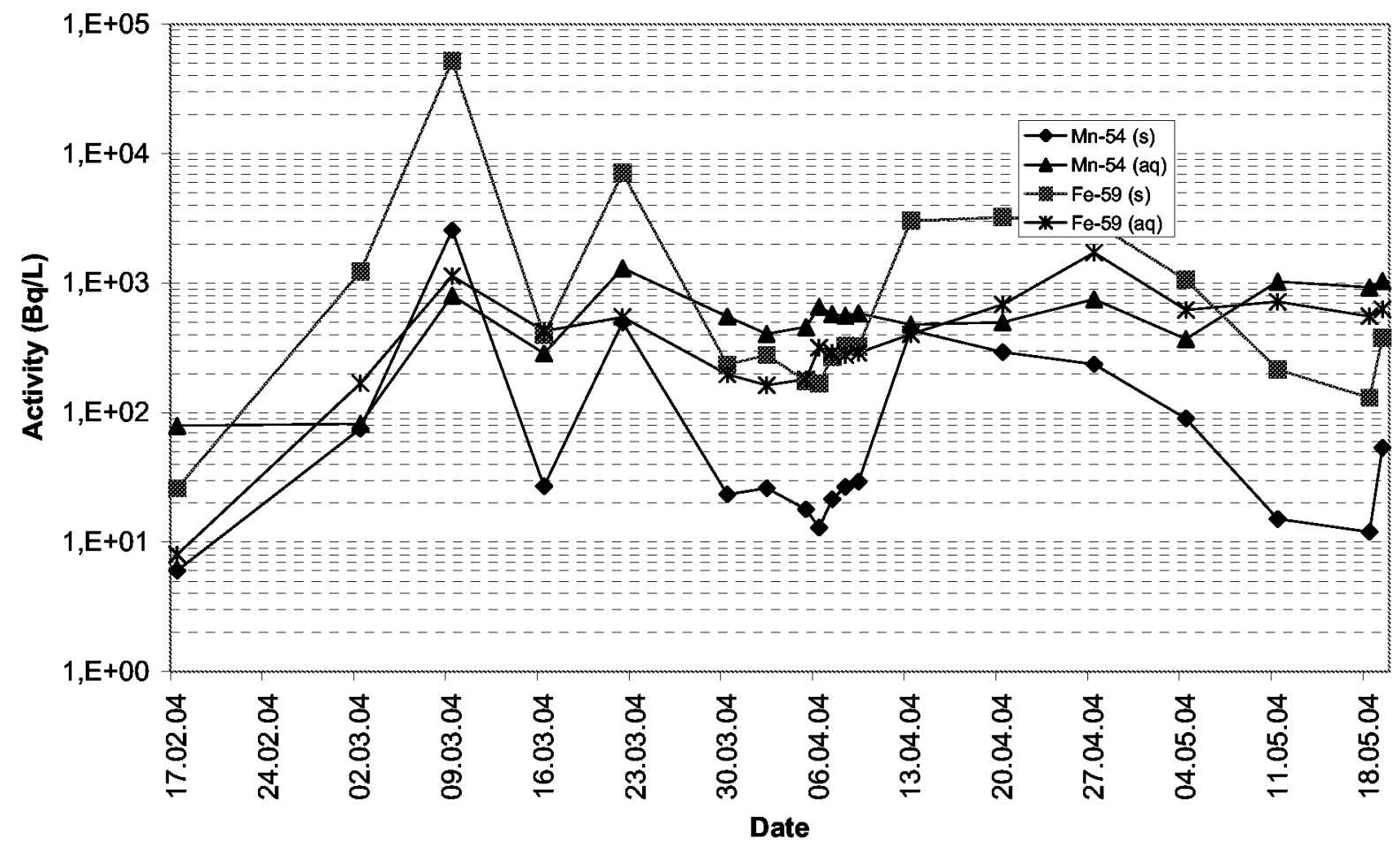

Figure 7-14

Activities of ${ }^{54} \mathrm{Mn}$ and ${ }^{59} \mathrm{Fe}$ during Phase 1 Test 2 


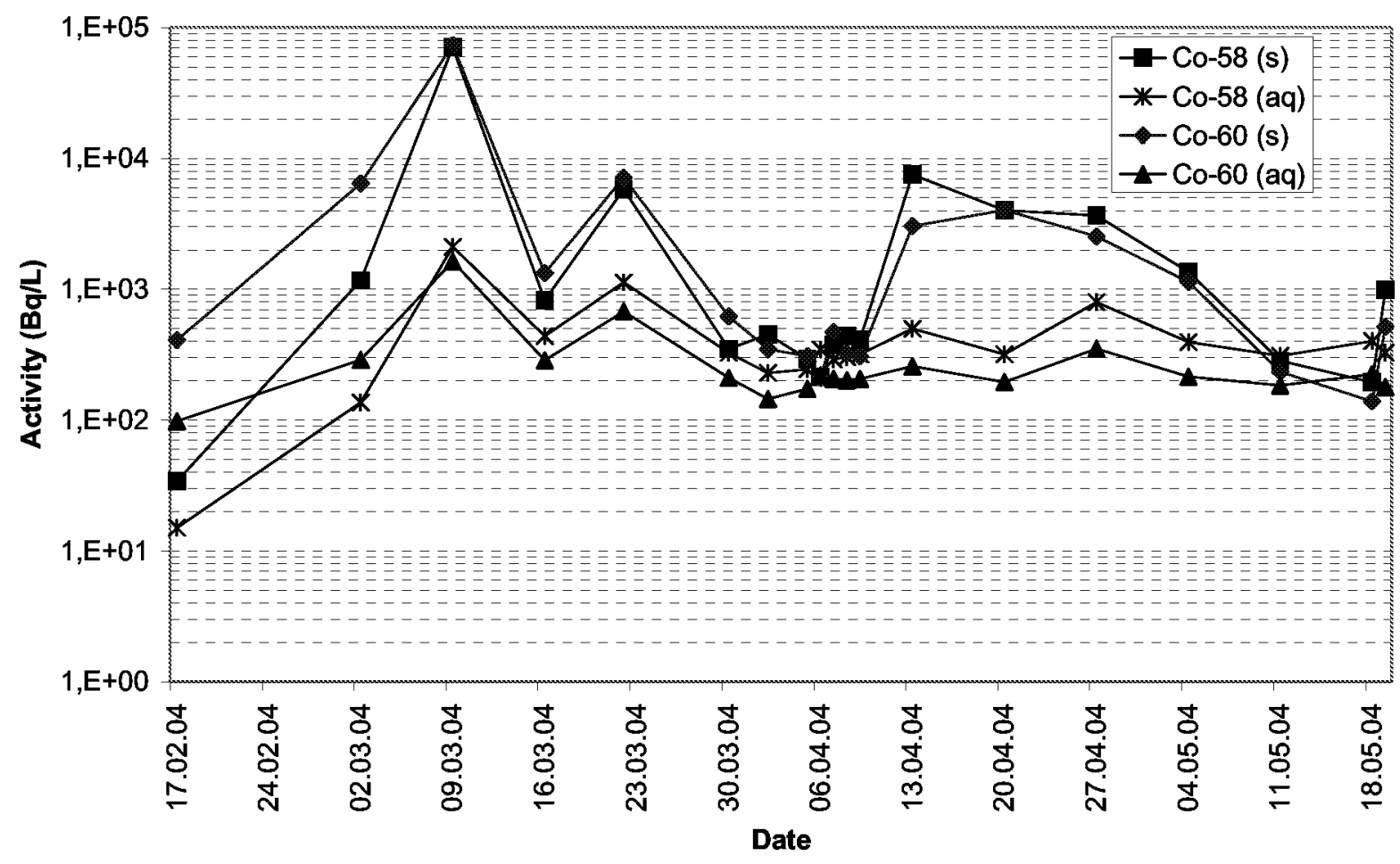

Figure 7-15

Activities of ${ }^{58} \mathrm{Co}$ and ${ }^{60} \mathrm{Co}$ during Phase 1 Test 2

During the second cycle, the frequency of diameter measurements was reduced compared with the first cycle. This was done to minimise the risk of crud dissolution caused by the flow and temperature perturbations that accompanied the lifting of the fuel rod from the bundle. Figure 7-16 compares traces taken immediately before injection of the Fe-Ni-EDTA solution commenced (at 173 FPD) and before the assembly power and coolant inlet temperature were increased (at 232 FPD). As in the measurements from Phase 1, Test 1, the diameter from the later measurement was the smaller of the two, indicating continuing clad creepdown and no significant deposition. This latter measurement is compared in Figure 7-17 with a trace taken 25 FPD after the power and temperature increases. The traces from the lower third of the rod are similar, whereas along the upper section, the later trace has moved upwards relative to the earlier, which (from the magnitude of the calibration steps) is indicative of deposition of a crud layer of approximately $10-20 \mu \mathrm{m}$. 
Results: Phase 1, Test 2

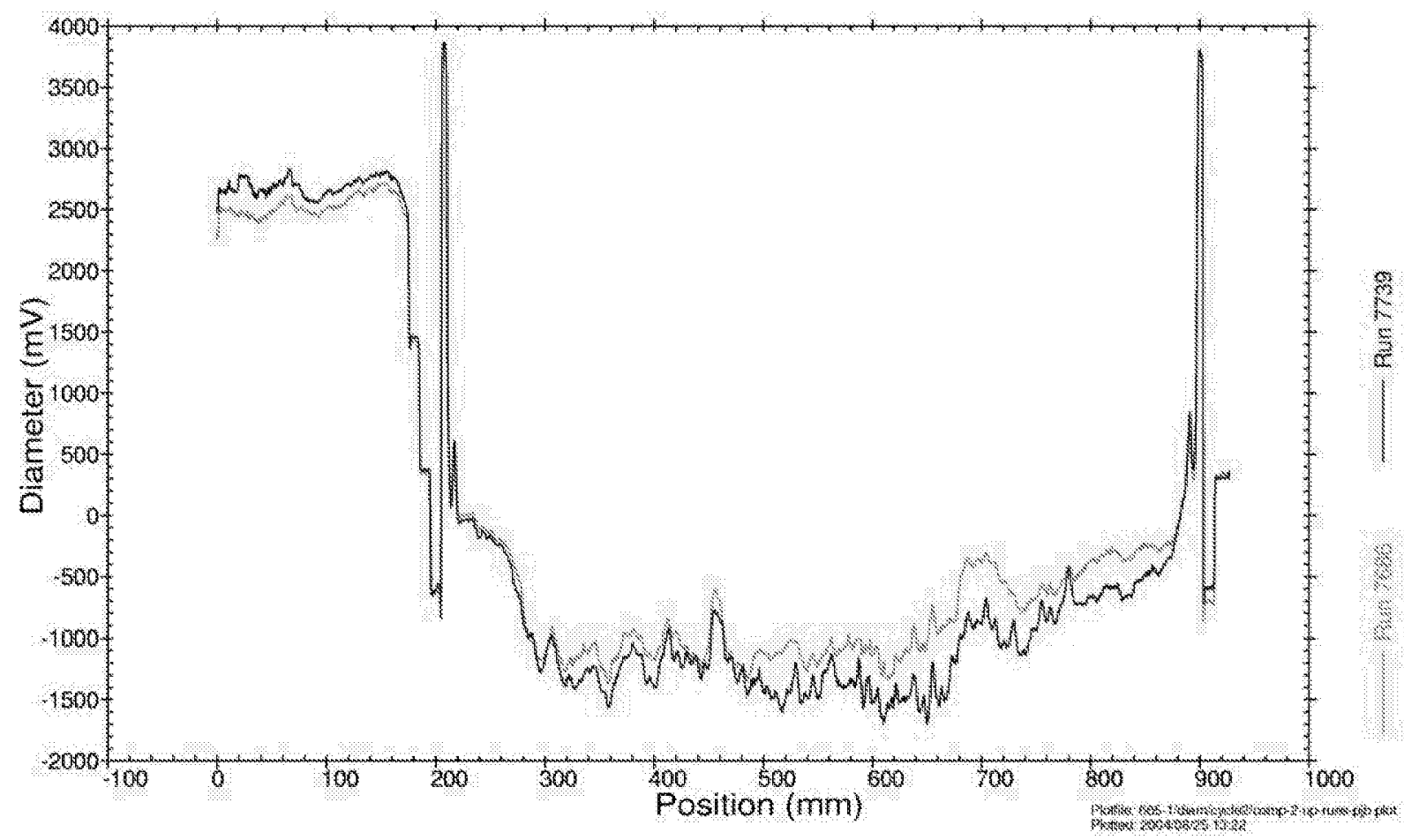

Figure 7-16

Comparison of diameter traces taken before EDTA solution was injected and before assembly power and coolant temperature were increased

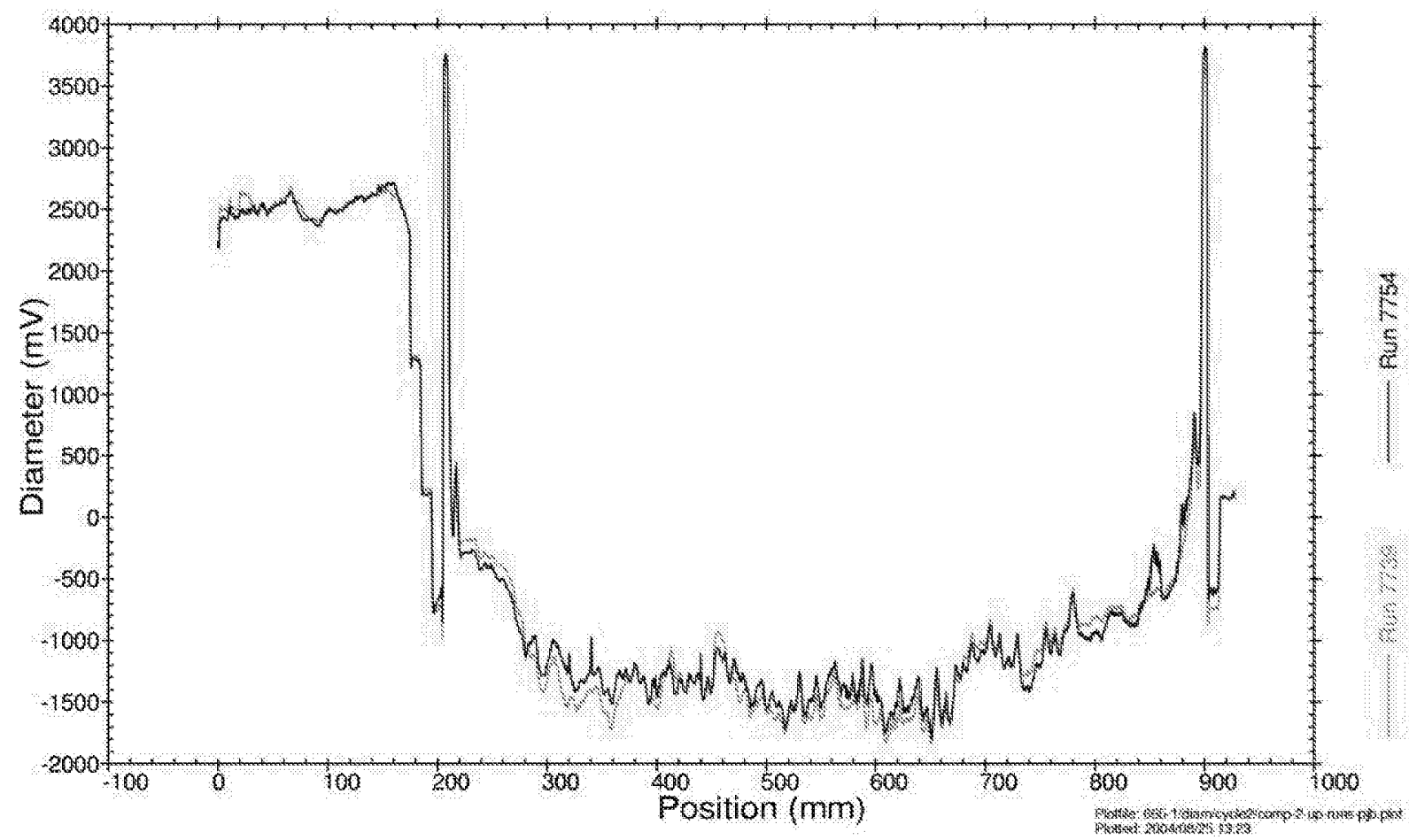

Figure 7-17

Comparison of diameter traces taken before assembly power and coolant temperature were increased and 25 FPD later 
Data from the instrumentation included to detect power changes caused by boron incorporation into the crud are shown in Figures 7-18 (neutron detector signals), 7-19 (coolant temperature rise over the fuel bundle) and 7-20 (cladding elongation measurements). Unfortunately, the lower neutron detector in the test rig became faulty early in the cycle, and thus a neutron detector comparison similar to that done for the first cycle (Figure 4-21) is not possible. Instead, the ND signals from neighboring test rigs have been used. This approach is considered valid because any changes in IFA-665 ND signals that were caused by global reactor operations would also affect the other test rigs, hence any changes that were limited to IFA-665 would be observable. In Figure 7-18, the ND signals from the pressure flask and the upper two instruments inside the test rig have been normalised to the ND signals at equivalent axial positions from the three nearest test rigs. There were no significant differences between the normalised ND signals from the outside of the pressure flask and the inside of the test rig.

No clear evidence for AOA symptoms was obtained, which was probably because the duration of the test following crud formation was only 30 days.

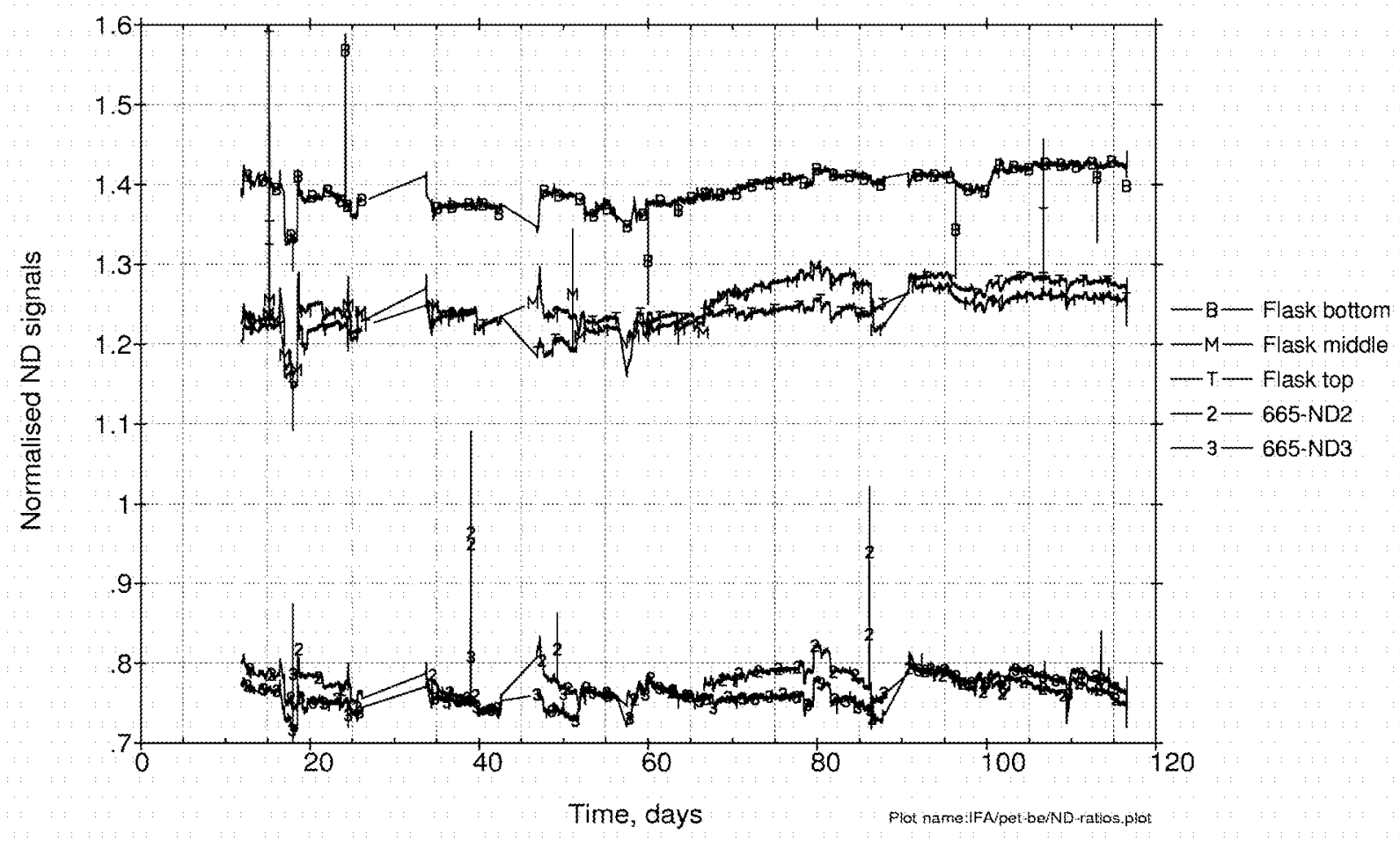

Figure 7-18

Normalised neutron detector signals during Phase 1 Test 2 

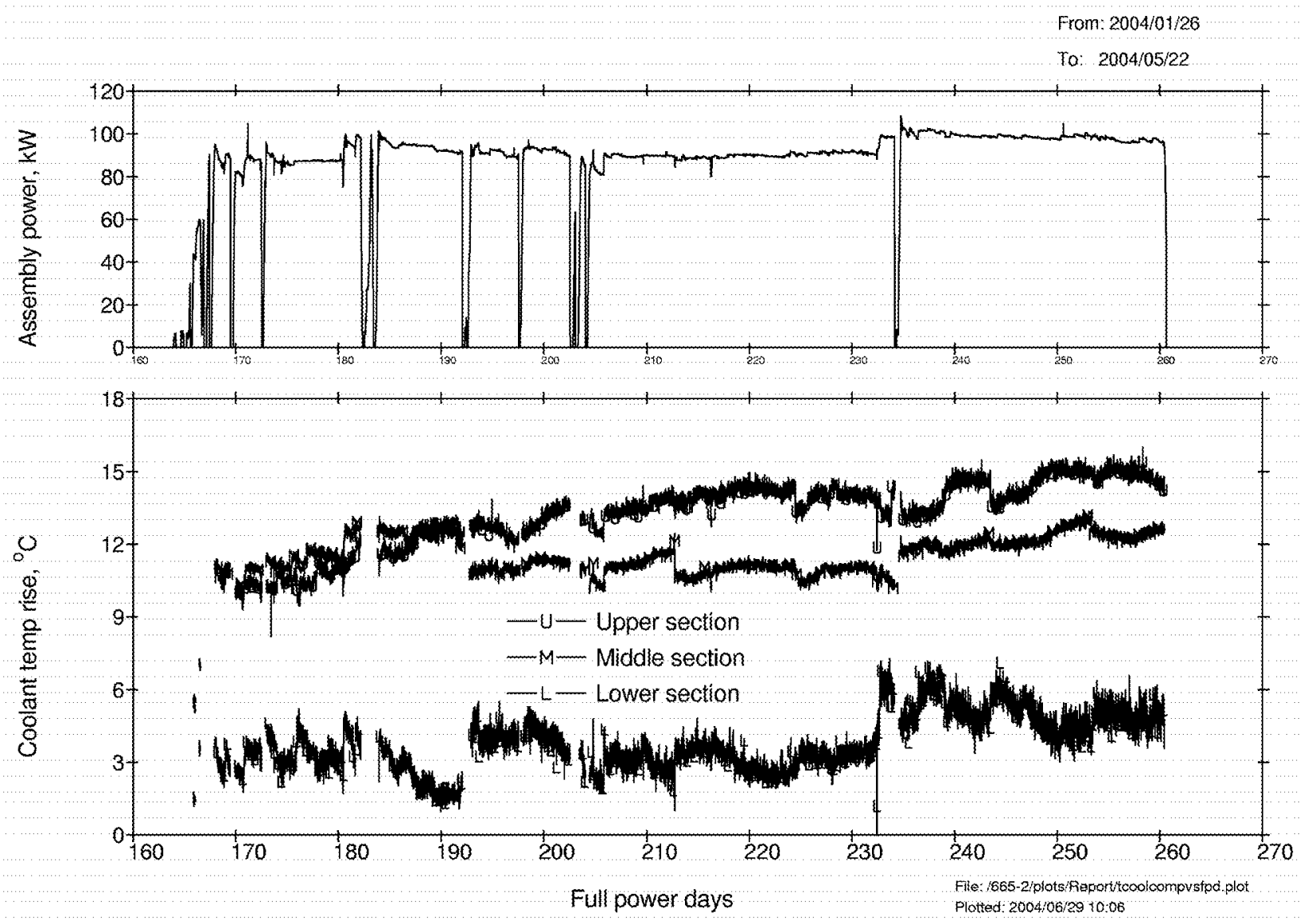

Figure 7-19

Increase in coolant temperature over lower $(0-200 \mathrm{~mm})$, middle $(201-400 \mathrm{~mm})$ and upper (401- $600 \mathrm{~mm}$ ) sections of the fuel bundle 


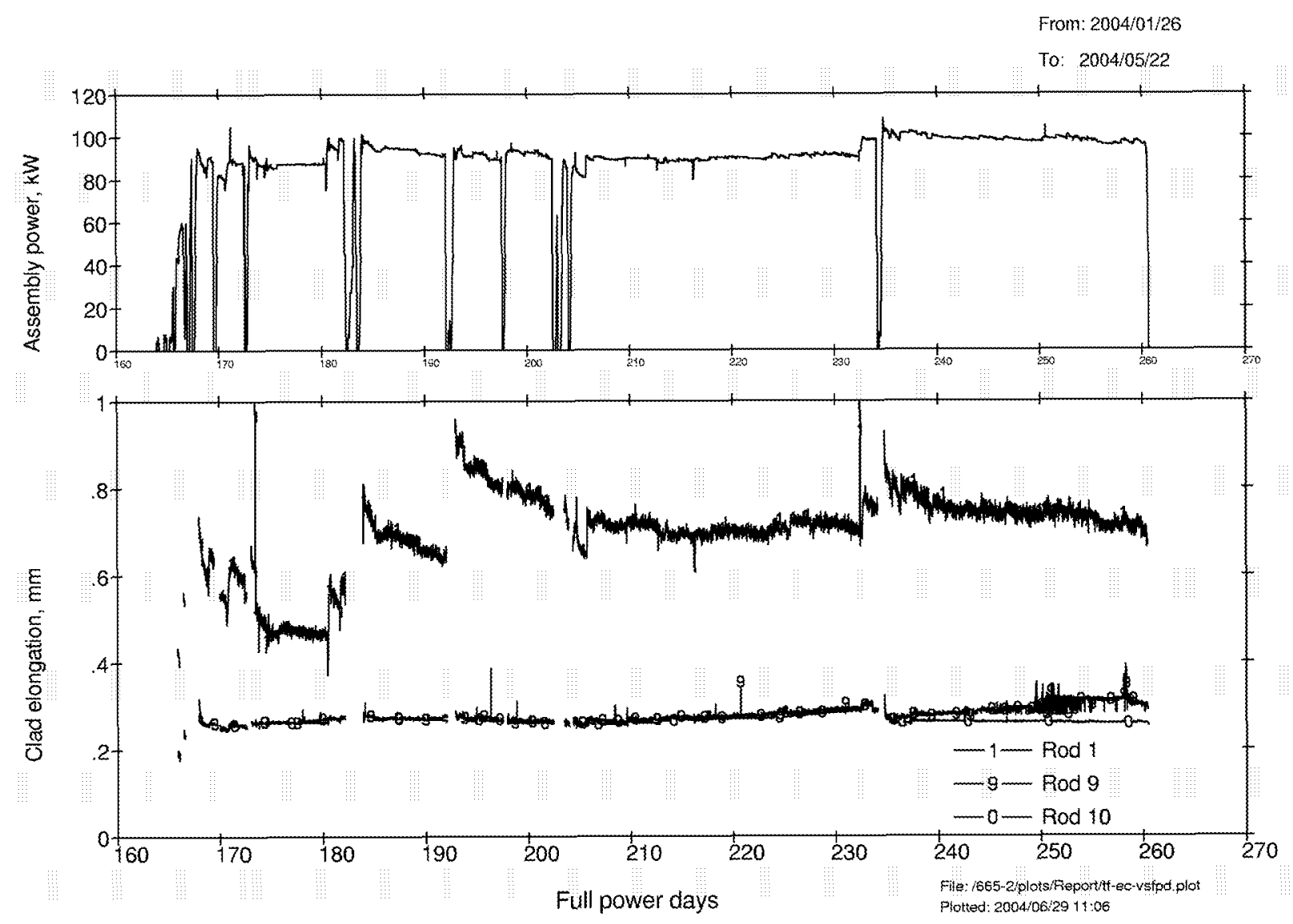

Figure 7-20

Cladding elongation measurements during Phase 1 Test 2

During the reactor shutdown at the end of Phase 1, Test 2, the loop chemistry was adjusted with the objective of minimising dissolution of the fuel crud: the coolant was maintained alkaline by continuously replacing the loop water with water containing $3.15 \mathrm{ppm} \mathrm{LiOH,} \mathrm{whilst}$ simultaneously removing boron by ion exchange.

After the reactor shutdown, the test rig was transferred to a handling and inspection compartment for PIE examinations. These are presented in Chapter 9. 



\section{8 \\ DISCUSSION: PHASE 1,TEST 2}

As during the first cycle of the experiment, attempts to accelerate crud deposition by injection of non-soluble iron and nickel - in this case in colloidal form - appeared to have an adverse effect in that the coolant flowrate through the test rig was seen to increase as a result of the injections, implying that the injections resulted in removal of crud deposits from test rig surfaces. This suggests that it is not trivial to prepare material for injection that has the same physical characteristics as that which leads to deposition in-plant.

It was also seen that, under the conditions of this experiment, addition of soluble iron and nickel was not sufficient by itself to form crud - at the point at which the test assembly power and coolant inlet temperature were increased, over $9 \mathrm{~g}$ each of $\mathrm{Fe}$ and $\mathrm{Ni}$ had been injected into the loop, corresponding to a possible concentration in the coolant of over $130 \mathrm{ppm}$.

The simultaneous increases in assembly power and coolant inlet temperature resulted in deposition of crud onto the fuel surfaces. It was not possible to perform these changes sequentially as there was insufficient time left in the reactor cycle, hence it cannot be stated whether one or both changes caused crud formation.

As stated in Chapter 3, when setting the test conditions, the mass evaporation rate was chosen as the parameter that should be similar to that in PWRs that have experienced AOA. In this way it was hoped to make the test as realistic as possible, by minimising the effects on the test of the differences between the Halden reactor and a PWR. Some of these differences are listed in Table 8-1 (the PWR data have been taken from Chapter 3). In addition there are large differences in geometry, and hence in flow patterns, between IFA-665 and a PWR, and the stochastic nature of crud deposition should be noted. In a PWR, crud deposition may not occur until more than one year's operation. These differences may explain why it was necessary to operate with a higher mass evaporation rate in IFA-665 to deposit crud. 
Table 8-1

Comparison of thermal-hydraulic conditions in IFA-665 with those in a PWR

\begin{tabular}{|l|l|l|}
\hline & \multicolumn{1}{|c|}{ PWR } & \multicolumn{1}{c|}{ IFA-665 } \\
\hline $\mathrm{T}_{\text {in }},{ }^{\circ} \mathrm{C}$ & 293 & $290-294$ \\
\hline $\mathrm{T}_{\text {out }},{ }^{\circ} \mathrm{C}$ & 338 & $310-325$ \\
\hline Minimum subcooling, ${ }^{\circ} \mathrm{C}$ & 7 & 20 \\
\hline Fuel stacklength, $\mathrm{m}$ & 4 & 0.6 \\
\hline Coolant flowrate, $\mathrm{m} / \mathrm{s}$ & 5 & 1 \\
\hline
\end{tabular}




\section{CRUD ANALYSES AFTER PHASE 1,TEST 2}

\subsection{Crud sampling}

The test rig was removed from the reactor and transferred to a handling and inspection compartment. Firstly, the test rods were photographed, without removing them from the rig.

Crud samples were taken by pressing small pieces of adhesive tape onto the crud surface. A total of eight samples were taken on transparent tape, and one additional sample was taken onto dense tape. Some damage (melting) occurred to the tape due to the high temperature of the test rods.

Samples were taken from two rods: one of $9.5 \mathrm{~mm}$ clad OD (Rod 10) and one of $7.25 \mathrm{~mm}$ OD (Rod 8). Four axial locations were sampled from each rod, as follows (where the axial positions are measured from the lower end of the rod):

- Rod 8: $\quad 8-12 \mathrm{~cm}, 8-40 \mathrm{~cm}, 8-48 \mathrm{~cm}, 8-57 \mathrm{~cm}$;

- $\quad$ Rod 10: $\quad 10-12 \mathrm{~cm}, 10-40 \mathrm{~cm}, 10-48 \mathrm{~cm}, 10-57 \mathrm{~cm}$.

\subsection{Crud analyses}

\section{Light optical microscopy (stereo microscope)}

In a stereomicroscope the crud morphology on the transparent tape can be examined from both sides, namely at the crud - clad interface (face 1) and at the waterside of the crud (face 2). The crud samples were examined and photographed in an Olympus SZ60 stereomicroscope at magnification $63 \mathrm{x}$ with the illumination from below. In this illumination mode boiling chimneys should be visible as tiny bright pores / holes. Photos were also taken with the ordinary illumination arrangement from above, with the crud facing up.

\section{Scanning electron microscopy (SEM)}

For SEM analyses, it is standard procedure to render the crud samples conductive by coating them with a thin layer of carbon. However, during the coating process of sample $10-12 \mathrm{~cm}$, the tape was damaged due to overheating. To prevent damage to the remaining seven samples, a thin gold layer was sputtered onto the crud surfaces. The crud (face 1) was examined up to a magnification of 4,000x in the secondary electron image (SEI) mode in the SEM (model JEOL 6100). 


\section{Elemental analysis by energy dispersive $x$-ray analysis (EDS)}

EDS analyses of the crud were performed in the SEM, which was equipped with a Link Si(Li) detector and AN 10,000 software. The crud was analysed for $\mathrm{Fe}, \mathrm{Ni}, \mathrm{Zr}, \mathrm{Cr}, \mathrm{Co}$, and $\mathrm{Mn}$ (EDS cannot be used for analysis of carbon and boron).

\section{Crud thickness estimate}

An estimate was made of the crud thickness of sample 10-48 cm. A cross-section of crud / transparent tape was cut with a scalpel and fixed with carbon tape to a holder, in order to keep the cross section of the crud layer vertical during the SEM examination. The surface was coated with gold to prevent charging of the crud and the tape. The sample was examined in both secondary (SEI) and backscattered (BEI) mode. The BEI gives contrast due to atomic numbers. Light elements (phases) appear dark and heavy elements are bright. In BEI the crud layer appears bright and the tape becomes dark. Photos were taken in both modes at magnifications 1,500x and 2,500x.

\subsection{Results}

\section{Visual appearance}

The presence of crud, inferred from the diameter gauge measurements, was confirmed by the visual inspection. The crud deposits were located along the upper $40 \mathrm{~cm}$ of the fuelled sections (i.e. those with high enrichment fuel). Photographs showing the upper section of the fuel and the boundary between the high and low enrichment regions are shown in Figures 9-1 and 9-2. In the photographs, one $9.5 \mathrm{~mm}$ OD rod is shown in the centre, flanked by two $7.25 \mathrm{~mm}$ OD rods. 


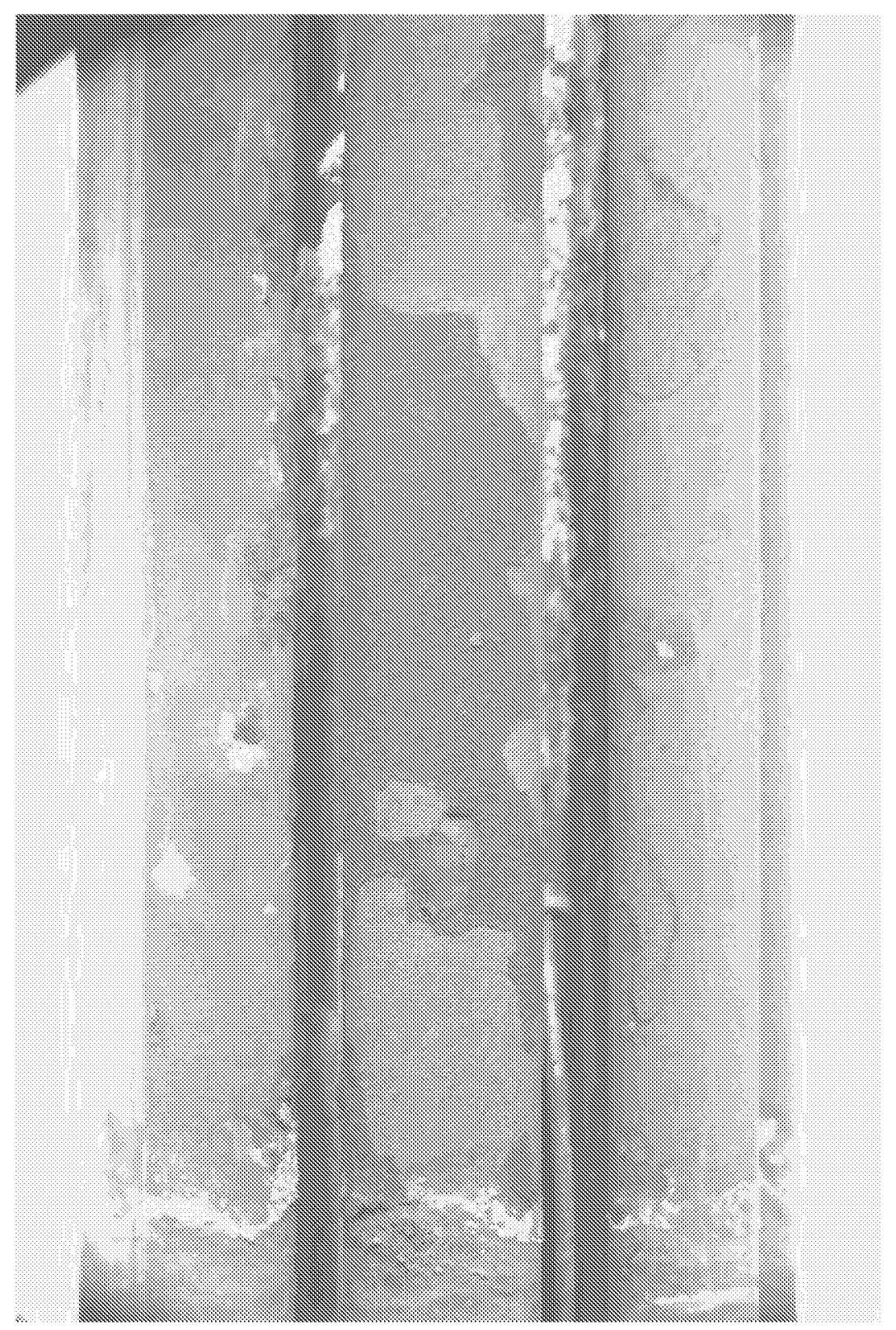

Figure 9-1

Crud deposits on upper section of fuel bundle 
Crud Analyses after Phase 1, Test 2

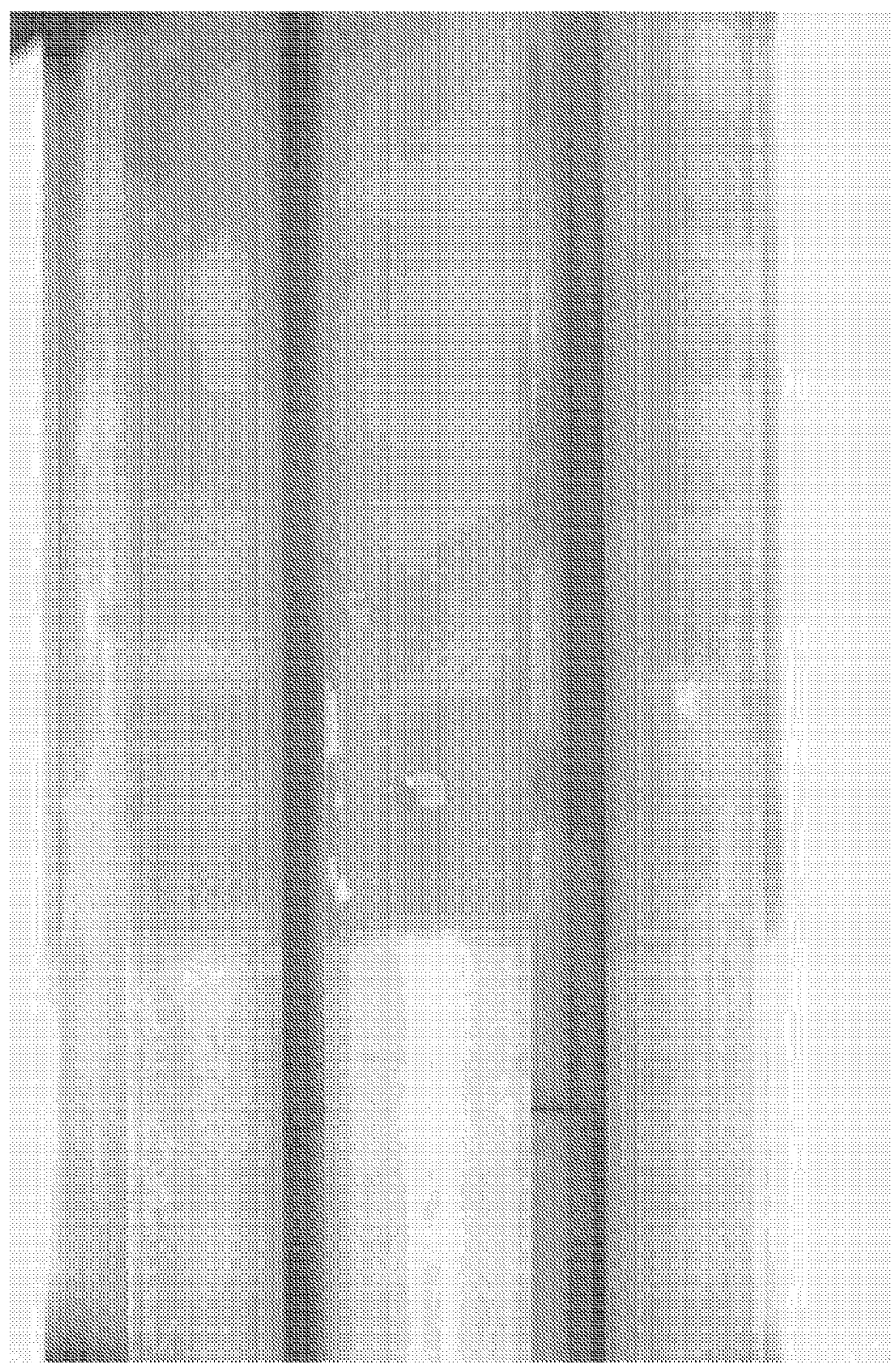

Figure 9-2

Photograph showing crud deposition commencing at boundary between low and high enrichment fuel 


\section{Crud morphology}

The presence of boiling chimneys was difficult to discern, which may be because a thick and dense crud layer is difficult to observe in transmitted light. In addition, it may not be possible to observe boiling chimneys unless the sample consists of an intact flake, which was probably not the case in these analyses. Cracks and pores were observed in the tape in some of the samples, which may have been due to damage occurring to the tape during sampling. Figures 9-3 and 9-4 show LOM analyses of sample $10-57 \mathrm{~cm}$ illuminated, respectively, from below and above. SEM analyses showed an increasing deposit thickness from the bottom to the top of the rods. Figures 9-5 and 9-6 show crud deposits from sample 10-57 cm at magnifications of 50x and 4000x. A possible boiling chimney is shown in Figure 9-6; from similar features, the existence of boiling chimneys was possible on samples $8-48 \mathrm{~cm}, 8-57 \mathrm{~cm}, 10-40 \mathrm{~cm}, 10-48 \mathrm{~cm}$ and 10-57 cm.

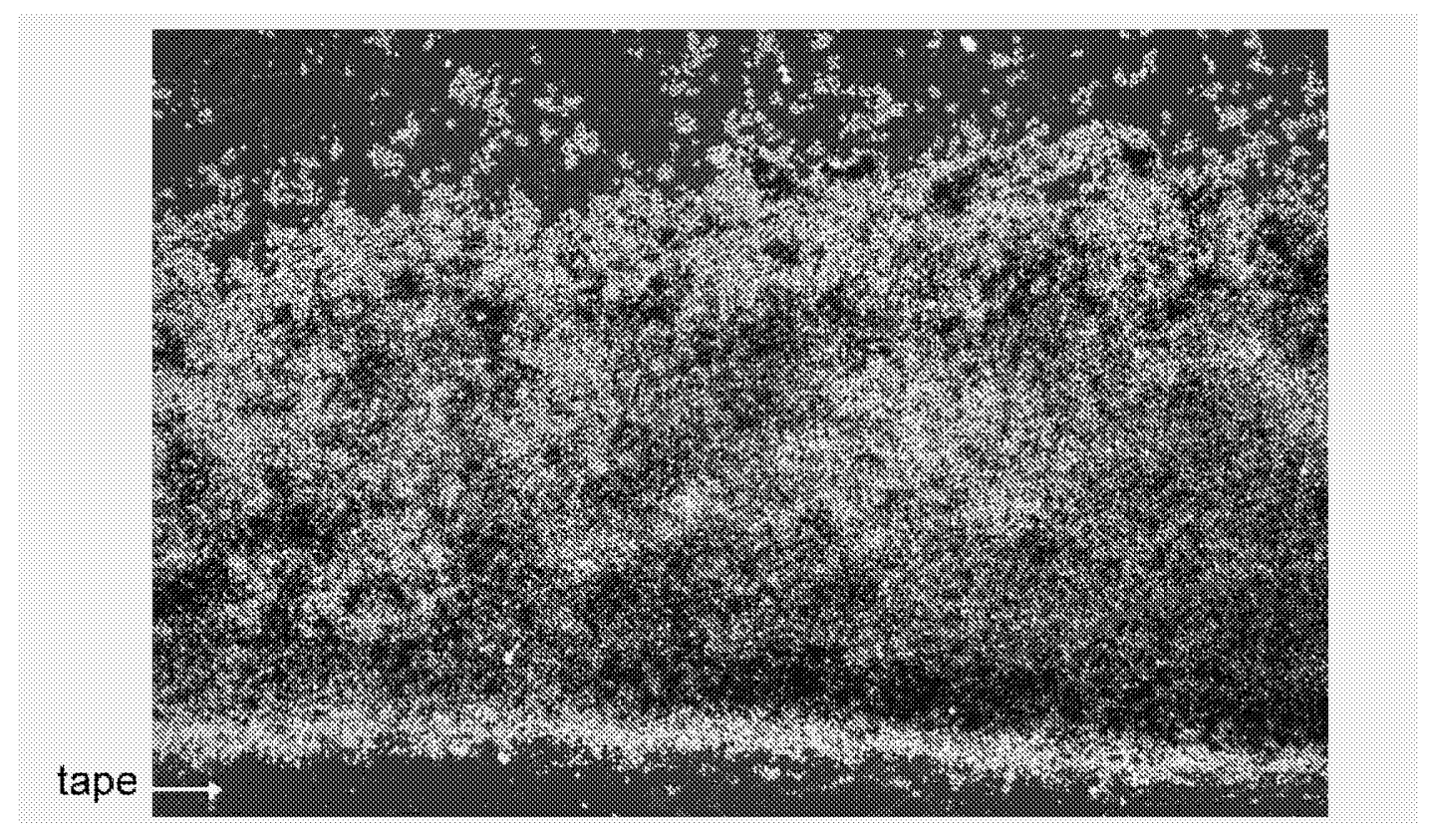

\section{Figure 9-3}

LOM analyses of sample $10-57 \mathrm{~cm}$, illuminated from below (Face 1) 
Crud Analyses after Phase 1, Test 2

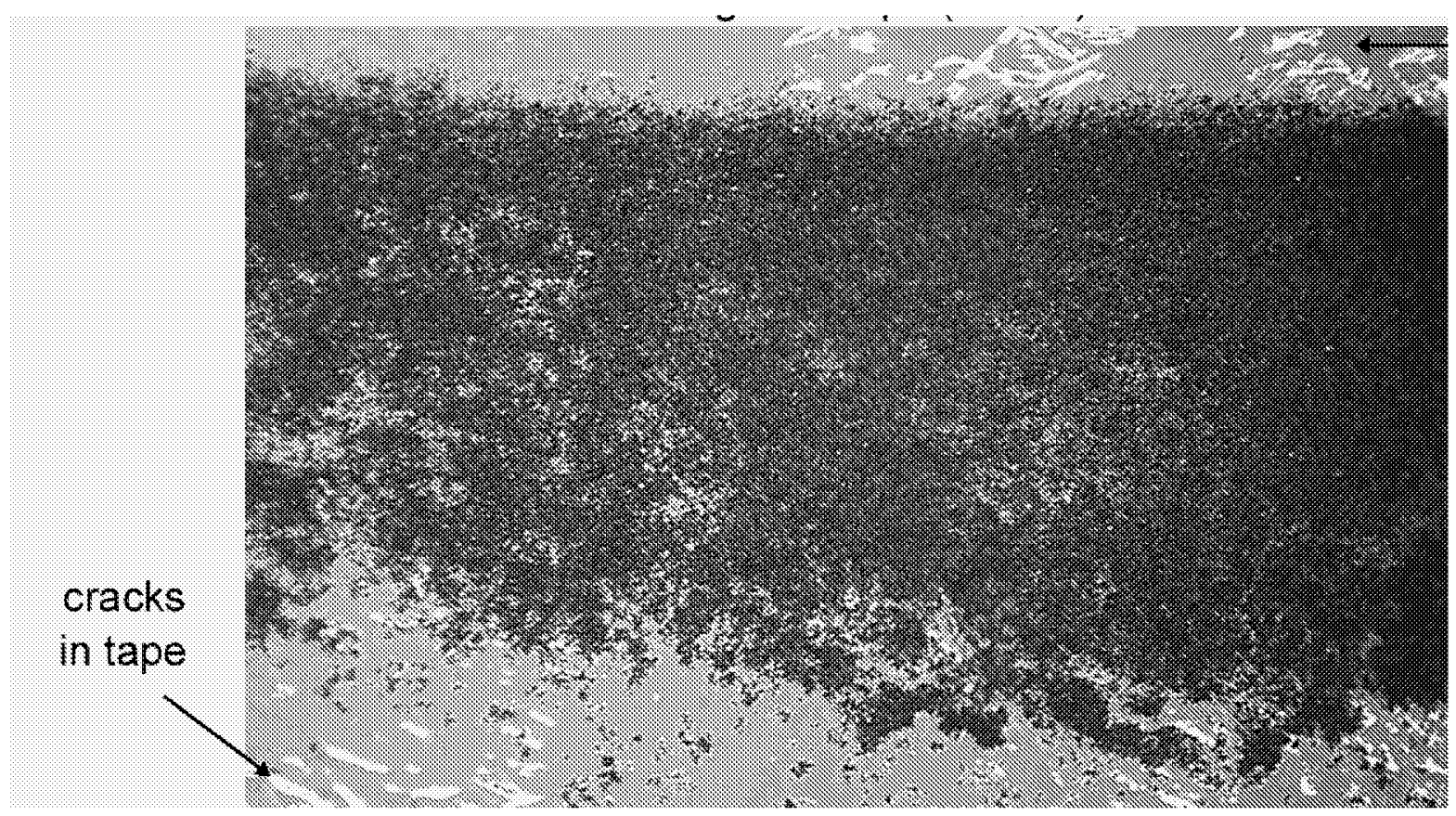

Figure 9-4

LOM analyses of sample $10-57 \mathrm{~cm}$, illuminated from above (Face 2) 


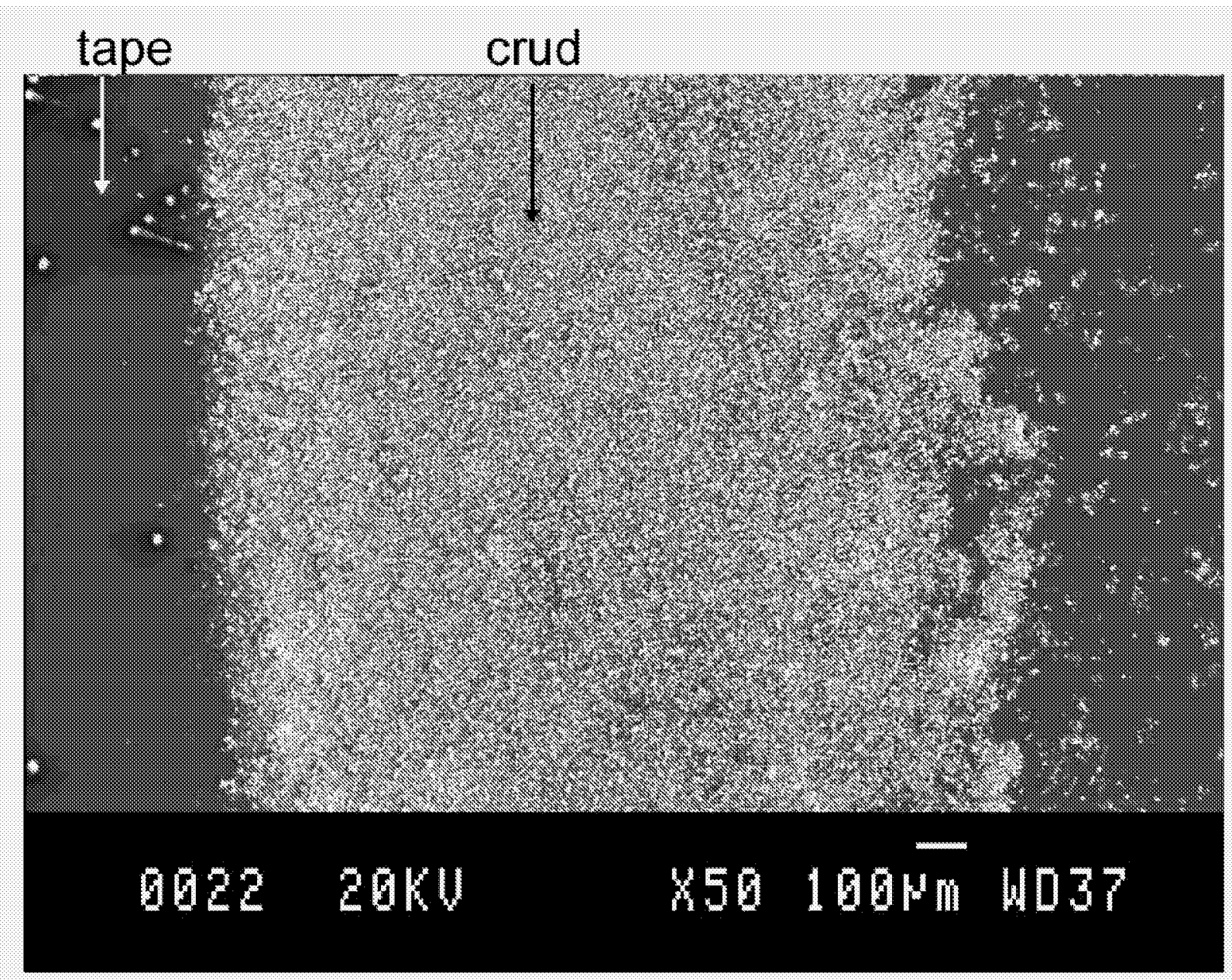

Figure 9-5

SEM analyses of sample $10-57 \mathrm{~cm}$ : $50 x$ magnification 


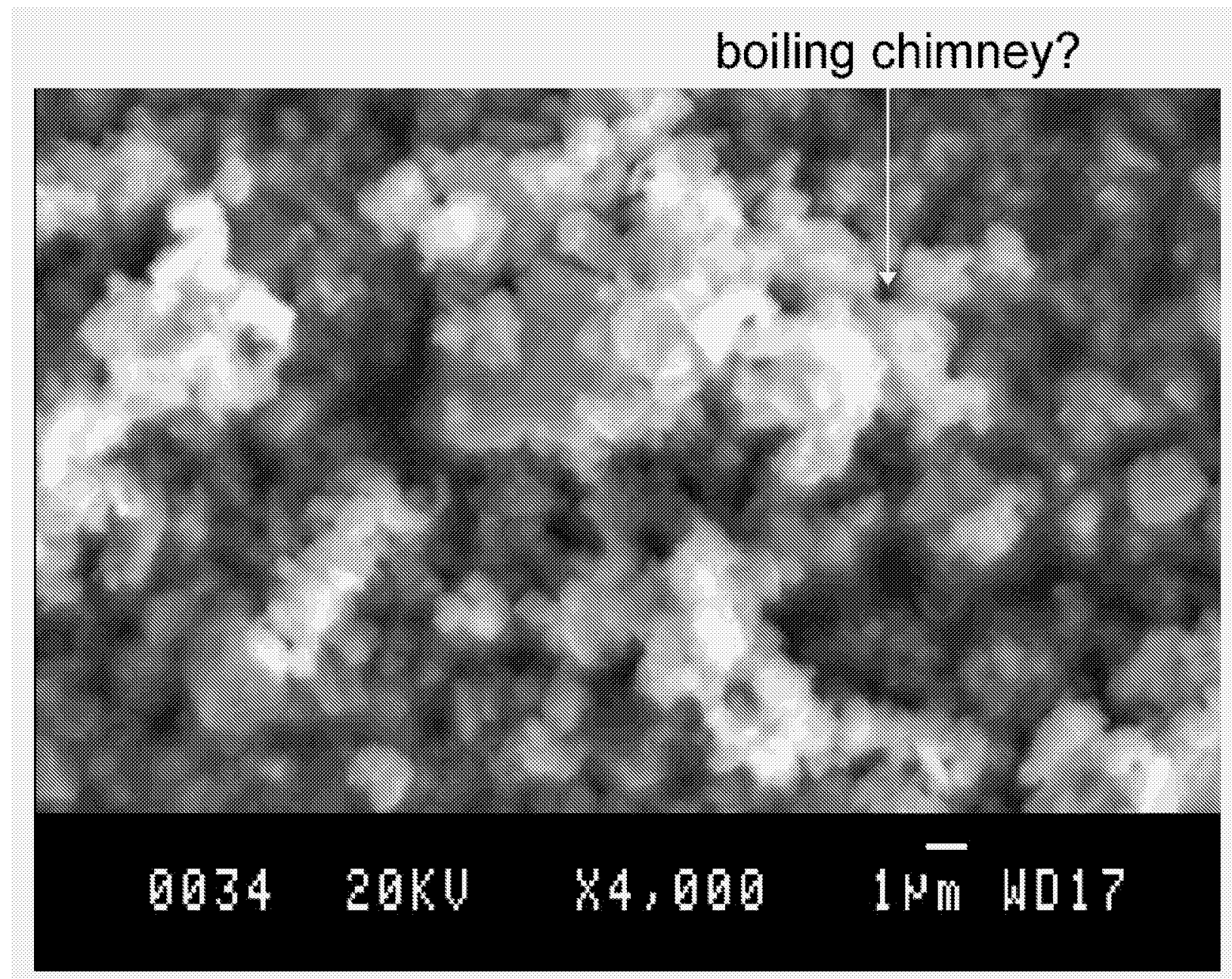

Figure 9-6

SEM analyses of sample $10-57 \mathrm{~cm}$ : $4000 x$ magnification

\section{Elemental analyses}

The lowermost sample from Rod 10 could not be analysed by EDS due to the problems encountered when applying the carbon coating. For the lowermost position on $\mathrm{Rod} 8, \mathrm{Fe}, \mathrm{Ni}, \mathrm{Cr}$ and $\mathrm{Zr}$ were observed. All other samples also contained these elements, plus Mn. The elements were homogeneously distributed in the samples. Ratios of $\mathrm{Ni}$ to $\mathrm{Fe}$ in the samples are listed in Table 9-1. These tended to increase from the bottom to the top of the rod, especially for Rod 8, but the changes were relatively small. These changes correlate with the fact that the solubility of $\mathrm{Ni}$ decreases with increasing temperature [1]. 
Table 9-1

$\mathrm{Ni}$ : Fe ratios in crud samples

\begin{tabular}{|c|c|c|}
\hline \multirow{2}{*}{ Rod } & $\begin{array}{c}\text { Axial height } \\
\text { (mm from bottom of rod) }\end{array}$ & Ni : Fe ratio \\
\hline \multirow{3}{*}{8} & 40 & 0.19 \\
\cline { 2 - 3 } & 48 & 0.22 \\
\cline { 2 - 3 } & 57 & 0.27 \\
\hline \multirow{3}{*}{10} & 40 & 0.23 \\
\cline { 2 - 3 } & 48 & 0.22 \\
\cline { 2 - 3 } & 57 & 0.25 \\
\hline
\end{tabular}

\section{Estimate of crud thickness}

The crud layer was estimated to be $20-25 \mu \mathrm{m}$ thick. Given the uncertainties in the method used, this value can be considered to be in good agreement with that obtained from the diameter gauge measurements, i.e. 15 - $20 \mu \mathrm{m}$. 



\section{0 \\ TEST SPECIFICATIONS: PHASE 1, TEST 3}

The time during which Test 2 was operated with crud loaded on the fuel surfaces (less than one month) was too short to develop symptoms of AOA. Hence, a third test cycle was performed (within the Joint Program of the Halden Project) to attempt to measure a power reduction due to boron incorporation into the crud. The test conditions chosen were those under which crud had deposited during the latter part of Phase 1, Test 2, i.e.:

- Coolant inlet temperature $294^{\circ} \mathrm{C}$;

- $\mathrm{PH}_{300^{\circ} \mathrm{C}}=7.0$;

- Injection of Fe-Ni-EDTA solution.

Additionally, it was decided to run the loop purification system at a constant, but low, flowrate, in order to avoid the large fluctuations in chemistry conditions that occurred when the system was put into operation to reduce anion levels during Cycle 2. 



\section{1 \\ RESULTS: PHASE 1, TEST 3}

The third cycle of the test (Phase 1, Test 3) commenced irradiation in July 2004 and operated for 88 FPD until October 2004. Test rig power and assembly burn-up are shown in Figure 11-1. The period included several power transients and short shutdowns, all of which were connected with other test rigs. The total duration of Phase 1 (three cycles) was 349 FPD, with a final assembly burn-up of $12 \mathrm{MWd} / \mathrm{kg} \mathrm{UO}_{2}$.
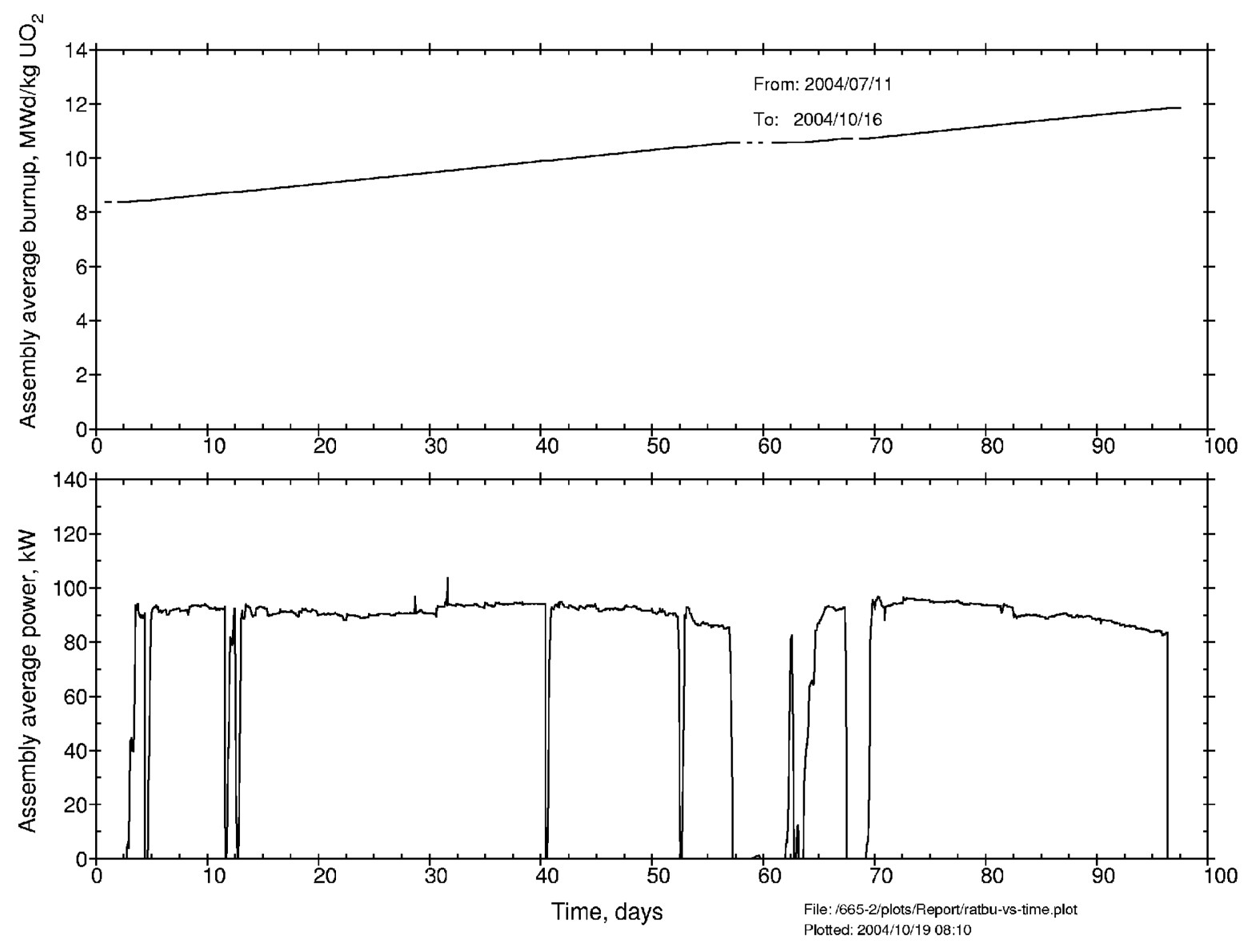

Figure 11-1

Assembly power and burn-up during Phase 1 Test 3 
Bulk chemistry conditions are shown in Figure 11-2. The loop purification system was operated constantly, but at a much lower flowrate than in Cycles 1 and 2, with the aim of preventing the large fluctuations in chemistry conditions that occurred in Cycle 2 when the system was put in use to reduce anion levels (see Chapter 7). In the first two cycles, a 17-litre deep bed mixed resin demineraliser was employed through which the flowrate was $150 \mathrm{l} / \mathrm{h}$. For the third cycle, two one-litre beds (one with anion, and one with cation, resin) were connected in parallel with the 17litre bed. The flowrate through these smaller beds was $8.5 \mathrm{l} / \mathrm{h}$. Although there were fluctuations in the loop Li levels, the calculated $\mathrm{pH}_{300^{\circ} \mathrm{C}}$ was reasonably steady, with a mean value of $6.95 \pm$ 0.15 . The measured conductivity values, at approximately $10 \mu \mathrm{S} / \mathrm{cm}$, were lower than the theoretical value of approximately $30 \mu \mathrm{S} / \mathrm{cm}$ (Chapter 4), indicating a fault in the instrument, but the trends are considered to be reliable. As in the second cycle, hydrogen levels were above the detection limit of the $\mathrm{H}_{2}$ sensor (10 ppm), due to decomposition products of EDTA.
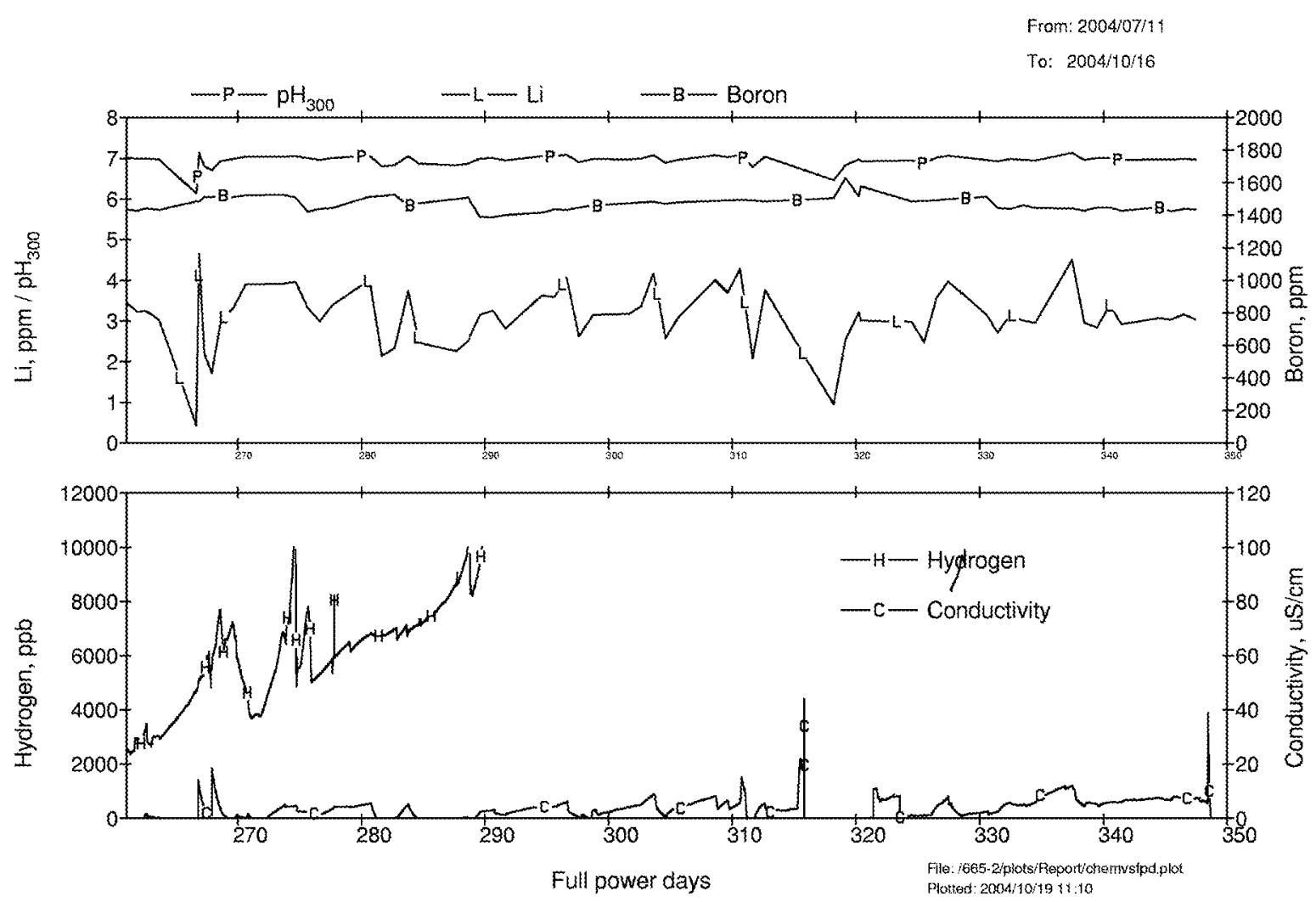

Figure 11-2

Water chemistry conditions during Phase 1 Test 3 
Thermal-hydraulic conditions are shown in Figure 11-3. The assembly power (approximately 90 $\mathrm{kW}$ ) was lower than that during the latter stages of Phase 1, Test 2, and was due to the different core configurations of the reactor in the two cycles. The coolant flowrate decreased throughout the entire cycle, suggesting corrosion product deposition in the test rig; the value at the end of the test (approximately $0.65 \mathrm{~m} / \mathrm{s}$ ) was 41 percent lower than that at the start of the first cycle (Chapter 4).

Generally, the temperature rise over the fuel showed a slow but steady increase over the duration of the test, which correlates with the reduction in coolant flowrate. However, there were two periods during which the temperature rise tended to decrease: (i) the period from approximately 290 to 310 FPD, and (ii) the last 15 FPD of the cycle.
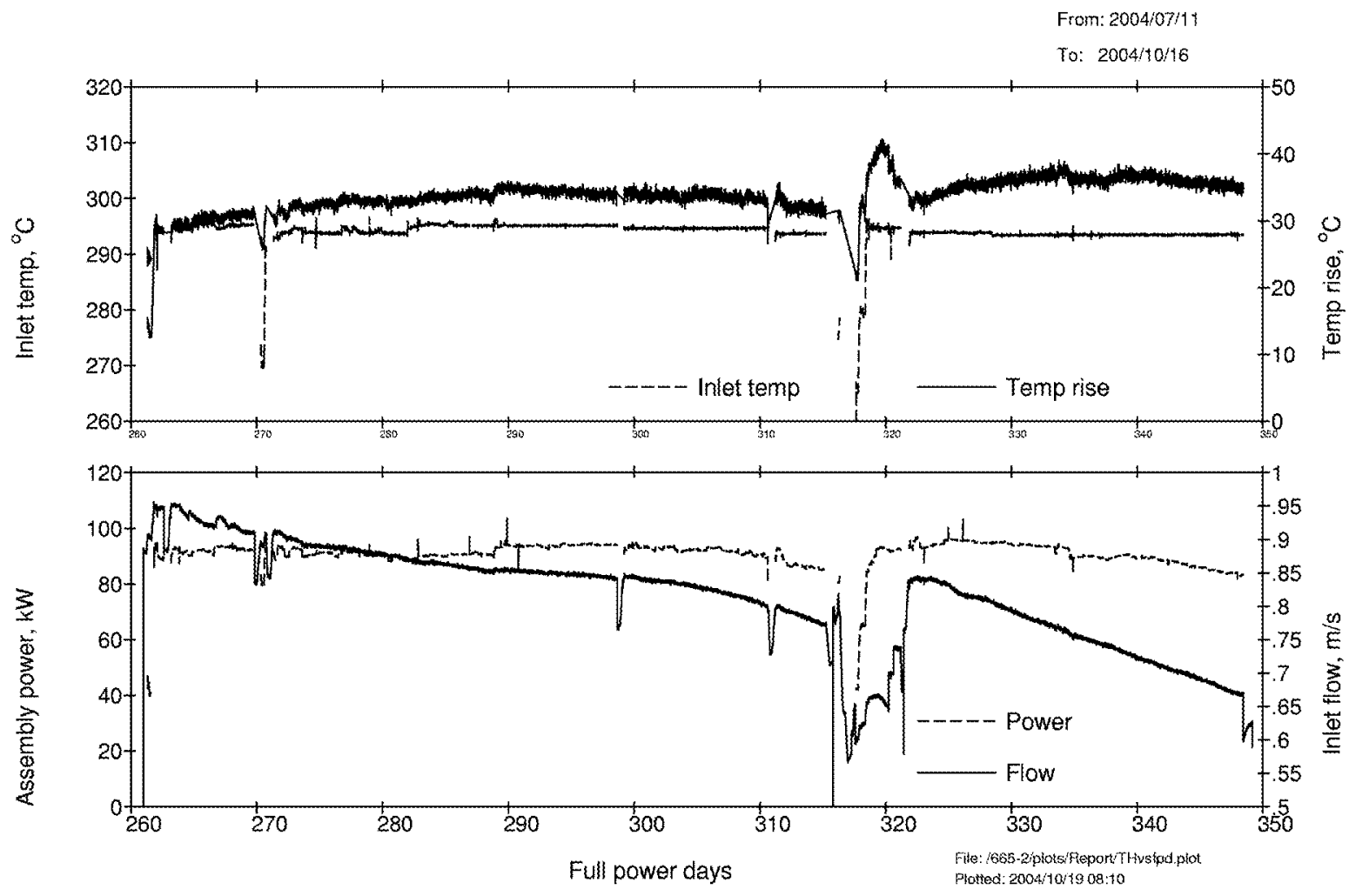

Figure 11-3

Thermal-hydraulic conditions during Phase 1 Test 3 
Heat fluxes throughout the cycle are shown in Figure 11-4. The maximum values were similar to those at the start of the second cycle, at approximately 860 to $900 \mathrm{~kW} / \mathrm{m}^{2}$.
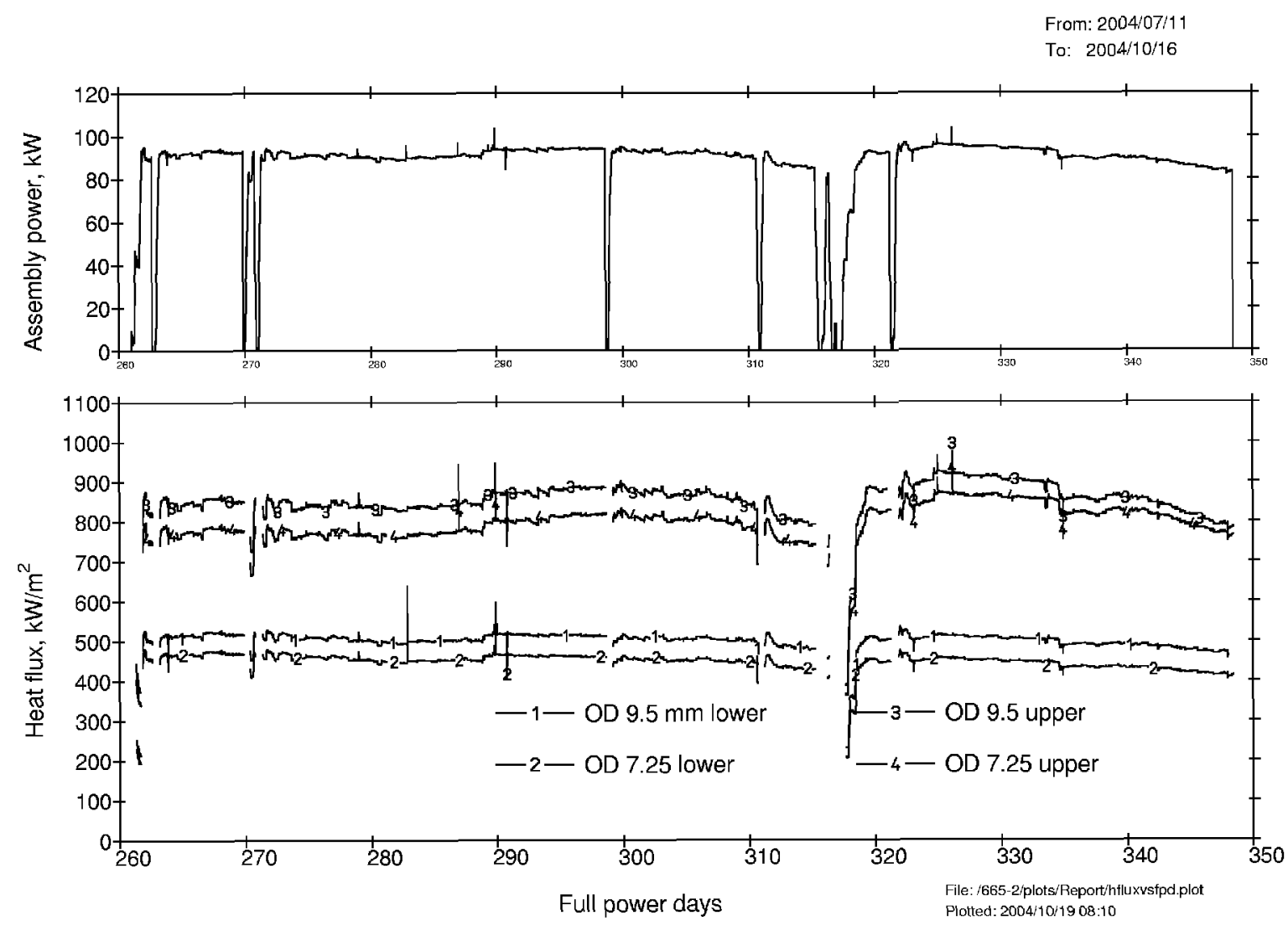

Figure 11-4

Heat flux at the clad surface during Phase 1, Test 3

Calculated mass evaporation rates during the cycle are listed in Table 11-1.

Table 11-1

Mass evaporation rates during Phase 1, Test 3

\begin{tabular}{|c|c|}
\hline Full power days & Mass evaporation rate $\left(\mathrm{kg} / \mathrm{h}-\mathbf{m}^{2}\right)$ \\
\hline 265 & 4840 \\
\hline 288 & 5500 \\
\hline 340 & 5170 \\
\hline
\end{tabular}


The values were thus within the range of those during Phase 1, Test 2 (see Table 7-1). The different rates were caused by the variations in assembly power and coolant flowrate.

Injection of the Fe-Ni-EDTA complex started on Day 3 of the cycle, as soon as full reactor power had been reached. As during the majority of the previous cycle, the Fe and $\mathrm{Ni}$ concentrations in the stock solution were $125 \mathrm{ppm}$. Injection was maintained (except during shutdowns) until the end of the test. Figure 11-5 shows the masses of Fe and Ni injected, together with the concentrations that would have arisen if all of the injected material remained in the coolant. By the end of the cycle, over $9 \mathrm{~g}$ each of $\mathrm{Fe}$ and $\mathrm{Ni}$ had been injected, corresponding to a maximum concentration of $130 \mathrm{ppm}$.

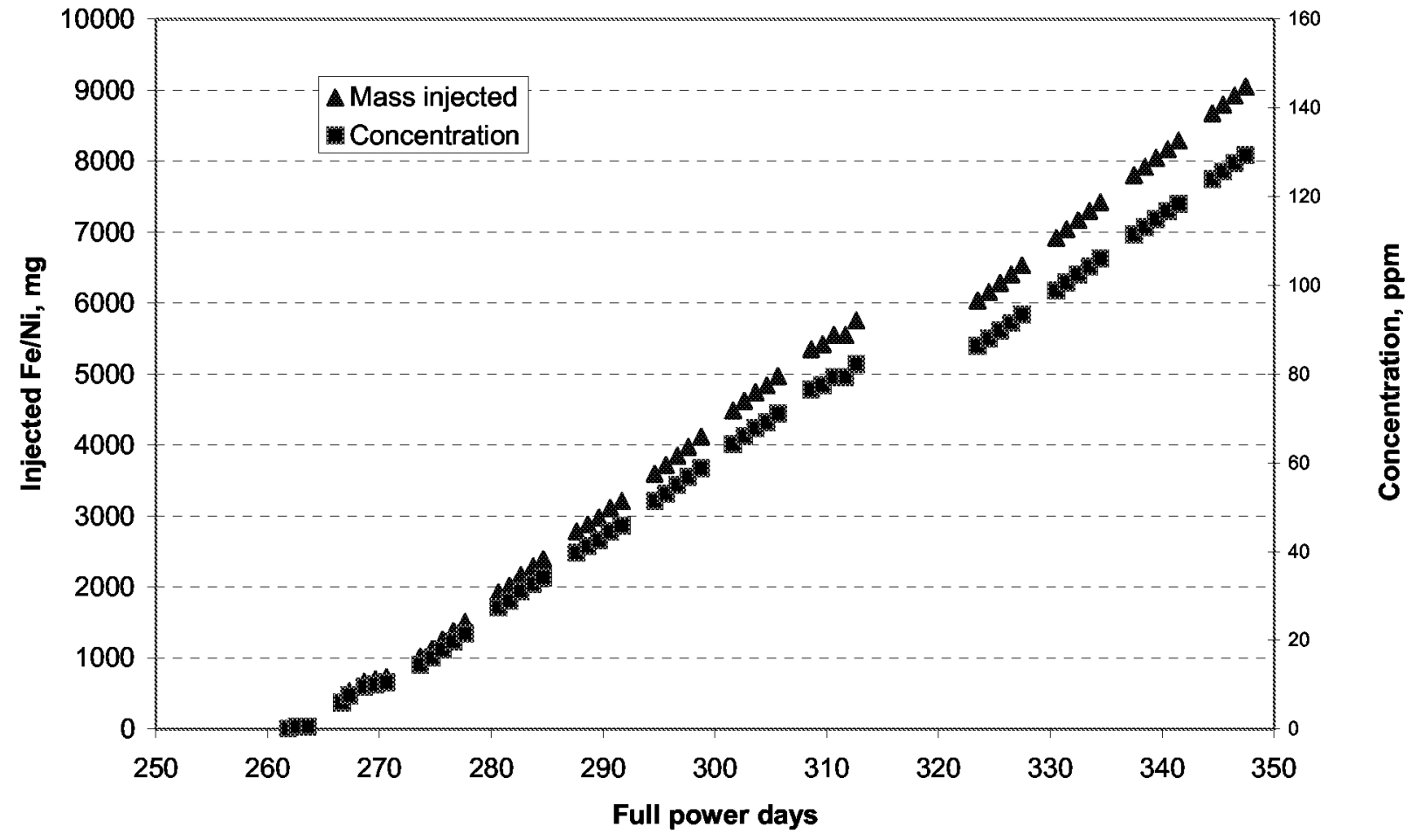

Figure 11-5

Details of injection of Fe-Ni-EDTA solution during Phase 1 Test 3

Measured concentrations of formate and acetate anions throughout the cycle are shown in Figure 11-6. As in Cycle 2, the levels were in the ppm range, with acetate approximately an order of magnitude higher than formate. Concentrations of acetate increased during the cycle, due to the low flowrate through the purification system. 


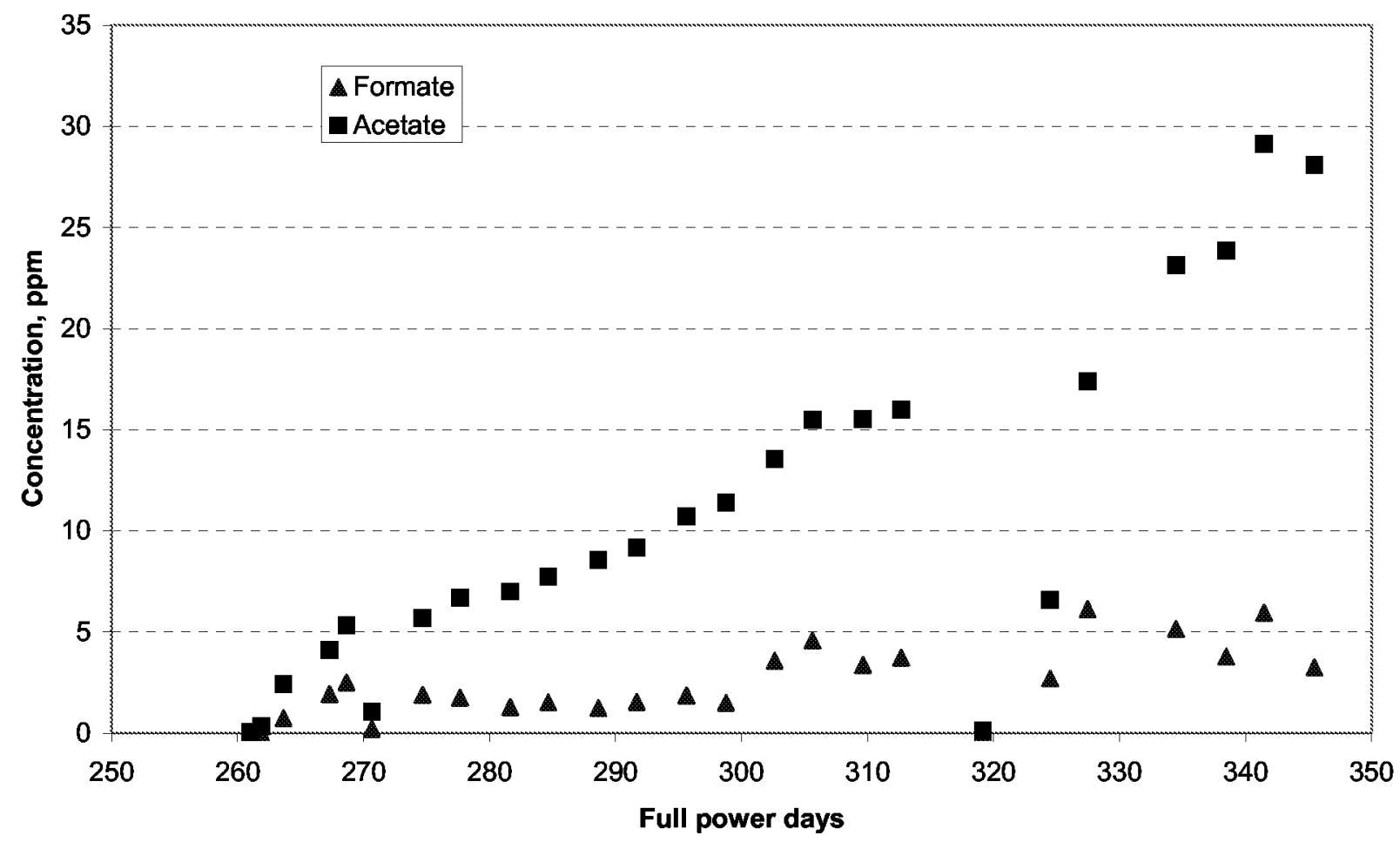

Figure 11-6

Formate and acetate concentrations in the coolant during Phase 1 Test 3

Iron and nickel concentrations in the loop coolant are shown in Figure 11-7, and the Fe:Ni ratios in Figure 11-8. Concentrations of dissolved iron were mostly in the range from 10 to $15 \mathrm{ppb}$, with an average of $13 \mathrm{ppb}$. Nickel levels were mostly between 1 and $3 \mathrm{ppb}$, with an average of $1.8 \mathrm{ppb}$. These average Fe and $\mathrm{Ni}$ levels were 1.6 and 1.8 times higher, respectively, than those in the second cycle, showing that injection of the EDTA complex continued to raise $\mathrm{Fe}$ and $\mathrm{Ni}$ levels above solubility concentrations. The iron/nickel ratio of the dissolved species varied between 5 and 12, with an average of 7.0. Noting that the concentrations of the two elements in the EDTA solution were the same, this average can be interpreted in two ways. Firstly, precipitation kinetics were higher for nickel than for iron. Secondly, the solid compounds that were likely to be formed were magnetite $\left(\mathrm{Fe}_{3} \mathrm{O}_{4}\right)$ and nickel oxide (NiO) (see next paragraph). Since the solubility of magnetite is the higher of the two compounds, soluble Fe levels would be higher than those for $\mathrm{Ni}$.

Concentrations of particulate iron varied considerably during the reactor cycle. Some very high levels were measured (up to $160 \mathrm{ppb}$; these values are not plotted for reasons of clarity), which were due to crud bursts caused by shut-downs. Nickel levels were generally less than $10 \mathrm{ppb}$, but some values of up to $35 \mathrm{ppb}$ were measured. However, during steady-state conditions, levels of particulates were low and constant. Iron levels were in the range from 2 to $9 \mathrm{ppb}$, with an average of $5 \mathrm{ppb}$. Nickel levels were $0.4-2.7 \mathrm{ppb}$, with an average of $1.5 \mathrm{ppb}$. The average $\mathrm{Fe} / \mathrm{Ni}$ ratio in the particles was 3.3, which is significantly different from the value of 2 for $\mathrm{NiFe}_{2} \mathrm{O}_{4}$. The excess of iron and nickel in the coolant could have deposited as either (i) monometallic solids or (ii) as nickel ferrite and monometallic solids. If iron is present in excess, 
it is kinetically more favourable to form a single spinel than the energetically more stable mixed oxide $\left(\mathrm{NiFe}_{2} \mathrm{O}_{4}\right)$, in which case iron would have formed magnetite. This is in accordance both with the reducing conditions and the colour of the precipitates on the particle filters. In the case of nickel, it can be concluded from the grey to black colour of the filters, that nickel oxide, rather than metallic $\mathrm{Ni}$, was formed. ( $\mathrm{NiO}$ is normally green, but can also exhibit a grey/black colour).

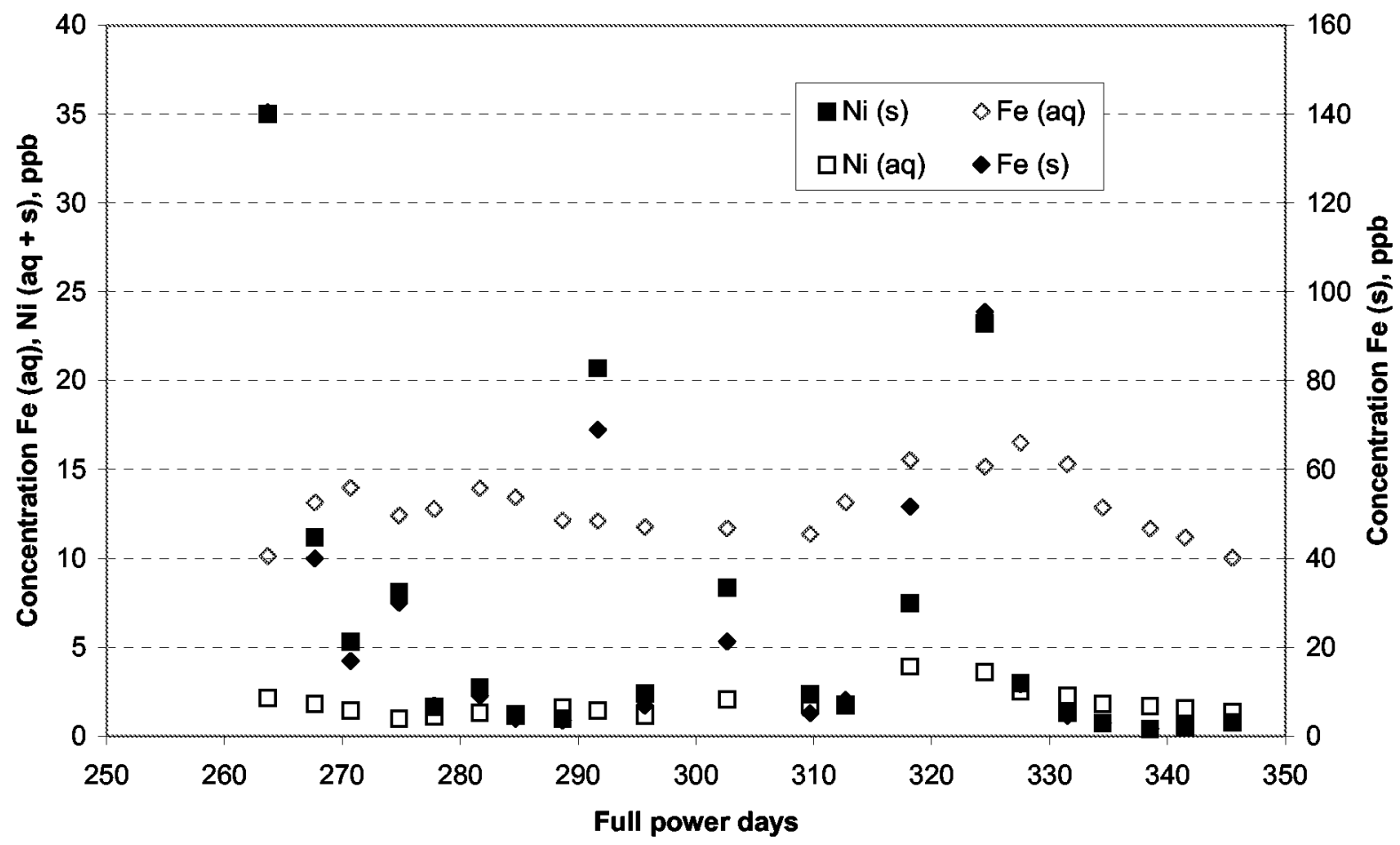

Figure 11-7

Coolant Fe and Ni concentrations during Phase 1 Test 3 


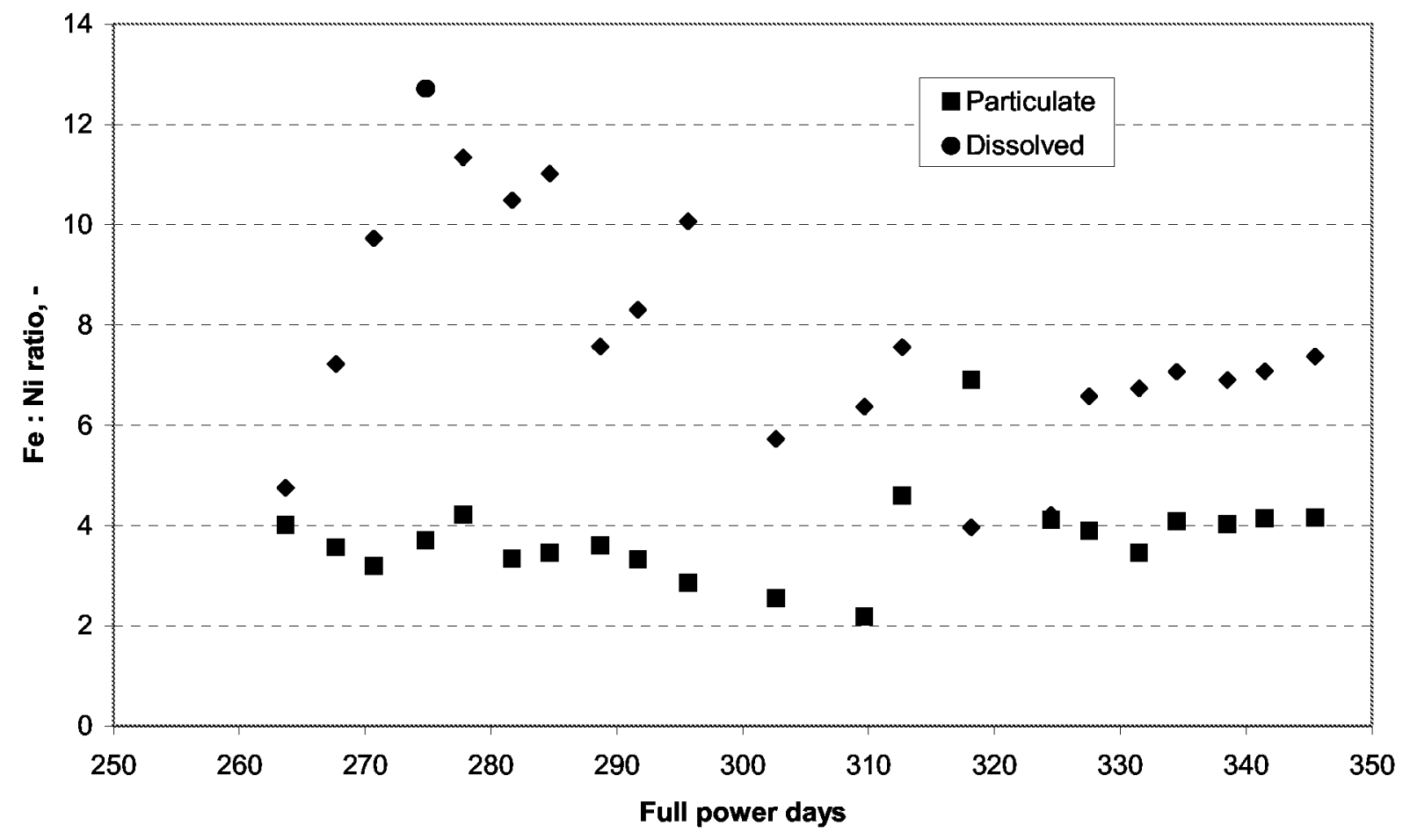

Figure 11-8

Fe:Ni ratios during Phase 1 Test 3

Results from gamma spectrometry analyses of coolant samples throughout the cycle are shown in Figures 11-9 $\left({ }^{51} \mathrm{Cr}\right), 11-10\left({ }^{54} \mathrm{Mn}\right.$ and $\left.{ }^{59} \mathrm{Fe}\right)$ and $11-11\left({ }^{58} \mathrm{Co}\right.$ and $\left.{ }^{60} \mathrm{Co}\right)$. These results are similar to those from Cycle 2. The activity of ${ }^{51} \mathrm{Cr}$ was predominantly in particulate, rather than dissolved form. Dissolved ${ }^{51} \mathrm{Cr}$ was only observed after a start-up or shut down, which would be expected under the reducing conditions in the loop. The activities of ${ }^{54} \mathrm{Mn}$ and ${ }^{59} \mathrm{Fe}$ were also mostly in particulate form, and the curves are parallel. This parallel behaviour was also seen for the dissolved species. The activities of dissolved ${ }^{54} \mathrm{Mn}$ and ${ }^{59} \mathrm{Fe}$ were fairly stable, indicating stable conditions in the loop, with the exception of the last peak, which was due to a shutdown and the low purification flow. The activities of ${ }^{58} \mathrm{Co}$ and ${ }^{60} \mathrm{Co}$ in particulate and dissolved species also showed the same trends. 


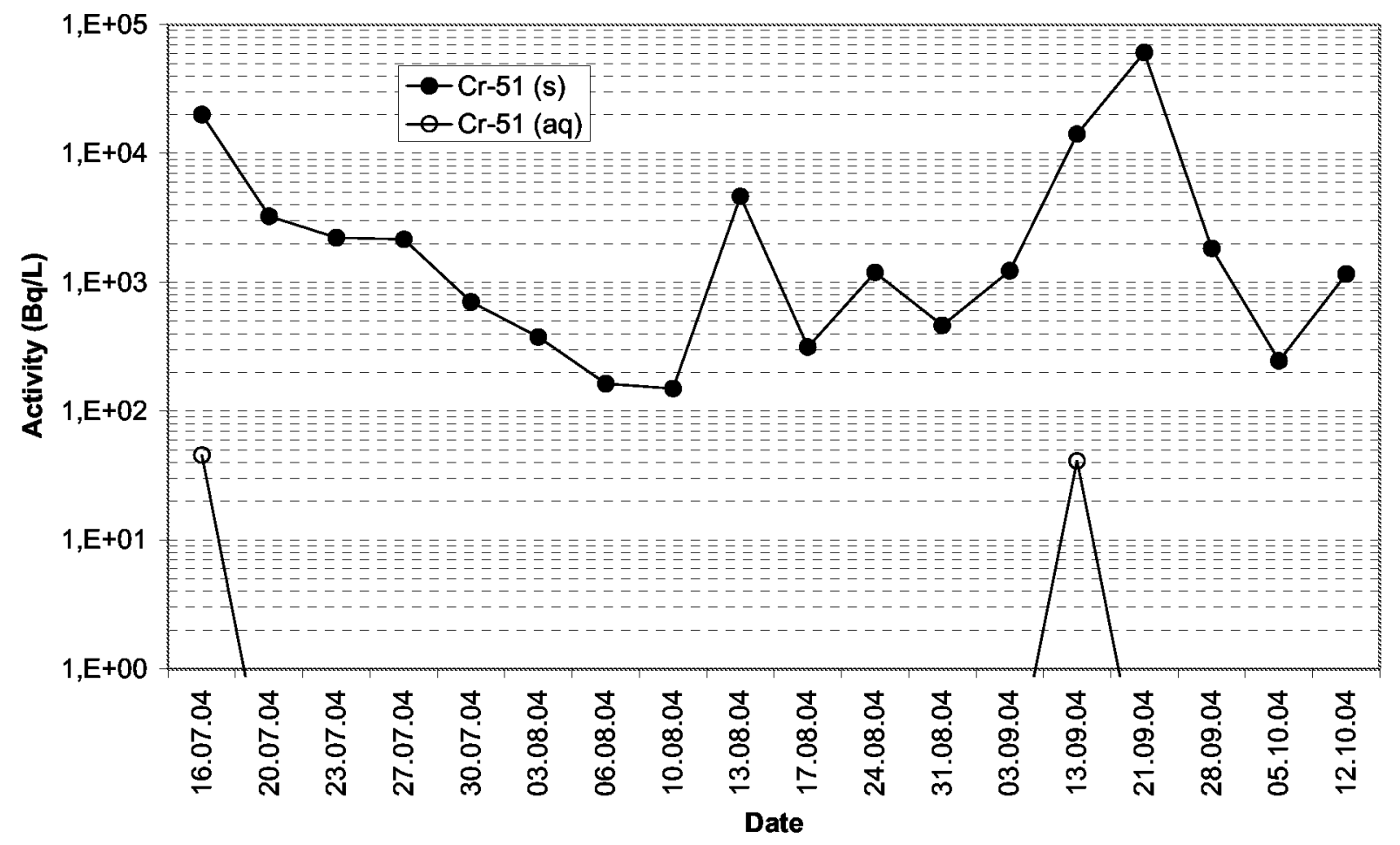

Figure 11-9

Activities of ${ }^{51} \mathrm{Cr}$ during Phase 1 Test 3

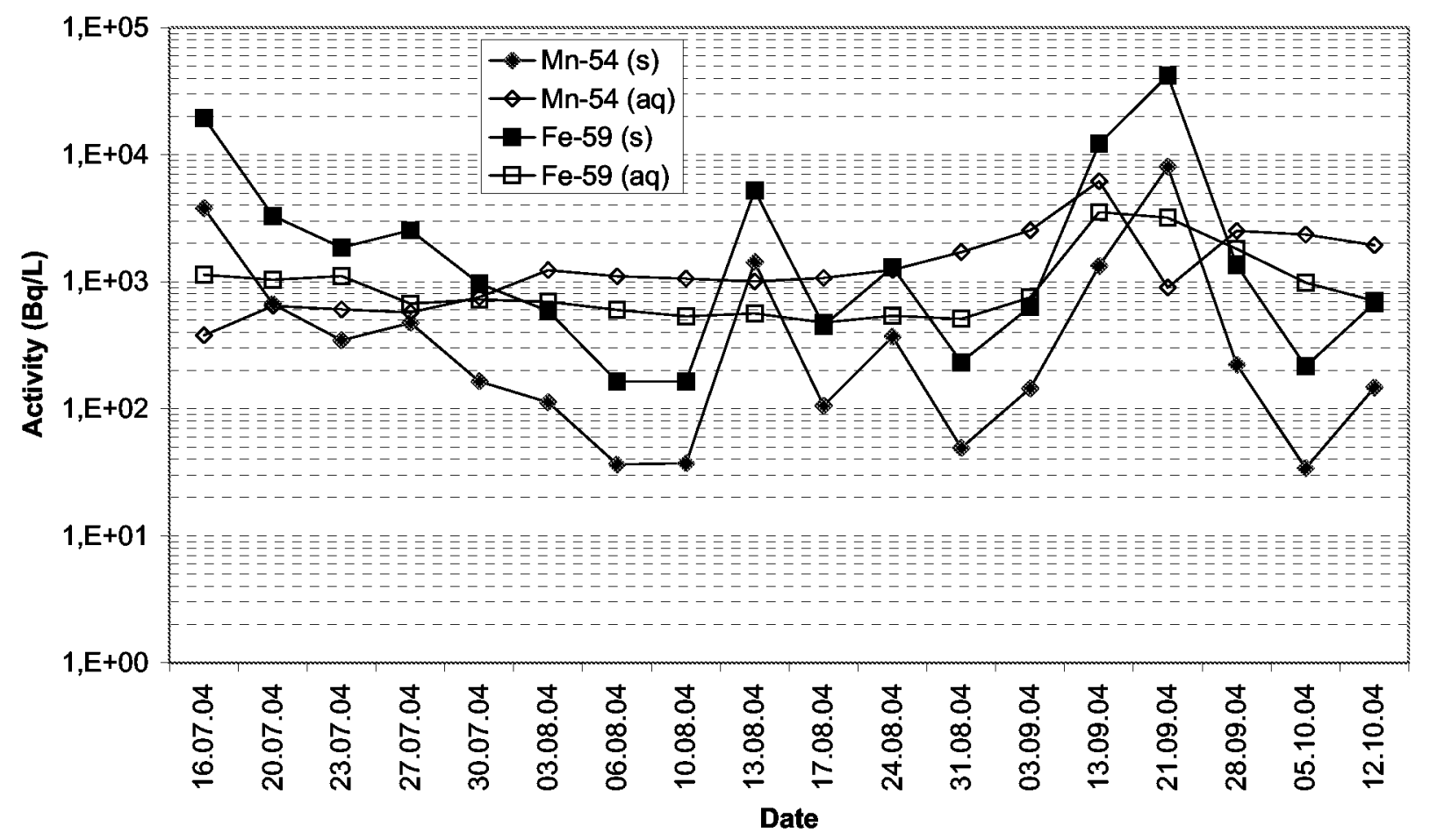

Figure 11-10

Activities of ${ }^{54} \mathrm{Mn}$ and ${ }^{59} \mathrm{Fe}$ during Phase 1 Test 3 


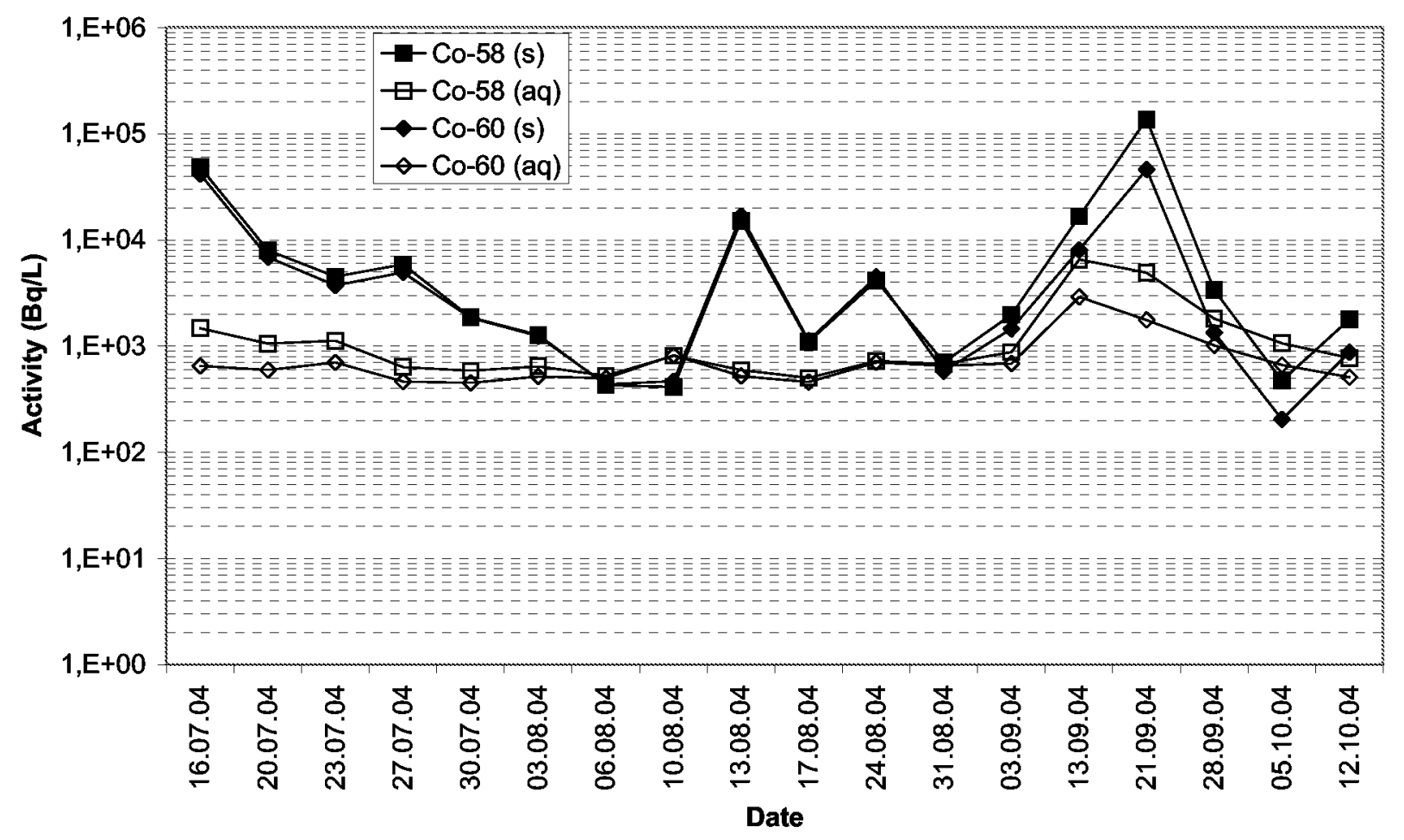

Figure 11-11

Activities of ${ }^{58} \mathrm{Co}$ and ${ }^{60} \mathrm{Co}$ during Phase 1 Test 3

When attempting to take diameter measurements at the start of the cycle, difficulties were experienced in lowering the test rod back into the fuel bundle. Hence, the decision was taken to stop the measurements for safety reasons as the experiment could not have continued if the rod could not have been reinserted.

Data from the instrumentation included to detect power changes caused by boron incorporation into the crud are shown in Figures 11-12 to 11-16. Figure 11-12 shows the increase in coolant temperature over the three axial sections of the fuel bundle. In the first two cycles, the increase in coolant temperature over the lower $200 \mathrm{~mm}$ of the fuel bundle was less than $6^{\circ} \mathrm{C}$, while the increases over the middle and upper sections were between 9 and $15^{\circ} \mathrm{C}$ (Figures 4-22 and 7-19). However, in the third cycle, the temperature increases over all three sections were similar at between 9 and $15^{\circ} \mathrm{C}$. The reasons for the different behaviour in this cycle are not clear, but may be due to the lower coolant flowrate, which would increase temperature over the lower section. 

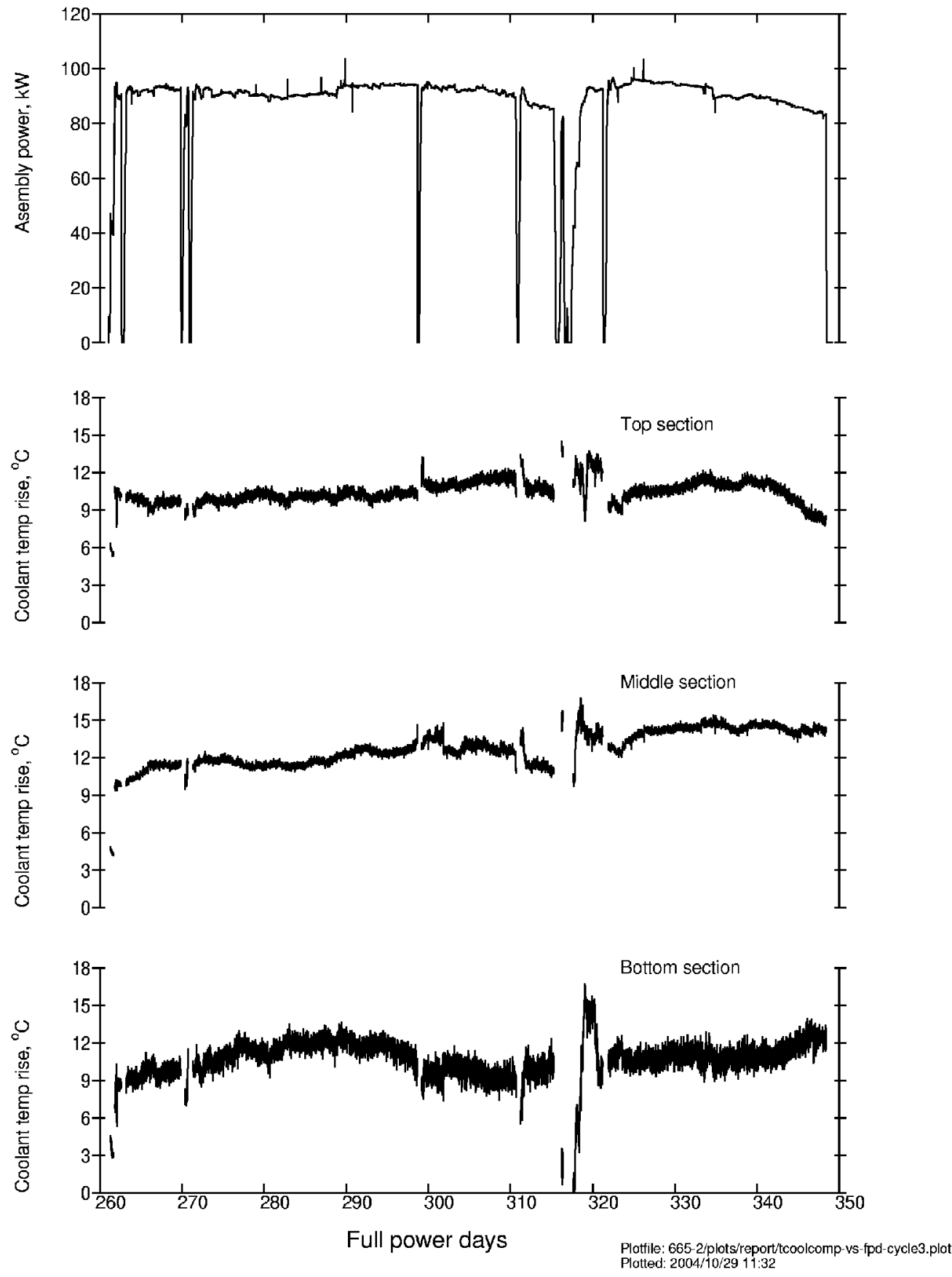

Figure 11-12

Increase in coolant temperature over lower $(0-200 \mathrm{~mm})$, middle $(201-400 \mathrm{~mm})$ and upper $(401-600 \mathrm{~mm})$ sections of the fuel bundle 
As noted in Chapter 7, the lowermost neutron detector in the test rig became faulty during the early part of Phase 1 , Test 2 , and hence the ND signals from neighbouring test rigs have been used to check for flux depressions in IFA-665. These test rigs and the ND signals used are listed in Table 11-2.

Table 11-2

Neutron detectors used in analysis

\begin{tabular}{|c|c|c|c|c|}
\hline \multirow{2}{*}{ IFA-665 } & \multicolumn{2}{|c|}{ Pressure flask } & \multicolumn{3}{|c|}{ Neighbouring test rigs } \\
\cline { 2 - 5 } & & IFA-663 & IFA-658 & IFA-653 \\
\hline ND3: 1229 & NDs 9-12: 1229 & ND3: 1373 & ND2: 1215 & ND2: 1240 \\
\hline ND2: 1000 & NDs 5-8: 1000 & ND2: 1138 & & \\
\hline ND1: 770 & NDs 1-4: 770 & ND1: 830 & ND1: 775 & ND1: 880 \\
\hline
\end{tabular}

The values refer to the height of the ND above the reactor bottom plate, in $\mathrm{mm}$.

Figure 11-13 shows the signals from the NDs listed in Table 9-2 during the cycle. From approximately 30 to 55 days (when there was a shutdown), NDs 2 and 3 from IFA-665 (Lines 2 and 3 ) showed a steadily decreasing trend. This trend was not seen for any of the signals from the other test rigs. After the shutdown, the signals from NDs 2 and 3 returned to the same levels as before the reduction was first observed (at approximately 30 days). From 70 days a decrease was again observed: although other ND signals decreased, the rate of decrease in IFA-665 was significantly higher. During these periods, the signals from the outside of the pressure flask also showed a decreasing trend, but the rates of decrease were lower than those of the NDs in the centre of the test rig. 


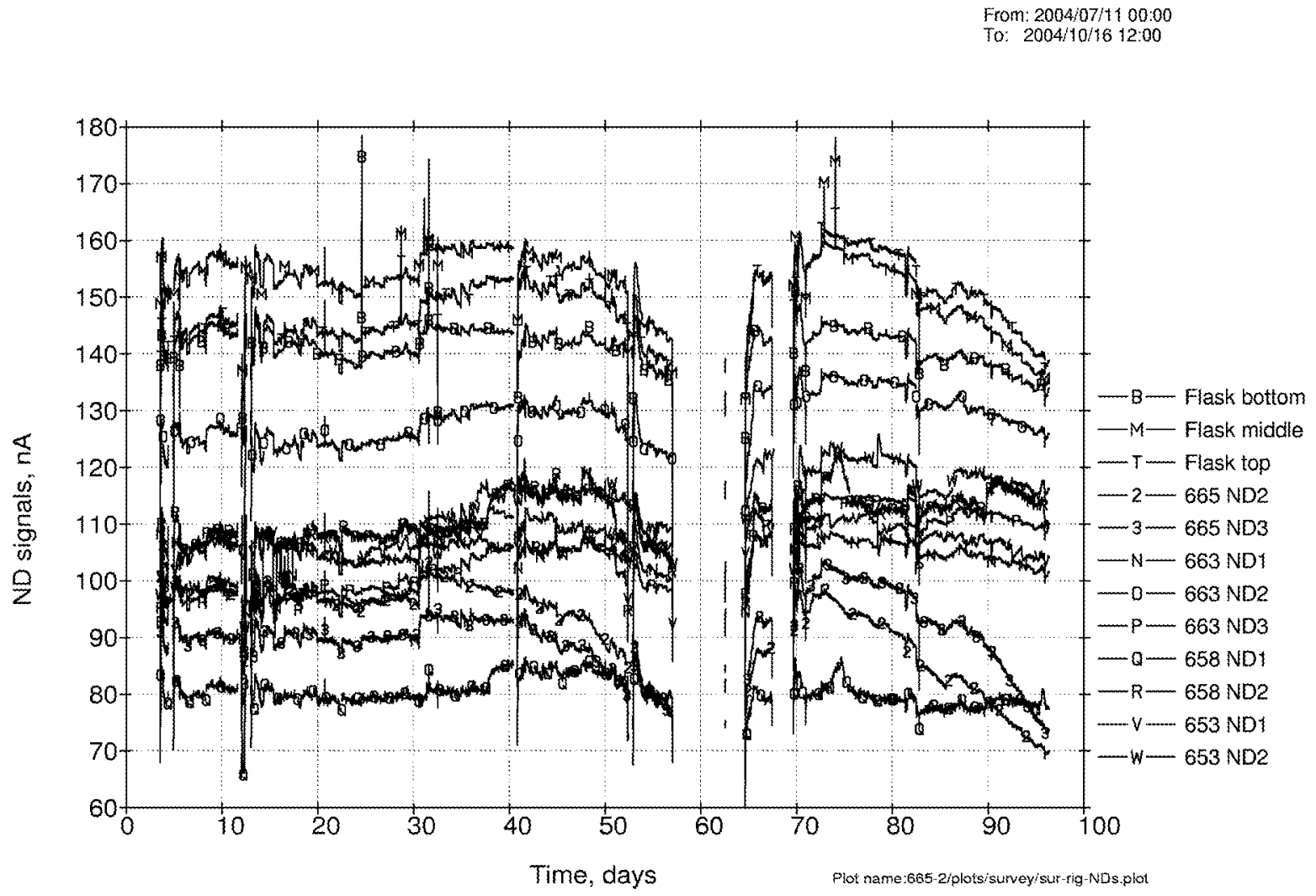

Figure 11-13

ND signals from IFA-665, the rig pressure flask and three neighbouring test rigs during Phase 1, Test 3

To show this effect more clearly, Figure 11-14 shows the ND signals from IFA-665 and the pressure flask normalised to the signals from the NDs at corresponding axial locations in the other three test rigs. The normalised signals from the bottom section of the pressure flask (Line B) show no downward trend. This indicates that power variations measured by these sensors were similar to those in the other rigs. For the middle and upper sections of the pressure flask, a reduction was seen from 33 days. However, for the IFA-665 signals, a strong downwards trend was seen, showing that the upper section of the fuel bundle was losing power at a higher rate than the three surrounding rigs. 


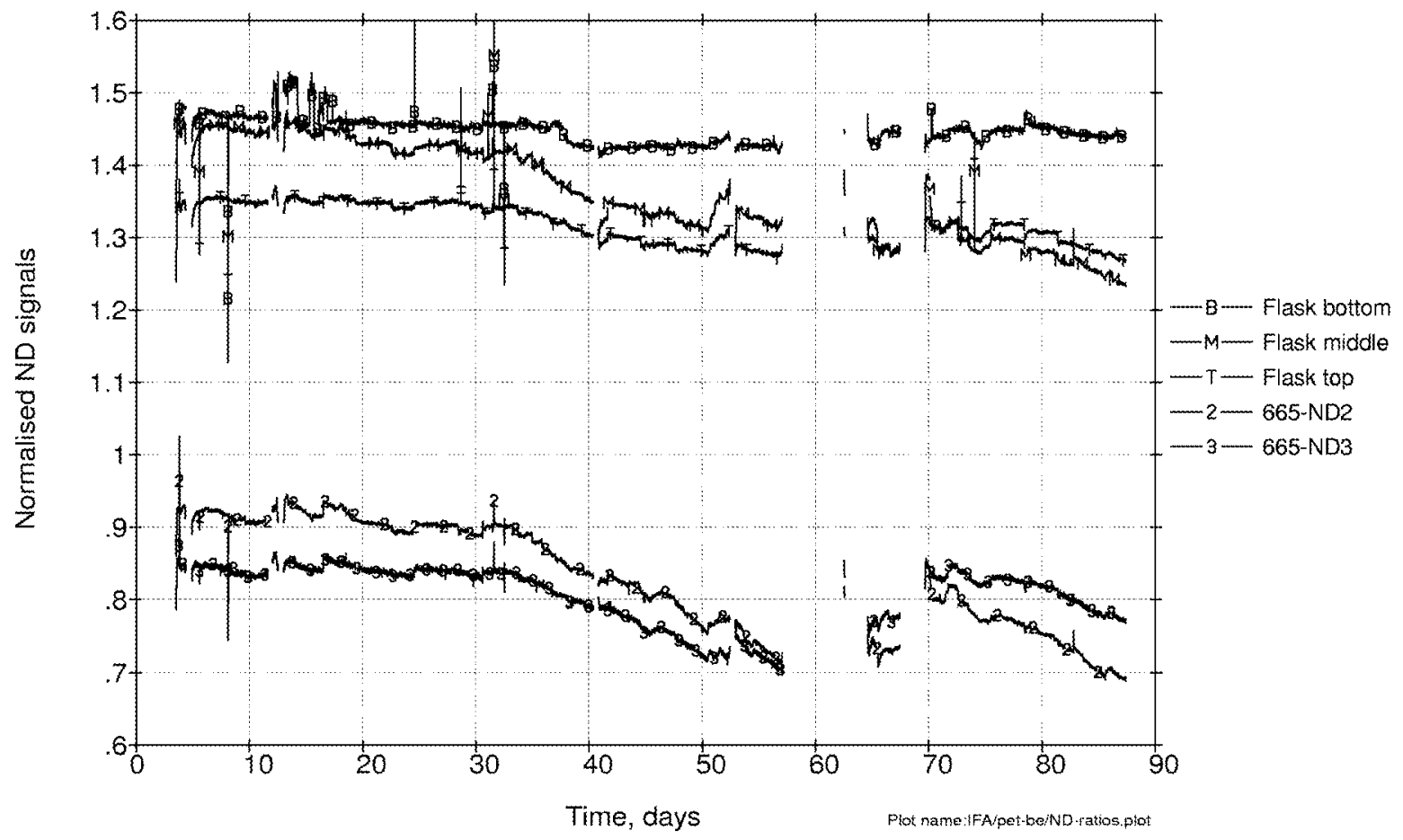

Figure 11-14

IFA-665 and pressure flask ND signals normalised to neighbouring test rig ND signals during Phase 1, Test 3

It would be expected that a reduction in power in the upper section of the fuel would be accompanied by a corresponding decrease in the coolant temperature. In this case, the situation is complicated because throughout the period of interest the coolant flowrate was decreasing and the assembly power (as determined from the pressure flask NDs) varied by $10 \mathrm{~kW}$ (Figure 11-3). A decrease in power would result in a lower increase in coolant temperature, while a lower flowrate would increase the coolant heat-up. However, inspection of the total coolant temperature rise over the fuel bundle (Figure 11-3) shows that although the general trend was for this parameter to increase, there were two periods where a decrease occurred (i.e. (i) from 290 to 310 FPD, and (ii) from 338 FPD to the end of the test). These two periods correspond with the times during which the ND signals from IFA-665 were decreasing with respect to the signals from the other rigs.

To show this more clearly, the coolant temperature (DT) measurements have been normalised to the temperature increase measured by the bottom-most DTs (where one phase flow, and hence no significant crud deposits, are expected) and to the signals from the NDs on the bottom section of the pressure flask. These results are shown in Figure 11-15. For the first period (up to 57 days), the normalised temperature from the DTs covering the axial range from 845 to $985 \mathrm{~mm}$ (which cover the upper portion of the fuel section with low-enriched $\mathrm{UO}_{2}$ and the lower $(85 \mathrm{~mm}$ ) section of fuel with high-enriched $\mathrm{UO}_{2}$ ) shows no significant change, while the results for the uppermost DTs show a decreasing trend. These results thus support the ND signals, and suggest 
that the power in the upper section of the fuel bundle was reducing. However, for the period after the short shutdown (from 65 days), the evidence is not so clear: only from 90 days can similar behaviour to that above be observed.

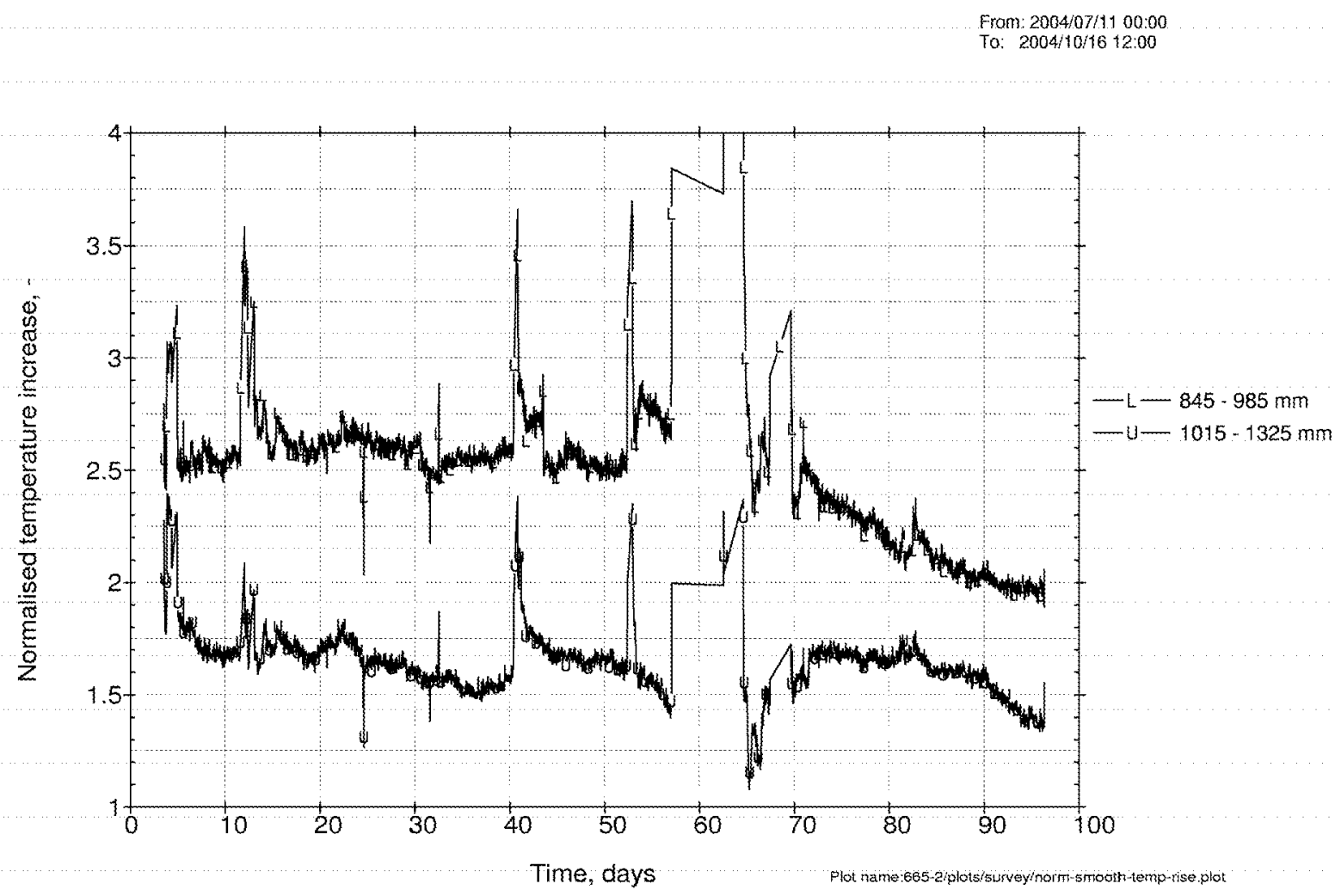

Figure 11-15

IFA-665 coolant temperature rise over fuel bundle, normalised to pressure flask ND signals during Phase 1, Test 3

Cladding elongation measurements are shown in Figure 11-16. The signals from rods 1 and 10 appear to be unreliable. The clad elongation in Rod 9 increased despite the relative power drop of the upper and middle sections of the fuel bundle, which may indicate a clad temperature rise due to a higher thermal resistance caused by formation of a crud layer. 


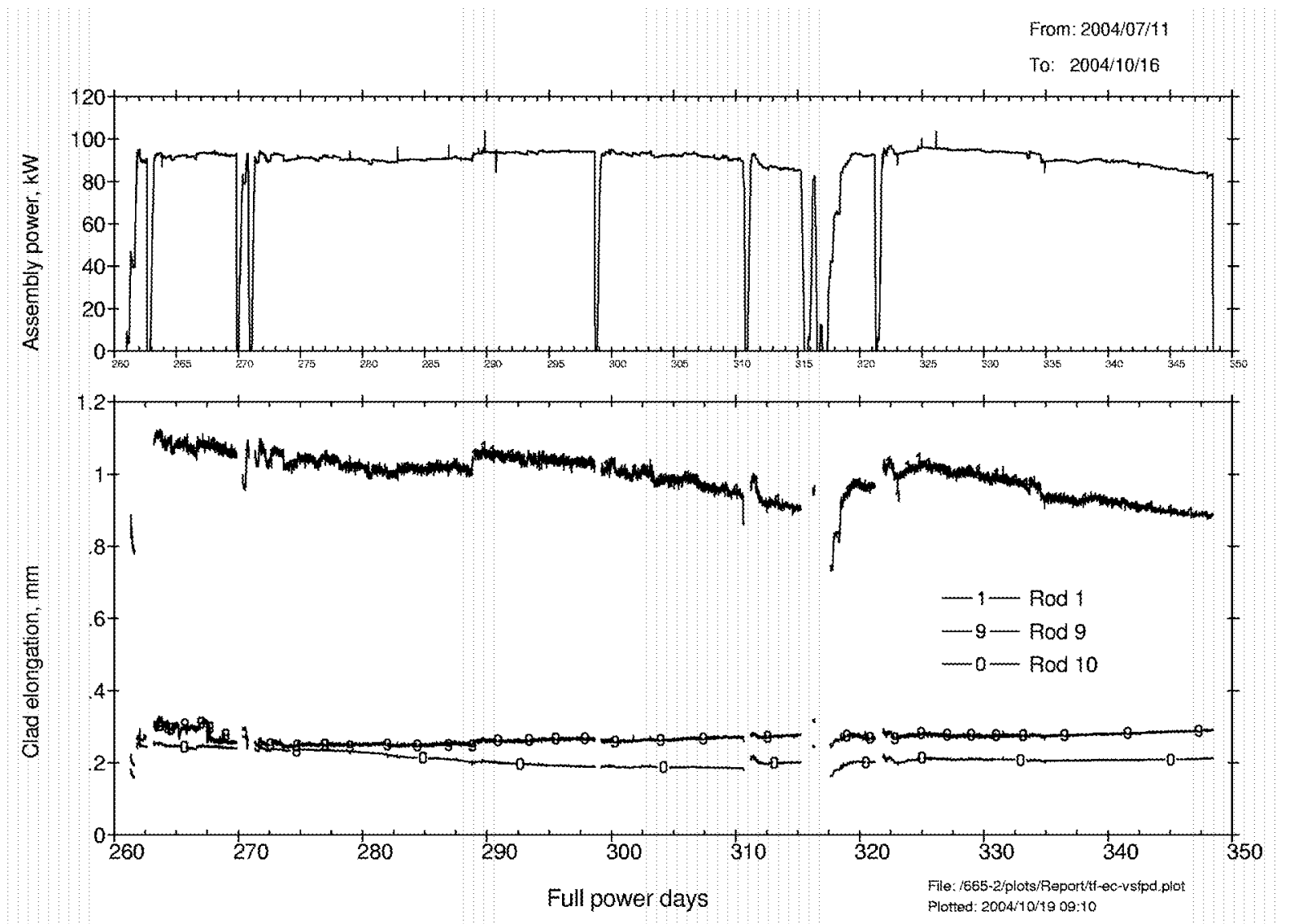

Figure 11-16

Cladding elongation measurements during Phase 1 Test 3

As during the reactor shutdown at the end of Phase 1, Test 2, the loop chemistry was maintained alkaline with the objective of minimising dissolution of any fuel crud. The reactor was shutdown with a planned scram. The rig temperature decreased by $40^{\circ} \mathrm{C}$ over a period of five minutes, and by a further $25^{\circ} \mathrm{C}$ during the following hour. The coolant Li content increased from 3.04 to 12.38 ppm during this period (Figure 11-17). This significant return is consistent with observations made at commercial reactors that have experienced AOA and is a key operating parameter for utilities to monitor when diagnosing AOA [3]. Thus, the lithium return data offer supporting evidence of AOA to the ND signal responses discussed previously. Subsequent to the lithium return measurements after shutdown, the Li removal column was operated to remove excess $\mathrm{Li}$, while in parallel, exchange of water started to reduce the boron content.

After unloading from the reactor, photographs were taken of all eight rods, and crud scrapes were taken for determination of the composition and morphology of the crud. The results of these PIE analyses will be presented separately. 


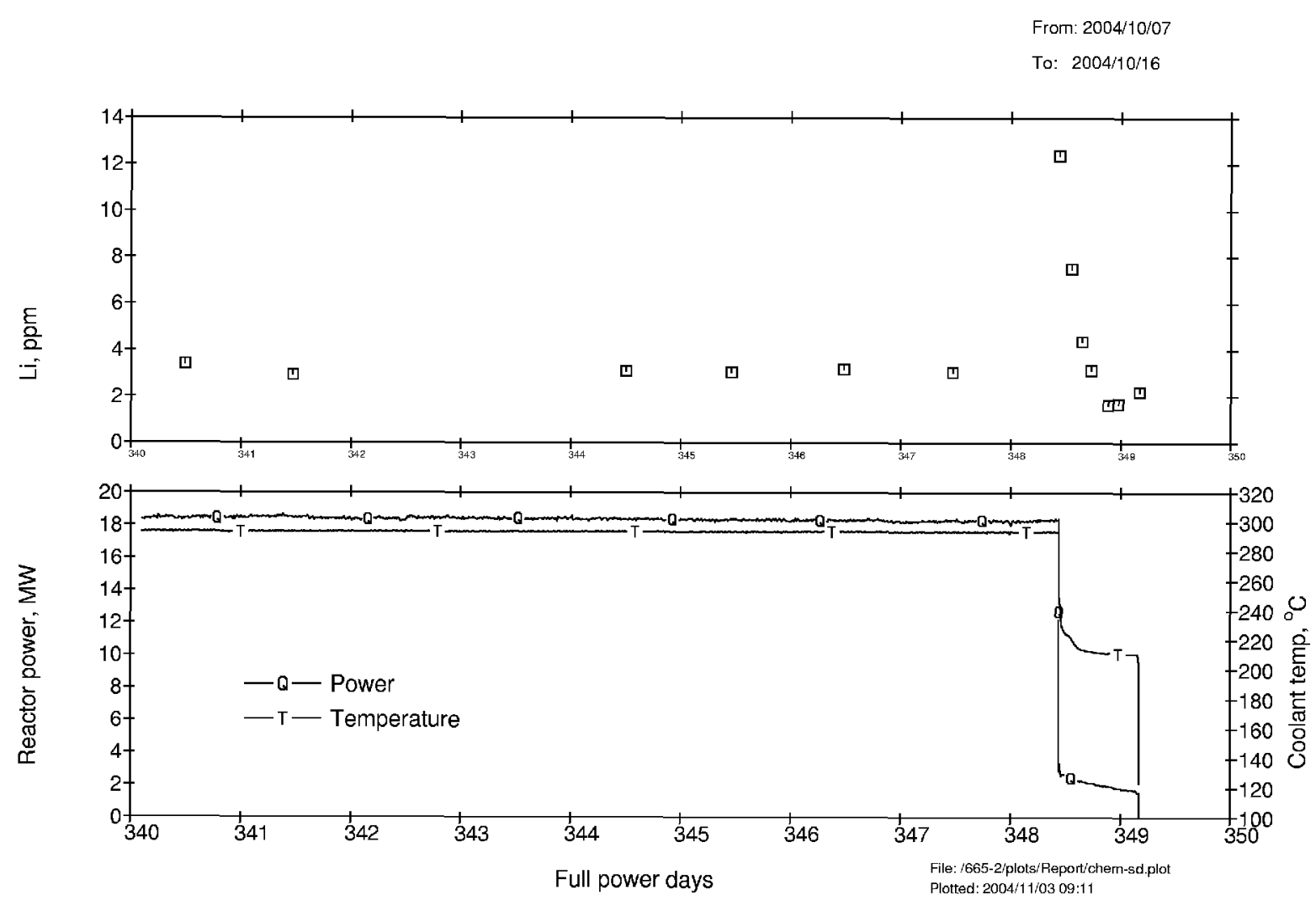

Figure 11-17

Coolant Lithium Return during Phase 1 Test 3 Shutdown 



\section{2 \\ DISCUSSION: PHASE 1, TEST 3}

During two periods in Phase 1, Test 3, neutron detector and coolant thermocouple measurements show that the power in the upper $400 \mathrm{~mm}$ of the fuel bundle decreased with respect to both the power in the lower $200 \mathrm{~mm}$ of the fuel bundle and to the power in neighbouring test rigs. This confirms that the power reduction was not caused by global reactor operations, but was due to a process that was limited to the upper section of the fuel in IFA-665. The most likely cause of this is a crud layer containing boron; i.e. an AOA effect. Although the heat flux in the third cycle was lower than that during the second cycle which resulted in deposition of crud (it was not possible to confirm crud formation on-line during the third cycle due to the problems with operation of the diameter gauge), the presence of the existing $\sim 15-20 \mu \mathrm{m}$ crud layer on the test rods at the start of the third cycle may have promoted further deposition and accompanying boron incorporation.

The two periods during which the flux depression occurred were separated by a reactor shutdown. Boron return would be expected during the shutdown, and hide-out would recommence when the reactor returned to full power. This would explain the delay in the reemergence of AOA symptoms after the return to power following the shutdown.

The large factor-of-four increase in Li concentration during the Cycle 3 shutdown has not previously been observed during shutdowns in PWR loops in the Halden reactor. During the shutdown after Cycle 2, only a minor Li increase was observed ( 10 percent), which may have been due to other processes than Li return.

This increase in Li during the Cycle 3 shutdown is in agreement with the other results from Cycle 3 that indicated crud deposition and boron hide-out. The continuous decrease in coolant flowrate was due to a high deposition rate of crud on all system surfaces, including the fuel clad, due to the large amount of injected material (from the EDTA solution). This is supported by the measured amounts of solids and dissolved species in the loop, which were low compared with the amounts injected. Both the neutron detector signals and the shutdown behaviour of Li indicated the presence of entrained boron in fuel crud that produced AOA symptoms.

The large increase in Li during the Cycle 3 shutdown is also in agreement with the behaviour observed in PWRs that have experienced AOA. 


\subsection{Correlation between Lithium Return and Measured Flux Depression}

An analysis was performed to determine whether the Li return data correlate with the measured flux depression. As discussed in Chapter 11, following the reactor scram at the end of the cycle, the Li concentration increased from 3.04 to $12.38 \mathrm{ppm}$, i.e. by $9.34 \mathrm{ppm}$. Given a loop volume of 70 litres (Chapter 2), this concentration corresponds to $0.65 \mathrm{~g}$ or 0.094 moles of Li. Assuming a 1:1 molar ratio of $\mathrm{Li}$ to $\mathrm{B}$ in the fuel crud (i.e. formation of $\mathrm{LiBO} 2$, see Chapter 1) and uniform crud deposition along the upper $40 \mathrm{~cm}$ of the fuel bundle, the boron loading in the crud is calculated to be $120 \mathrm{mg} / \mathrm{dm} 2$.

Figure 3-1 shows the results of calculations to predict the flux depression caused by incorporation of boron into the fuel crud. By extrapolation, this plot can be used to estimate the flux depression from the boron loading calculated above (since the calculations showed a linear change in flux with boron loading). As shown in Figure 12-1, a boron loading of $120 \mathrm{mg} / \mathrm{dm} 2$, with a B-10 enrichment of $40 \%$, would result in a flux depression of approximately 20 percent.

The signals from the neutron detectors positioned in the centre of the test rig are shown in Figure 11-13. During the period from 70 days (after the short reactor shutdown) until the end of the cycle (when the Li return was observed), the signals from NDs 2 and 3 in IFA-665 decreased by approximately 25 to 30 percent. Given the assumptions in the calculated value of the flux change (mainly that the boron was deposited uniformly along the upper $40 \mathrm{~cm}$ of each fuel rod), the agreement between the calculated and measured values is good, and it can be concluded that the Li return data and measured flux depressions correlate well.

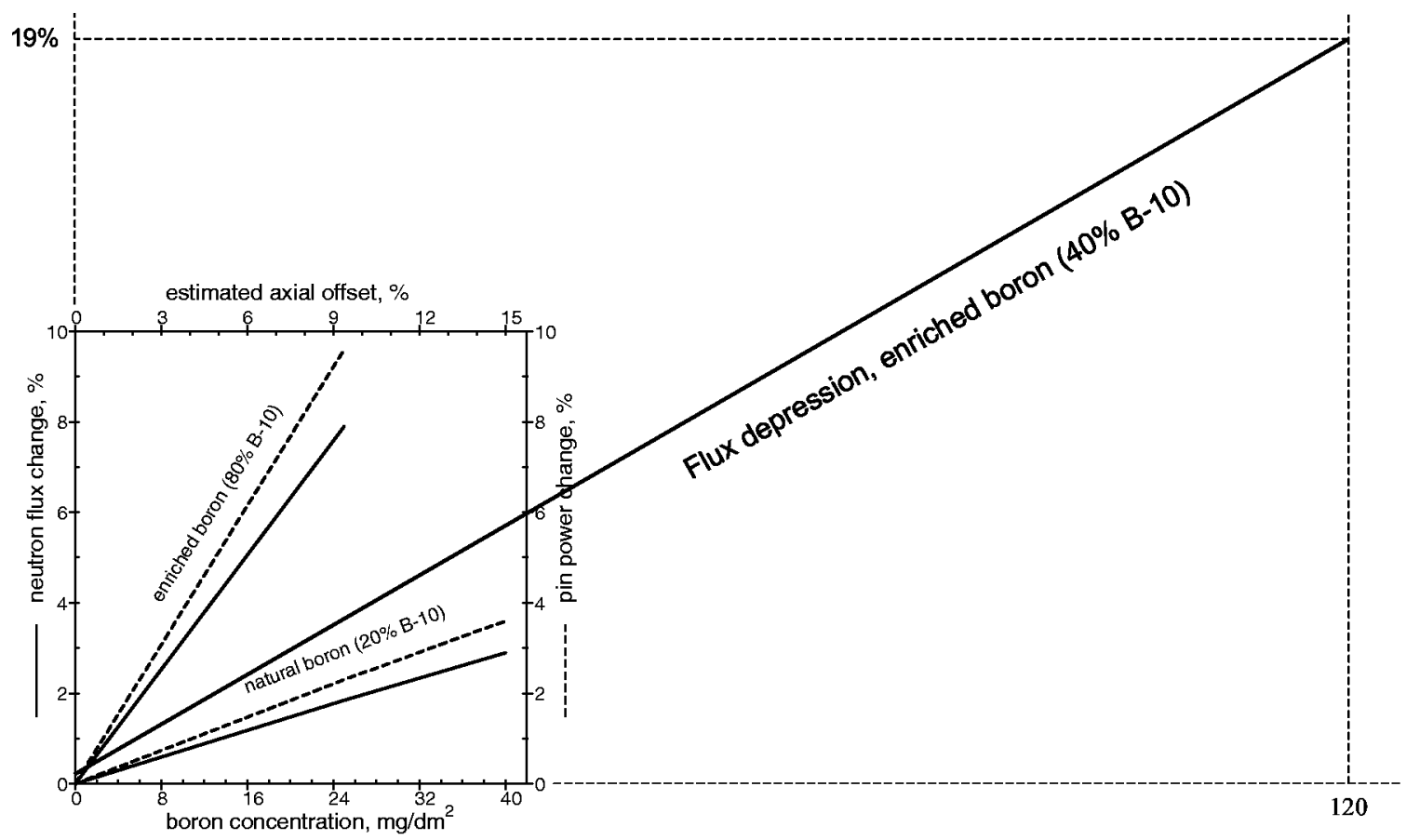

Figure 12-1

Calculated flux depression in Phase 1, Test 3 from Li return data and extrapolation of Figure 3-1 


\section{3 \\ SUMMARY AND CONCLUSIONS}

The main objective of IFA-665 was to deposit crud on fuel rods operating under PWR thermalhydraulic and water chemistry conditions, and to measure the resulting power reduction due to incorporation of boron into the crud.

The test rig was housed in a pressure flask connected to a PWR loop, and included eight fuel rods, one of which could be hydraulically withdrawn into the upper part of the pressure flask and scanned by a diameter gauge to detect crud deposition. Rod instrumentation included fuel centreline thermocouples and clad elongation detectors. Rig instrumentation included neutron detectors (NDs) and coolant thermocouples. The NDs were located both inside and outside of the pressure flask in order to determine the flux depression caused by boron in the crud.

There were three thermal-hydraulic requirements for the test:

- A mass evaporation rate in the range from 980 to $2440 \mathrm{~kg} \mathrm{~h}^{-1} \mathrm{~m}^{-2}$.

- An axial temperature increase along the fuel rods of $\geq 17^{\circ} \mathrm{C}$.

- Onset of boiling approximately halfway along the fuel rods.

\section{Test 1}

The first cycle of the test was operated for 160 days at power. Water chemistry conditions were $3.15 \mathrm{ppm} \mathrm{LiOH}$ and $1400 \mathrm{ppm}$ boron $\left(\mathrm{pH}_{300^{\circ} \mathrm{C}}=7.0\right)$. The coolant inlet temperature was $290 / 294^{\circ} \mathrm{C}$, with a calculated mass evaporation rate of $3200 \mathrm{~kg} / \mathrm{h} \mathrm{m}{ }^{2}$ along the upper half of the fuel bundle. The maximum heat flux at the clad surface was $850 \mathrm{~kW} / \mathrm{m}^{2}$.

Three methods were used to attempt to accelerate crud formation: (i) injection of simulated crud particles $\left(\mathrm{NiFe}_{2} \mathrm{O}_{4}\right.$ ); (ii) $\mathrm{pH}$ transients (reduction of $\mathrm{pH}_{300^{\circ} \mathrm{C}}$ from 7.0 to as low as 6.0 for periods of 48 hours); and (iii) oxygen addition transients. While the $\mathrm{pH}$ transients resulted in movement of large amounts of corrosion products around the loop, no significant deposition onto the fuel surfaces was measured.

\section{$\underline{\text { Test } 2}$}

For the second irradiation cycle, several steps were undertaken to attempt to deposit crud by increasing the concentrations of Fe and $\mathrm{Ni}$ in the coolant. Firstly, the coolant $\mathrm{pH}$ was reduced from 7.0 to 6.5 (by reducing the $\mathrm{LiOH}$ concentration from 3.15 to $0.95 \mathrm{ppm}$ ). Later in the cycle, $\mathrm{pH}$ was increased to 7.0 , by increasing the $\mathrm{LiOH}$ concentration to $3.15 \mathrm{ppm}$. 
Once stable operating conditions had been achieved (after approximately 10 days), an Fe-NiEDTA solution $(0.062 \mathrm{~g} / \mathrm{l} \mathrm{Fe} \& \mathrm{Ni})$ was injected continuously into the coolant. Measured soluble $\mathrm{Fe}$ and Ni concentrations were approximately two and eight times, respectively, higher than during the first cycle.

Third, an Fe/Ni colloid suspension was injected into the loop. Each injection resulted in a calculated instantaneous ( $\mathrm{Fe}+\mathrm{Ni}$ ) concentration of $500 \mathrm{ppb}$. A total of 57 injections were done over a period of 43 days. The injections were then stopped after it was observed that they resulted in an increase in rig flowrate, which implied that crud deposits were being removed by the colloids.

A further step was to reduce loop purification flow so that elevated corrosion product levels could be maintained; the circuit was operated only to maintain anion concentrations within allowable limits. This method of operation resulted in large fluctuations in coolant conductivity, which rose due to formation of anions (formate and acetate) from breakdown of EDTA, and was then reduced by operation of the deep bed demineraliser. Measured hydrogen concentrations were significantly higher than the target value of $2-4 \mathrm{ppm}$; and were due to breakdown of EDTA.

After 69 full power days of operation, there was still no evidence of significant crud formation. Hence, rig power was increased by 10 percent and the inlet temperature was raised from 290 to $294^{\circ} \mathrm{C}$. These changes resulted in an increase in maximum heat flux from 860 to $980 \mathrm{~kW} / \mathrm{m}^{2}$, and a 100 percent increase in the coolant mass evaporation rate (to $5800 \mathrm{~kg} / \mathrm{h} \mathrm{m}^{2}$ ) compared with the beginning of the cycle.

These more severe thermal-hydraulic conditions rapidly resulted in crud deposition; a layer of approximately $15 \mu \mathrm{m}$ was indicated by diameter measurements. The presence of crud was confirmed by visual inspection at the end of the cycle. No clear evidence for AOA symptoms was obtained, which was probably because the duration of the test following crud formation was only 30 days.

\section{$\underline{\text { Test } 3}$}

The third cycle was conducted under the same conditions as those at the end of the second cycle: coolant inlet temperature $294^{\circ} \mathrm{C}, \mathrm{pH}_{300^{\circ} \mathrm{C}} 7.0$, and injection of the Fe-Ni-EDTA solution. During this cycle, the neutron flux in the upper section of the fuel bundle decreased with respect to both the power in the lower section of the fuel bundle and to the power in neighbouring test rigs. Then, during the Cycle 3 shutdown, the loop Li concentration increased by a factor of four. Such a Li return, which was not observed during the Cycle 1 or 2 shutdowns or in other PWR loops in the Halden reactor, is a common indicator of AOA.

It was concluded that these combined effects were due to incorporation of boron into the crud layer; i.e. an AOA effect. Because diameter gauge measurements were not possible during this cycle, crud samples were taken after the shutdown with the intention to determine thickness and other characterizations. Results from this work were not available to report here. 


\section{4 \\ REFERENCES}

1. P L Frattini, J Blok, S Chauffriat, J Sawicki and J Riddle, Axial offset anomaly: coupling PWR primary chemistry with core design, Water chemistry of nuclear reactor systems 8,22 26 October 2000, Bournemouth, UK, (BNES, London, UK, 2000).

2. J Blok, S Chauffriat and P Frattini, Modelling the axial offset anomaly in PWRs, Chimie 2002, 22 - 26 April 2002, Avignon, France, (SFEN, Paris, France, 2002).

3. PWR Axial Offset Anomaly (AOA) Guidelines, Revision 1, EPRI, Palo Alto, CA: 2004. 1008102.

4. Rootcause Investigation of Axial Power Offset Anomaly, EPRI, Palo Alto, CA: 1997. TR108320.

5. Adsorption of Boric Acid on Synthetic Fuel Crud Oxides, EPRI, Palo Alto, CA: 2002. 1003384.

6. Characterization of Corrosion Product Deposits on the Callaway Cycle 9 PWR Core, EPRI, Palo Alto, CA: 2001. 1003129.

7. Pressurized Water Reactor Fuel Cleaning Using Advanced Ultrasonics, EPRI, Palo Alto, CA: and AmerenUE, Fulton, MO: 2002. 1001052.

8. Ultrasonic Fuel Cleaning Efficacy Campaign Results at Callaway, EPRI, Palo Alto, CA: 2002. 1003229.

9. B Fellers, D Perkins, J Bosma and J Deshon, Elevated-constant $\mathrm{pH}$ control assessment at TXU's Comanche Peak steam electric station, Chimie 2002, 22 - 26 April 2002, Avignon, France, (SFEN, Paris, France, 2002).

10. Assessment of Elevated pH Program for Comanche Peak Steam Electric Station, EPRI, Palo Alto, CA, and TXU Electric, Glen Rosa, TX: 2001. 1006282.

11. C. J. Wood, Developments in nuclear power plant water chemistry, Water chemistry of nuclear reactor systems 8, 22 - 26 October 2000, Bournemouth, UK, (BNES, London, UK, 2000).

12. PWR Fuel Impact Assessment for Injecting Zinc at a High-Duty PWR: Callaway Plant, EPRI, Palo Alto, CA: 2003. 1007857. 
13. V. Goehlich and J. Florinski, Enriched boric acid for pressurised water reactors, Chemistry in water reactors: operating experience and new developments, 24 - 27 April 1994, Nice, France (SFEN, 1994).

14. U. Kasemeyer and W. H. Beere, Capabilities and verification of the HELIOS lattice code for the Halden boiling water reactor, Halden Project Report HWR-609, 1999.

15. J. Deshon (EPRI), private communication, 2001.

16. K. Svanholm, In-pile power calibration methodology at the HBWR, Halden Project Report HWR-559, 1998.

17. G. C. W. Comely, The significance of corrosion products in water reactor coolant circuits, Progress in Nuclear Energy, Vol 16, No 1, 1985.

18. B. Beverskog and I. Puigdomench, Corrosion Science, 39 (1997) 1107.

19. A. T. Donaldson and C. Vitanza, Crud deposition on fuel rods as consequence of spikes in the concentration of water additives in a PWR loop, Halden Project Report HWR-407, 1994.

20. S. K. Yagnik, PWR fuel cladding corrosion tests with coolant zinc, paper presented at the Halden Project EHPG meeting, Loen 1999.

21. F. Barrera, Fuel rod crud deposition: effects of heat load, Halden Project Report HWR-618, 1999. 

Program:

Nuclear Power

\section{About EPRI}

EPRI creates science and technology solutions for the global energy and energy services industry. U.S. electric utilities established the Electric Power Research institute in 1973 as a nonprofit research consortium for the benefit of utility members, their customers, and society. Now known simply as EPRI, the company provides a wide range of innovative products and services to more than 1000 energyrelated organizations in 40 countries. EPRl's multidisciplinary team of scientists and engineers draws on a worldwide network of technical and business expertise to help solve today's toughest energy and environmental problems.

EPRI. Electrify the World
WARNING: This Document contains information classified under U.S. Export control regulations as restricted from export outside the United States. You are under an obligation to ensure that you have a legal right to obtain access to this information and to ensure that you obtain an export license prior to any re-export of this information. Special restrictions apply to access by anyone that is not a United States citizen or a Permanent United States resident. For further information regarding your obligations, please see the information contained below in the section entitled “Export Control Restrictions.”

\section{Export Control Restrictions}

Access to and use of EPRI Intellectual Property is granted with the specific understanding and requirement that responsibility for ensuring full compliance with all applicable U.S. and foreign export laws and regulations is being undertaken by you and your company. This includes an obligation to ensure that any individual receiving access hereunder who is not a U.S. citizen or permanent U.S. resident is permitted access under applicable U.S. and foreign export laws and regulations. In the event you are uncertain whether you or your company may lawfully obtain access to this EPRI Intellectual Property, you acknowledge that it is your obligation to consult with your company's legal counsel to determine whether this access is lawful. Although EPRI may make available on a case by case basis an informal assessment of the applicable U.S. export classification for specific EPRI Intellectual Property, you and your company acknowledge that this assessment is solely for informational purposes and not for reliance purposes. You and your company acknowledge that it is still the obligation of you and your company to make your own assessment of the applicable U.S. export classification and ensure compliance accordingly. You and your company understand and acknowledge your obligations to make a prompt report to EPRI and the appropriate authorities regarding any access to or use of EPRI Intellectual Property hereunder that may be in violation of applicable U.S. or foreign export laws or regulations.

\footnotetext{
(6) 2004 Elecrric Power Research Institure (EPRI), Inc. All rights reserved. Electric Power Research Institute and EPRI are registered service marks of the Electric Power Research Institute, Inc. EPRI. ELECTRIFY THE WORLD is a service mark of the Electric Power Research Institute, Inc.

63 Printed on recycled paper in the United States of America
} 